«IPO UNDERPRICING AND AFTERMARKET PRICE ACCURACY: AUCTIONS VS. BOOKBUILDING IN JAPAN»

TIMO LEHMANN

MATTHIAS WEBER

WORKING PAPERS ON FINANCE No. 2021/02

SWISS INSTITUTE OF BANKING AND FINANCE (S/BF - HSG)

JANUARY $6^{\mathrm{TH}}, 2021$ 


\title{
IPO Underpricing and Aftermarket Price Accuracy: Auctions vs. Bookbuilding in Japan
}

\author{
Timo Lehmann* Matthias Weber $\$$
}

6 January 2021

\begin{abstract}
We analyse a regulatory change in the Japanese IPO market that created an abrupt shift from hybrid price-discriminatory auctions to bookbuilding. We find that bookbuilding leads to significantly higher underpricing than hybrid price-discriminatory auctions. Further, we find evidence that price accuracy tends to be higher for auctions than for bookbuilding. The results hold under a variety of OLS specifications and with regression discontinuity designs exploiting the abrupt change of the regulation. The results suggest that the interests of issuers and underwriters are not aligned. The popularity of bookbuilding seems puzzling from this perspective.
\end{abstract}

Keywords: Underpricing, Price Accuracy, Initial Public Offering, Bookbuilding, Auction, Japan

JEL classification: G30, G32, G38, G12

\section{Acknowledgments}

We thank Prof. Takeshi Kaneko from Keio University (Tokyo, Japan) and Prof. Richard H. Pettway from the University of Florida (Gainesville, US), who kindly shared their data with us. We thank Olimpia Carradori for comments and suggestions.

\footnotetext{
*University of St. Gallen and ZETRA International AG. Email: timo.1@bluewin.ch.

§ University of St. Gallen. Email: matthias.weber@unisg.ch.
} 


\section{Introduction}

An initial public offering (IPO) is an important milestone for a company. For the first time, demand and supply translate into a valuation. The issuer faces the problem that there is ex ante substantial uncertainty about the valuation of the company. While an overvaluation by the issuer can result in the failure of the IPO, an undervaluation leads to a wealth transfer from the issuer to the first investors.

Bookbuilding, which originated in the United States, is nowadays the predominant price discovery method for IPOs in most markets worldwide. It superseded other price discovery methods in almost all markets it was introduced in (Jagannathan, Jirnyi \& Sherman, 2015). In the bookbuilding process, the investment bank takes on a central role and has pricing and share allocation discretion. Market demand is assessed prior to the IPO through the investment bank by inviting selected institutional investors to so-called roadshow meetings. Afterwards, these investors submit indications of interest that are aggregated in an order book. The order book should reflect market demand and help the underwriter to price and allocate the shares. Bookbuilding is generally found to lead to substantial share price increases on the first trading day of the IPO stock (the terms underpricing, initial return and return on the first trading are interchangeable). Loughran and Ritter (2002) show that IPOs in the US between 1990 and 1998 left over USD 27 billion on the table. This is more than twice the amount of fees paid to investment banks and more than three times the aggregate earnings of these IPO firms in the year before the IPO. These numbers indicate a significant wealth loss by the issuer due to underpricing. This raises the question of whether the bookbuilding method is efficient.

Auctions are other price discovery methods that are often discussed as alternative to bookbuilding and widely used to price other securities (e.g., government bonds). Several countries used auctions in different forms to price and allocate IPOs at some point in time. While Japan and Taiwan used hybrid price-discriminatory ("pay-what-you-bid") auctions, Israel and France used uniform-price auctions. Auctions have the advantages that they provide full transparency on pricing and allocation of shares and that they allow a larger number of investors to participate. There is (some) empirical evidence that auctions lead to lower underpricing than bookbuilding (Beierlein \& Kato, 2003, comparing Japan and the US; Derrien \& Womack, 2003, for 
France; Kaneko \& Pettway, 2003, for Japan; Pukthuanthong, Varaiya \& Walker, 2007, for the US; Huang, Chiang, Lin \& Lin, 2017, for Taiwan).

It is puzzling that bookbuilding superseded the auction method in basically every market it was introduced, despite empirical evidence that bookbuilding leads to higher underpricing. In a theoretical model, Sherman (2005) argues that higher underpricing in bookbuilding is related to higher (aftermarket) price accuracy. Issuers value accurate prices, because price accuracy is related to reputational benefits, liquidity in the aftermarket and lower litigation risks, among other things (as outlined by Sherman \& Titman, 2002). Issuers compensate investors with higher underpricing for carefully evaluating their firm and sharing private pricing information. The model of Sherman (2005) is based on the assumption of aligned interests between the issuer and the underwriter. In this model, underpricing can be considered a price to be paid for higher (aftermarket) price accuracy.

The Japanese IPO market provides a unique institutional setting to analyse different IPO price discovery methods. Until 1997 Japanese regulation allowed only hybrid price-discriminatory auctions to price and allocate IPOs. On the $1^{\text {st }}$ of September 1997, bookbuilding was introduced as an alternative to the auction method. Interestingly, hybrid price-discriminatory auctions have not been used any longer after the introduction of bookbuilding.

We analyse two research questions. First, we analyse whether and how initial returns differ between IPOs using bookbuilding and IPOs using price-discriminatory auctions. Second, we analyse whether and how price accuracy in the aftermarket is different between the two IPO methods.

The first research question analyses the difference in underpricing. While the regulatory change provides a good opportunity to analyse this difference, the fact that bookbuilding and auctions appear at different time points (before September 1997 vs. thereafter) makes the issue non-trivial. To make sure that our results are not driven by the time dimension rather than the change in regulation, we provide a whole battery of analyses: (1) We vary the time window from which observations are included in OLS regressions, which include a set of control variables, analysing in how far the results are robust to including observations closer and further from the regulatory change. (2) We implement a regression discontinuity design with a global strategy; that is, we include also observations far from the regulatory change but allow for a variety of different 
polynomial specifications of time to account for the time dimension. (3) We implement a regression discontinuity design with a local strategy; that is, observations far from the regulatory change are excluded (we do this for different bandwidths) and local linear regressions are conducted (with different kernels, partly assigning more weight to the observations closer to the regulatory change). All these approaches in isolation have advantages and disadvantages but taken together they give a complete picture of what is happening and make sure that the results are robust.

Underpricing around the regulatory change in Japan has already been the subject of the study by Kaneko and Pettway (2003), who find higher underpricing under bookbuilding than under auctions with OLS regressions using data from January 1993 to December 2001. The biggest difference of our analysis of underpricing to theirs lies in the different methodology. Our underpricing analysis furthermore extends upon Kaneko and Pettway (2003) by the following: (i) We investigate an additional sample of IPOs from regional stock exchanges and the Second Sections of Tokyo Stock Exchange, Osaka Stock Exchange and Nagoya Stock Exchange. (ii) We analyse data that lasts up to 2007 (as compared to up to 2001).

The second research question considers aftermarket price accuracy. This is an important analysis, because it can shed light on whether potentially higher underpricing under bookbuilding is beneficial for the issuer (arising from the need to incentivize information acquisition; in this case, aftermarket price accuracy should be higher for bookbuilding) or detrimental (for instance due to a conflict of interest between issuer and underwriter; in that case, aftermarket price accuracy should be equal for both methods or higher for auctions). We proxy price accuracy by absolute abnormal buy-and-hold returns over a 12-month aftermarket period, which may be considered the best measure of price accuracy from the viewpoint of the issuer (e.g., if the risk of selling shares later is considered). We again conduct a variety of different analyses, with OLS regressions, a regression discontinuity design with a global strategy (using several polynomial specifications for time) and a regression discontinuity design with a local strategy (using different kernels and bandwidths). Aftermarket price accuracy proxied by absolute abnormal returns has not yet been analysed in the setting of the Japanese regulatory change. Pettway, Thosar and Walker (2008) analyse aftermarket stock price volatility with OLS and find that volatility is higher for stocks of book-built IPOs than for stocks with an IPO auction. 
We find robust empirical evidence that underpricing in Japan is higher for bookbuilding than for hybrid price-discriminatory auctions. The results of a multiple linear regression analysis indicate that bookbuilding leads to initial returns that are substantially (up to 38 percentage points) higher. The global strategy of the regression discontinuity design confirms these findings. However, the estimates are sensitive to the order of the polynomial time trend. The local strategy of the regression discontinuity design also indicates that there is a difference in underpricing but at a lower level. Our findings are consistent across different Japanese stock exchanges. The magnitudes are economically relevant. The average wealth loss for issuers resulting from choosing bookbuilding over auctions is estimated to be between USD 3.2 million and USD 11.2 million.

Further, we find that hybrid price-discriminatory auctions lead to higher price accuracy in the secondary market than bookbuilding. This finding is again robust to using different methodology and consistent across the different stock exchanges. This result contradicts the prediction of the model by Sherman (2005). Therefore, our results indicate that the assumption of aligned interests between the issuer and the underwriter is not valid for the Japanese market. Instead, the results suggest that conflicts of interest between issuer and underwriter may be a reason for the particularly high underpricing for bookbuilding.

The remainder of the paper is organised as follows. Section 2 discusses the related literature. In Section 3, we describe the institutional setting of the Japanese IPO market. Section 4 introduces the methodology. The data is described in Section 5. Our results on underpricing are shown in Section 6 and the results on price accuracy in Section 7 . Section 8 puts the findings in perspective, provides some additional analysis to make the interpretation of our main results clearer and discusses potential limitations of the methodology. Section 9 concludes.

\section{Related Literature}

Underpricing, defined as the excessive initial return of IPOs, is a phenomenon that was first documented by Stoll and Curley (1970), Logue (1973), Reilly (1973), and Ibbotson (1975) in the US. The finding that IPOs exhibit an excessive first-day return is very robust. Ritter (2003) summarizes the average underpricing of IPOs in 38 countries for periods between 1960 and 2000. IPOs in all 38 countries are underpriced with average initial returns ranging from $5.4 \%$ in Denmark (1984-1998) to $256.9 \%$ in China (1990-2000). A more recent overview of underpricing 
for Asia-Pacific markets is provided by Albada and Yong (2019), who report average initial returns from $15.8 \%$ in Hong Kong (1980-2013) to 118.4\% in China (1990-2013). For Japan, they report an average underpricing of $41.7 \%$ for the period 1970 to 2013.

Ritter and Welch (2002) argue that the key to understanding underpricing lies in the price formation process. A wide variety of theoretical concepts try to explain the existence and variability of underpricing. According to Rock (1986), underpricing is required to overcome a Winner's Curse faced by uninformed (retail) investors. Others describe underpricing as compensation for informed (institutional) investors for their participation in the price discovery process (Benveniste \& Spindt, 1989). A variety of authors focus on the relationship and the information asymmetry between issuers and underwriters and attribute the existence of underpricing to agency costs, bargaining power and litigation risks (Baron, 1982; Tinic, 1988; Loughran \& Ritter, 2002). Furthermore, some authors note that underpricing is used to signal quality and leave a "good taste" with investors (Allen \& Faulhaber, 1989; Welch, 1989). Welch (1992) attributes underpricing to the existence of informational cascades. Investors imitate the behaviour of other investors and underpricing is required to prevent the first few investors from withdrawing from the offer. Ritter (1991) argues that there is an overvaluation in the early aftermarket that increases initial returns. All these concepts are not mutually exclusive and their importance may differ across time, price discovery method and country (Ritter, 2003).

One strand of the IPO literature investigates the relation between the IPO price discovery method (the IPO mechanism) and underpricing. In the following, we first briefly discuss the theoretical literature on IPO mechanisms and then turn to the empirical literature.

\subsection{IPO Mechanisms: Theory}

Benveniste and Spindt (1989) are the first to model the bookbuilding process in detail. They argue that underwriters induce informed investors to reveal private information by compensating them through underpricing and preferential share allocation. Private information obtained by the underwriter from informed investors is only partially used to adjust the offer price while; underpricing is used to reward investors. In Hanley (1993), the expected profit for informed investors from revealing private information is a function of underpricing and share allocation. The underwriter must guarantee to increase underpricing or share allocations to induce informed investors to reveal private information. 
Benveniste and Spindt (1989) assume that private information for informed investors is costless. Sherman (2000) and Sherman and Titman (2002) build upon this model but assume that investors have to invest in research about the IPO firm to generate information. Therefore, private information is not given, but can be steered by incentivising investors to invest in research. Higher information production and the revelation of more private information by informed investors leads to more accurate prices in the aftermarket. Sherman and Titman (2002) argue that issuers value price accuracy for a variety of reasons. One reason, why issuers prefer an accurate aftermarket price is that they are risk averse and want to have an accurate aftermarket price for potential follow-on offerings.

Sherman (2005) compares price-discriminatory auctions and bookbuilding with costly information acquisition in a theoretical model and concludes that bookbuilding is the favourable price discovery method. She emphasizes two advantages of bookbuilding over pricediscriminatory auctions. First, by having pricing and share allocation discretion, the underwriter can control information production by investors. If desired, the underwriter can induce investors to investigate the firm in more detail and grant them higher compensation in the form of higher underpricing and favourable share allocation. Auctions do not per se lead to too much or too little information production by investors, but they do not allow to control the level of investment in information acquisition. The second advantage of bookbuilding is a lower uncertainty about the number of investors participating in the IPO. With the auction method, there is no coordination of investors and hence the underwriter and the investor must make decisions without knowing how many investors participate in the IPO. If demand is too low, the auction may fail. If demand is too high, investors drive the price up which reduces potential profits for investors that should compensate for the costs of information gathering. Under the bookbuilding method these risks can be mitigated. The underwriter recruits selected investors and can guarantee them sufficient compensation for their efforts of evaluating the firm. This reduces the risk that the IPO fails and increases incentives for investors to carefully evaluate the firm.

The key underlying assumption of Sherman (2005) is that the underwriter acts in the best interest of the issuer. Thus, both issuer and underwriter prefer lower underpricing and also value (aftermarket) price accuracy (that underwriters may not always act in the best interest of issuers is one of the main points of criticism of bookbuilding; in auctions, pricing and allocation are transparent and the underwriter is only a facilitator of the process, which reduces potential 
conflicts of interest). ${ }^{1}$ Whether the channels in Sherman (2005) are behind actual behaviour in IPOs can empirically be tested: if that is the case, bookbuilding should lead to higher underpricing than auctions but also to higher price accuracy in the aftermarket (the higher underpricing is, in a way, the price to be paid for higher aftermarket price accuracy).

\subsection{IPO Mechanisms: Empirical Evidence}

There are a few studies comparing underpricing between IPO mechanisms (in particular between bookbuilding and auctions) in different parts of the world and very few studies comparing aftermarket price accuracy. Empirical research indicates that auctions lead to lower underpricing than bookbuilding. Kaneko and Pettway (2003) report for hybrid price-discriminatory auctions in Japan a much lower average initial return between January 1993 and September 1997 than for bookbuilding for the period October 1997 to December 2001. Following up on this, Pettway et al. (2008) investigate aftermarket stock price volatility (as a proxy of price accuracy), finding that auctions lead to less volatile aftermarket prices than bookbuilding. Based on a cross-country comparison, Beierlein and Kato (2003) find that initial returns are higher and price accuracy is lower for US bookbuilding than for Japanese hybrid price-discriminatory auctions. Further, they find an indication that price accuracy of auctions is higher than of bookbuilding.

Besides Japan, good institutional settings to compare IPO auctions and bookbuilding are rare. In Taiwan, a fixed-price method, hybrid price-discriminatory auctions and hybrid bookbuilding partly co-existed (hybrid here refers to a fixed-price offer with up to $50 \%$ allotment to a bookbuilding or auction offering). Huanget al. (2017) show that hybrid bookbuilding leads to higher initial returns than hybrid price-discriminatory auctions and that the auction method outperforms hybrid bookbuilding in the long-run. Derrien and Womack (2003) analyse French IPO data and find that uniform-price auctions are associated with lower underpricing than bookbuilding. In India, a regulatory change replaced bookbuilding with a "dirty" Dutch auction in November 2005. Additionally, a fixed-price method was available for issuers at any time.

\footnotetext{
${ }^{1}$ In a practice called spinning, underwriters in the US created personal brokerage accounts for firm executives during the dot-com bubble 1999/2000 (Liu \& Ritter, 2010). The underwriter promised to allocate shares of other underpriced IPOs to firm executives as compensation for selecting the underwriter for the IPO of their firm. The executives of the issuing firm were willing to hire an underwriter even though they could expect that this underwriter would significantly underprice the shares of their firm (Ritter, 2003). The practice is called spinning because the shares on the personal brokerage accounts were often sold ("spun") shortly after the IPO to realise returns. Tinic (1988) argues that underwriters intentionally underprice IPOs to reduce their litigation risk (since only investors that lose money are entitled to take legal action).
} 
Looking at the raw numbers, book-built IPOs had a higher average initial return one year before the regulatory change as compared to auctions within one year after the regulatory change (Bubna \& Prabhala, 2011). However, by using a difference-in-difference analysis with underpricing of the fixed-price method as a control group, Bubna and Prabhala (2011) find that bookbuilding is actually associated with lower underpricing. Although there are only very few observations available, Pukthuanthong et al. (2007) investigate the difference in underpricing between bookbuilding and "dirty" Dutch auctions in the US. Their findings suggest that bookbuilding leads to higher underpricing.

\section{Institutional Setting in the Japanese IPO Market}

The changing regulatory environment in the Japanese IPO market in the 1990s provides a unique testing ground to analyse hybrid price-discriminatory auctions and bookbuilding as IPO mechanisms.

\subsection{Hybrid Price-Discriminatory Auction}

After a political scandal in 1989, regulation ensured that IPOs used a hybrid price-discriminatory ("pay-what-you-bid") auction. There were several regulatory changes in the hybrid pricediscriminatory auction method during the period 1989 to 1992. The data for our paper starts in 1993 and does not further address these regulatory changes. From 1993 onwards, the regulatory environment was stable (for details, see Pettway \& Kaneko, 1996, and Kaneko \& Pettway, 2003).

The hybrid price-discriminatory auction method required issuers to offer at least $50 \%$ of shares on sale in an auction tranche. After the auction, the remaining shares were sold in a public offer tranche. The auction process started with the publication of a preliminary prospectus without any price information. About 10 days after the preliminary prospectus was published, the lower price limit on bids in the auction was defined. The underwriter selected (usually three) comparable companies and calculated an expected offer price for the IPO firm. The lower price limit on bids was then set $15 \%$ below the expected offer price and published in the first-revised prospectus. A one-day price-discriminatory auction took place around five days later. On the day of the auction, all bids were aggregated and the shares allocated. The highest bidders were served first until all shares were allocated or the lower price limit on bids was reached. Japanese regulation strictly forbid the participation of firm insiders and limited the number of shares that 


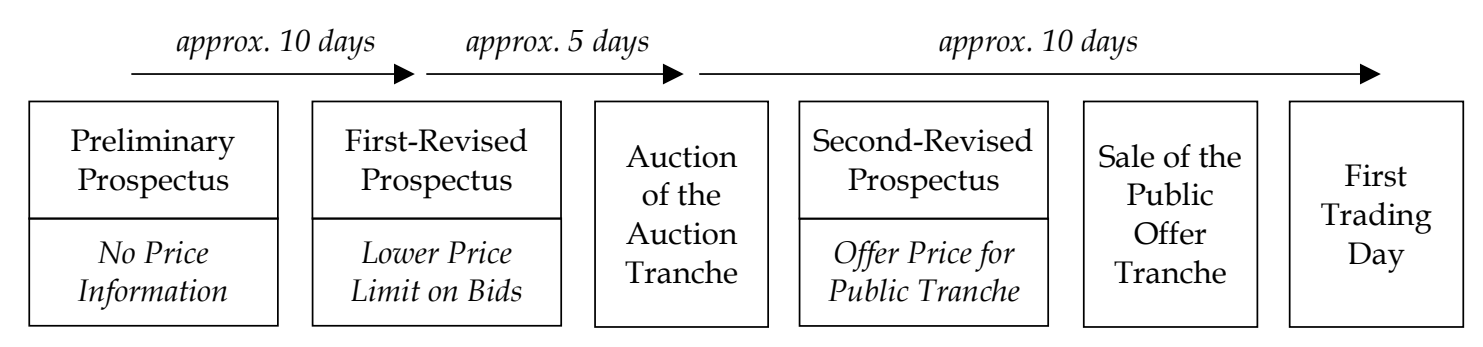

Figure 1: Japanese Hybrid Price-Discriminatory Auction Process

one investor could buy in the auction tranche to no more than 5,000. Kerins, Kutsuna and Smith (2007) mention that most underwriters in their sample even restricted the maximum number of shares to 1,000. A couple of days after the auction took place, the second-revised prospectus was published which included the offer price for the public offer tranche. The underwriter set the offer price for the public offer tranche but was constraint by the weighted average of successful bids in the auction tranche as an upper limit and by the lower price limit on bids in the auction tranche as a lower limit. The public offer tranche was a formal underwritten offering and the underwriter had allocation discretion. There was also a quantity restriction of 5,000 shares per investor in the public offer tranche. The number of days between the auction and the first trading day in our sample was between 6 and 15 days. Figure 1 summarizes the Japanese hybrid pricediscriminatory auction process (for more details on the specifics of the auction mechanism, see Kaneko \& Pettway, 2003, Kutsuna \& Smith, 2004, and Kerins et al., 2007).

\subsection{Bookbuilding}

On the $1^{\text {st }}$ of September 1997 Japanese regulators introduced the bookbuilding method as an alternative to hybrid price-discriminatory auctions. This regulatory change aimed at increasing participation of institutional investors in the IPO price discovery process, promoting access to capital markets for early-stage companies and providing the underwriter more pricing discretion (Kutsuna \& Smith, 2004). Price-discriminatory auctions were still possible but no longer used..2

\footnotetext{
2 Even though bookbuilding was officially introduced on the $1^{\text {st }}$ of September 1997, the first listing took place on the $30^{\text {th }}$ of September 1997. Therefore, we refer to the 30th of September 1997 as date of the policy change. One IPO auction took place after the 30th of September 1997 (on the $7^{\text {th }}$ of October 1997). We nevertheless define the $30^{\text {th }}$ of September 1997 as the date of the policy discontinuity since the two methods have an overlap of only one IPO.
} 


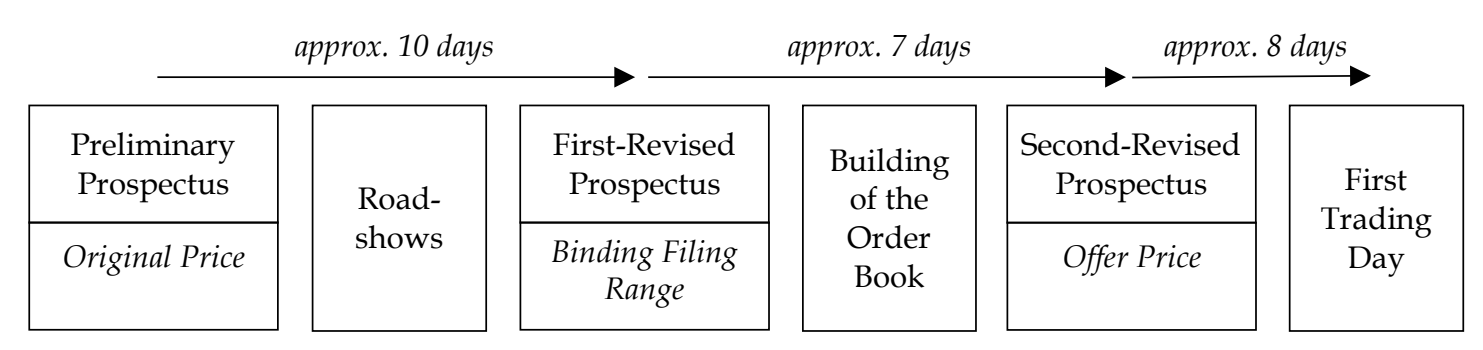

Figure 2: Japanese Bookbuilding Process

The bookbuilding process started with the publication of a preliminary prospectus that included an original price defined by the underwriter and the issuer. In the following ten days, roadshows with selected investors took place. After these roadshows, the first-revised prospectus was published that defined a filing range. In the Japanese bookbuilding method, this filing range was binding for the underwriter which means that the final offer price had to be within this range. ${ }^{3}$ In the following approximately seven days the order book was built. Typically, around 40 to 70 institutions submitted indications of interest which helped the underwriter to assess market demand. Once this process was completed, the underwriter defined the final offer price which was announced in the second-revised prospectus. The underwriter determined the percentage of shares sold to retail investors and allocated the shares. Usually, about 70 to 80 percent of shares were sold to retail investors. Approximately eight days later, the stocks were traded at the stock exchange for the first time. There is some indication that retail investors were substantial net sellers to institutions during the first trading days (Kutsuna, Smith \& Smith, 2009). The complete Japanese bookbuilding process is summarized in Figure 2 (for details on this process, see Kaneko \& Pettway, 2003, and Kutsuna et al., 2009).

\section{Methodology}

\subsection{Hypotheses}

We consider two null hypotheses. The first is the following:

- Null hypothesis 1: There is no difference in underpricing between hybrid pricediscriminatory auctions and bookbuilding.

\footnotetext{
${ }^{3}$ This is a difference to the US, where underwriters may price IPOs outside of the filing range (Bradley \& Jordan, 2002).
} 
The tests we consider are two sided, but the alternative hypothesis that seems most convincing is that bookbuilding leads to higher underpricing than auctions (in line with the empirical evidence provided by Kaneko \& Pettway, 2003, and Beierlein \& Kato, 2003).

The second null hypothesis we consider is the following:

- Null hypothesis 2: There is no difference in price accuracy in the secondary market between the two methods.

There are arguments for deviations in both directions. On the one hand, there is a theoretical argument. In the model by Sherman (2005) there is higher underpricing but also higher aftermarket price accuracy for bookbuilding. In her model, bookbuilding leads to underwriters having control over information production by investors via pricing and share allocation discretion. According to Sherman (2005) "more information production leads to more underpricing, a higher probability that the firm's true value is reflected in the initial trading price, and a lower probability of aftermarket price shifts". On the other hand, empirical evidence points in the other direction (Beierlein \& Kato, 2003; Pettway et al., 2008).

\subsection{Variable Definitions}

The dependent variables are underpricing and price accuracy. They are explained in Sections 4.2.1 and 4.2.2. The covariates (control variables) are introduced in Section 4.2.3.

\subsubsection{Underpricing}

Underpricing $y_{l}$, in percentage terms, is defined as the first-day return based on the offer price $O P$ and the closing share price on the first trading day $C P$ of IPO firm $l$ :

$$
y_{l}=\frac{C P_{l}-O P_{l}}{O P_{l}} * 100
$$

For bookbuilding, the offer price is equal to the offer price published in the second-revised prospectus. For the auction, there is an auction tranche and a public offer tranche with different offer prices. The offer price of the auction tranche is equal to the weighted average of successful bids in the auction. For the public offer tranche, the offer price is equal to the offer price published in the second-revised prospectus. Hence, underpricing for auctions is calculated based on the weighted average offer price of the two tranches. 


\subsubsection{Price Accuracy}

We proxy price accuracy by absolute abnormal returns (as, e.g., in Beierlein \& Kato, 2003). Therefore, we use absolute abnormal buy-and-hold returns over a 12-month aftermarket period (following Cai \& Wei, 1997, who argue that summing up abnormal returns over longer horizons is a source of bias).

We use two stock index benchmarks to calculate absolute abnormal buy-and-hold returns. First, the market-capitalization-weighted Topix index, which covers all domestic stocks listed in the First Section of Tokyo Stock Exchange. Second, the market-capitalization-weighted JASDAQ index which is constituted by all stocks traded at the JASDAQ stock exchange (Over-the-Counter market before 2004). ${ }^{4}$ By using stock index benchmarks, there is an inherent trade-off between comparability and new listing bias. Most IPOs in the sample are smaller and younger firms that are mainly listed at the JASDAQ stock exchange. Therefore, by choosing the JASDAQ index, IPO firms constitute to some extend the index itself. This problem is negligible in the broad Topix index. However, firms included in the Topix index are less comparable to the IPO firms in the sample. Therefore, we use both as benchmarks.

Absolute abnormal buy-and-hold returns $y_{l, t}$, in percentages, of IPO firm $l$ for a time window of 12 months or until delisting $(t)$ are calculated as follows:

$$
y_{l, t}=\left|\left(\frac{P_{t}-P_{0}}{P_{0}}-\frac{B_{t}-B_{0}}{B_{0}}\right) * 100\right|
$$

where $P_{t}$ equals the closing share price of the IPO stock $t$ months after the IPO; $P_{0}$ equals the closing share price of the IPO stock on the first trading day; $B_{t}$ equals the closing price of the benchmark stock index $t$ months after the IPO and $B_{0}$ equals the closing price of the benchmark stock index on the IPO date.

\subsubsection{Covariates}

We use six covariates to control for firm characteristics, IPO specific factors and market conditions. Appendix B provides the formulas for their calculations.

\footnotetext{
${ }^{4}$ For the mature firms analysed in the appendix, the market capitalization-weighted Topix and the share price-weighted Nikkei 225 serve as benchmarks.
} 
Firm Age (log): Firm age is calculated as the logarithm of the difference between the founding date and the IPO date. ${ }^{5}$

Expected Issue Size (log): Following Kaneko and Pettway (2003), we calculate the log expected issue size as the logarithm of the product of the expected offer price and the total number of shares on sale in the IPO. The expected offer price for the bookbuilding method is equal to the average of the upper and lower limit of the filing range as published in the first-revised prospectus. In the auction, the lower price limit on bids is equal to the implied price of a multiple valuation discounted by $15 \%$. Therefore, the expected offer price for the auction is equal to the lower limit on bids divided by 0.85 to account for the $15 \%$ discount. $^{6}$

Insider Sales (in \%): Secondary shares are existing shares sold by current shareholders in the IPO. On the other hand, primary shares refer to shares that are newly issued by the company in the IPO through a capital increase. The insider sales variable, in percentages, is calculated by dividing the number of secondary shares on sale by the total number of shares available for sale. ${ }^{7}$

Underwriter (dummy): A dummy variable is introduced which equals 1 for the five largest underwriters and 0 for all others..$^{8}$

\footnotetext{
5 Arikawa and Imad'eddine (2010), Kaneko and Pettway (2003), Kirkulak (2004), Kirkulak (2008) and Kirkulak and Davis (2005) show that underpricing in Japan tends to be higher for younger firms. Younger firms are associated with higher ex-ante price uncertainty which is expected to increase underpricing. ${ }^{6}$ Various authors find an inverse relation between issue size and underpricing in the US (Beatty \& Ritter, 1986; Ibbotson, Sindelar \& Ritter, 1994; Kaneko \& Pettway, 2003; Arikawa \& Imad'eddine, 2010). However, the issue size is endogenous to underpricing as shown by Habib and Ljungqvist (2001). Therefore, Kaneko and Pettway (2003) propose to use the expected issue size which is calculated based on the expected offer price instead of the actual offer price.

${ }^{7}$ Ljungqvist and Wilhelm (2003) show that a lower percentage of secondary shares on sale in the IPO leads to higher underpricing; they conclude that insiders bargain more aggressively when more secondary shares are on sale since higher underpricing directly reduces their wealth. Butler, Keefe and Kieschnick (2014), Kirkulak (2008) and Kirkulak and Davis (2005) also find that the percentage of secondary shares on sale has explanatory power for underpricing.

8 The five largest underwriters are Nomura (590 IPOs; 28\% market share), Daiwa (399 IPOs; 19\% market share), Nikko (345 IPOs; 16\% market share), Shinko (130 IPOs; 6\% market share) and Yamaichi (103 IPOs, 5\% market shares). Yamaichi operated from 1993 until bankruptcy in 1997. Shinko was formed in April 2000 as a merger of two smaller players. The market shares of these two underwriters are diluted by years they were not operating and the relative market shares in the years of operation were significantly higher. Note that Daiwa and Nikko changed names three times between 1993 and 2007 (Daiwa: Daiwa 1993-1999, Daiwa SB Capital Markets 1999-2001, Daiwa SMBC 2001-2007; Nikko: Nikko 1993-1999, Nikko Salomon Smith Barney 1999-2003, Nikko Citigroup 2003-2007).

Carter and Manaster (1990) find evidence for the US that IPOs underwritten by prestigious investment banks are associated with lower underpricing. For Japan, Arikawa and Imad'eddine (2010) and Kirkulak
} 
Market Return (in \%): The market return, in percentages, is calculated by the buy-and-hold market return for a period of 60 trading days prior to the IPO date. For IPOs listed at growth stock exchanges, the market return is calculated based on the JASDAQ index (for IPOs in the Mature Market Sample, the Topix index serves as proxy for market momentum). ${ }^{9}$

Market Volatility (in \%): Market volatility, in percentages, is calculated by the variance of daily market returns 20 trading days before the IPO. The JASDAQ index again serves as market index for growth stock exchanges (and the Topix for mature stock exchanges). ${ }^{10}$

\subsection{Linear Regression Analyses}

The influence of the policy discontinuity on underpricing and price accuracy is analysed by a set of multiple linear regressions. In the basic regression model, the dependent variable $y_{l}$ (underpricing or absolute abnormal buy-and-hold return) is regressed on an indicator variable Method that equals 0 for auctions and 1 for bookbuilding and covariate vector $x$ :

$$
y_{l}=\alpha+b_{1}\left(\operatorname{Method}_{l}\right)+b_{2} x_{l}+e
$$

The variable of interest is $b_{1}$, which captures the influence of the price discovery method on underpricing or price accuracy after controlling for firm characteristics, IPO specific factors and market conditions. As the time window around the regulatory change from which data is considered plays an important role, we analyse the robustness using data from a wide variety of different time windows.

\subsection{Regression Discontinuity Design}

A regression discontinuity design (RD or RDD; Thistlethwaite \& Campbell, 1960) is a nonexperimental approach to estimate treatment effects in non-experimental settings (Lee \& Lemieux, 2010). ${ }^{11}$ The idea is that treatment is determined quasi-randomly by an observable

(2008) find a positive relation between underwriter reputation and underpricing. Kaneko and Pettway (2003) and Beckman, Garner, Marshall and Okamura (2001) find no significant relation.

9 Derrien and Womack (2003) find a significant positive relationship between market returns and underpricing in France. Others find such an effect in the US (Butler et al., 2014; Lowry \& Schwert, 2004). Kaneko and Pettway (2003), Beckman et al. (2001), Kirkulak (2008) and Kirkulak and Davis (2005) confirm these results for the Japanese market.

${ }^{10}$ Various authors control for market volatility (e.g., Derrien \& Womack, 2003; Kaneko \& Pettway, 2003). Higher market volatility generally leads to higher underpricing.

${ }^{11} \mathrm{RD}$ has recently gained increasing popularity among researchers (Hausman \& Rapson, 2018). A growing number of publications that investigate the influence of policy changes use RD with time as running variable (e.g. Burger, Kaffine \& Yu, 2014; Davis \& Kahn, 2010). 
running variable. The excess of a known threshold (so-called cut point) by the running variable defines if an observation receives treatment. Ideally, the only difference between observations is that some of them got quasi-randomly assigned to receive treatment, in which case an unbiased estimator of the treatment effect can be obtained. In our case, time is the running variable and the 30th of September 1997 is the cut point. When the running variable exceeds the cut point, observations receive "treatment" in the form of being priced by bookbuilding instead of hybrid price-discriminatory auctions. Potential limitations related to the RD implementation in the context of the policy discontinuity in the Japanese IPO market are discussed in Section 8.4.

To estimate the treatment effect in a RD, the functional form of the underlying relation between the running variable (time) and the outcome (underpricing or price accuracy) needs to be specified. There are two types of strategies to specify the functional form (see Jacob, Zhu, Somers \& Bloom, 2012). First, the global strategy, which includes observations far away from the cut point. Every observation in the sample is used to model the outcome as a function of the running variable. The functional form of the running variable is specified with different high-order polynomials to minimize biases (Jacob et al., 2012).

On the other hand, in the local strategy, the sample data is narrowed down to observations very close to the cut point, which are most commonly analysed with a local linear regression model. These observations ideally only differ by getting quasi-randomly assigned to receiving treatment.

\subsubsection{Global Strategy}

In the regression model of the global strategy, the dependent variable $y_{l}$ (underpricing or absolute abnormal return) is regressed on an indicator variable Method that equals 0 for auctions and 1 for bookbuilding, a vector of covariates $x$ and a time trend $f$ (Time):

$$
y_{l}=\alpha+b_{1}\left(\text { Method }_{l}\right)+b_{2} x_{l}+f(\text { Time })+e
$$

The challenge in the global strategy is to find a good specification of $f$ (Time). The underlying idea is that there are time-varying factors that cannot be captured through covariates in vector $x$. Consequently, observations far away from the cut point are less informative about the effect of the policy change since they are biased by time-variations (Bento, Kaffine, Roth \& ZaragozaWatkins, 2014). By specifying the relation between time and the dependent variable, these timevarying effects may be captured. In RD, $f$ (Time) is usually specified as a polynomial. There is no consistent approach in the literature to identify the correct specification. Gelman and Imbens 
(2019) analyze first to sixth order polynomial specifications and find that the results of the global strategy are sensitive to the order of the polynomial. Therefore, we present the complete set of results for $f$ (Time) specified by first to sixth order polynomials.

\subsubsection{Local Strategy}

The local strategy should not be seen as a substitute but rather as a complement to the global strategy (Lee \& Lemieux, 2010). In the local strategy, we control for time-varying factors through a linear time trend within a local bandwidth of the policy discontinuity. The dependent variable $y_{l}$ is regressed on an indicator variable Method that equals 0 for auctions and 1 for bookbuilding, a vector of covariates $x$ and a linear time trend Time:

$$
y_{l}=\alpha+b_{1}\left(\text { Method }_{l}\right)+b_{2}(\text { Time })+b_{3} x_{l}+e
$$

Furthermore, a regression equation with an additional interaction term between the linear time trend Time and the indicator variable Method is also analysed:

$$
y_{l}=\alpha+b_{1}\left(\text { Method }_{l}\right)+b_{2}(\text { Time })+b_{3}(\text { Method }) *(\text { Time })+b_{4} x_{l}+e
$$

The main challenge in the local strategy is the specification of the bandwidth. The local strategy faces a trade-off between statistical power and proximity to the cut point. Larger bandwidths and therefore larger sample sizes have higher statistical power but at the same time the risk of misspecification and therefore biased results increases (Cattaneo, Titiunik \& Vazquez-Bare, 2020). We follow the suggestion by Imbens and Kalyanaraman (2012) to assess the sensitivity of the results on their bandwidth choice by presenting the results for a variety of bandwidths.

Local linear regressions also introduce a kernel that defines a weighting scheme (Cattaneo et al., 2020). The simplest form is a rectangular kernel which assigns every observation the same weighting leading to standard OLS. Other kernels, such as a triangular kernel or an epanechnikov kernel, assign observations closer to the cut point a higher weighting. We present the results of the local linear regression based on rectangular, triangular and epanechnikov kernels.

\section{Data}

The data consist of Japanese IPOs from January 1993 to December 2007. Before 1993 the regulatory environment was not stable with various changes in the auction method (Kaneko \& Pettway, 2003). Data after 2007 is not used to avoid distortions by the following financial crisis. There are 
2,175 Japanese IPOs in the sample. ${ }^{22}$ The data for the bookbuilding period is publicly available from Kaneko and Pettway's Japanese IPO Database (KP-JIPO). ${ }^{13}$ Data for the auction period is not publicly available and was kindly provided by Kaneko and Pettway. ${ }^{14}$ In addition to the data from Kaneko and Pettway, JASDAQ index prices and Topix index prices for the period October 1992 to December 2007 are obtained from Thomson Reuters Datastream (2020).

Regulated stock markets usually consist of three separate areas. There are the First Sections for large, established companies, the Second Sections for mid-sized companies and growth sections or new markets for early-stage, high growth companies with lower listing requirements (Boutron, Gajewski, Gresse \& Labégorre, 2006). The three largest stock exchanges in Japan (Tokyo, Osaka and Nagoya) had First and Second Sections for different company types (Japan Securities Research Institute, 2014). Further, there are various regional stock exchanges (e.g., Sapporo) that mainly targeted local medium-sized companies. Until 1999, no stock exchange had a specific section for growth companies. The only stock exchange that enabled early-stage companies to go public before 1999 was the Over-the-Counter (OTC) market (converted to JASDAQ in 2004; Japan Securities Research Institute, 2014). As a reaction to growing investor demand for access to earlystage companies at the end of the 1990s, stock exchanges introduced dedicated sections for growth companies.

The data cover IPOs across all Japanese stock exchanges. However, there are no observations for the First Sections of Osaka Stock Exchange and Nagoya Stock Exchange available and the data misses a significant number of IPOs in the First Section of Tokyo Stock Exchange. Consequently, the First Sections are not further analysed and 63 IPOs from the First Section of Tokyo Stock Exchange are removed from the sample. The remaining 2,112 IPOs are split into two samples. The first sample consists of mid-sized companies that were listed in the Second Sections of Tokyo

12 The sample originally consisted of 2,180 observations. This included four privatizations which are excluded from the analysis. Further, the information about the IPO of Club IT (SEC: 4347) is inconsistent: The upper limit of the filing range is unreasonably high at 20,020,219 Japanese Yen; we assume that the upper limit was accidentally overwritten with a date (2002/02/19). This IPO is therefore removed from the sample. Furthermore, the first day closing share price of Infocom (SEC: 4348) of $-99.2 \%$ is implausible and inconsistent with Thomson Reuters Datastream (2020); the value was therefore adjusted based on the data from Thomson Reuters Datastream (2020).

${ }^{13}$ https://www.fbc.keio.ac.jp/ kaneko/KP-JIPO/top.htm

14 A subsample of these data focusing on three Japanese stock exchanges (Over-the-Counter market, Mothers and NASDAQ-Japan) and covering the period 1993 to 2001 is investigated in the articles of Kaneko and Pettway (2003) and Pettway et al. (2008). 


\section{Table 1: Sample description \\ Japanese IPOs between 01/01/1993 and 31/12/2007}

GP stands for average gross proceeds. In auctions, gross proceeds are calculated as the number of shares sold in the auction tranche multiplied by the weighted average successful bid plus the number of shares sold in the public offer tranche multiplied by the offer price of the public offer tranche. In bookbuilding, gross proceeds are equal to the offer price multiplied by the number of shares sold. Gross proceeds in US dollars are calculated based on the USD/Yen spot rate on the IPO date. USD/Yen spot rates are obtained from Thomson Reuters Datastream (2020). The exchange rate for the period 01/01/1993 to 31/08/1993 is kept constant at the rate of the 01/09/1993 (1 USD = $104.94 \mathrm{Yen}$ ) due to limited data availability before 01/09/1993. For both samples, there are also four subsamples described. OTC is a subsample of IPOs at the Over-the-Counter market and JASDAQ. NASDAQJ is a subsample of IPOs at NASDAQ Japan and Hercules. Others is a subsample of IPOs at Neo, Centrex, Q-Board, Osaka New Market and Ambitious stock exchanges. TSE stands for Tokyo Stock Exchange, OSE for Osaka Stock Exchange and NSE for Nagoya Stock Exchange. Regional Exchanges is a subsample of IPOs at stock exchanges in Kyoto, Hiroshima, Niigata, Fukuoka and Sapporo.

Growth Market Sample

\begin{tabular}{|c|c|c|c|c|c|}
\hline & $\begin{array}{c}\text { Full } \\
\text { Sample }\end{array}$ & OTC & Mothers & NASDAQJ & Others \\
\hline Observations & 1,702 & 1,207 & 231 & 206 & 58 \\
\hline Auctions & 481 & 481 & 0 & 0 & 0 \\
\hline Bookbuilding & 1,221 & 726 & 231 & 206 & 58 \\
\hline Firm Age & 22.6 & 27.1 & 9.6 & 13.8 & 12.5 \\
\hline GP (million Yen) & $2,924.1$ & $2,980.9$ & $3,469.1$ & $2,593.4$ & 748.1 \\
\hline GP (million USD) & 26.6 & 27.4 & 31.1 & 22.7 & 6.7 \\
\hline
\end{tabular}

Mature Market Sample

\begin{tabular}{|c|c|c|c|c|c|}
\hline & $\begin{array}{c}\text { Full } \\
\text { Sample }\end{array}$ & $\begin{array}{l}\text { TSE } 2^{\text {nd }} \\
\text { Section }\end{array}$ & $\begin{array}{l}\text { OSE } 2^{\text {nd }} \\
\text { Section }\end{array}$ & $\begin{array}{l}\text { NSE } 2^{\text {nd }} \\
\text { Section }\end{array}$ & $\begin{array}{c}\text { Regional } \\
\text { Exchanges }\end{array}$ \\
\hline Observations & 410 & 174 & 143 & 44 & 49 \\
\hline Auctions & 200 & 54 & 84 & 30 & 32 \\
\hline Bookbuilding & 210 & 120 & 59 & 14 & 17 \\
\hline Firm Age & 34.9 & 35.2 & 35.4 & 38.3 & 29.6 \\
\hline GP (million Yen) & $4,948.0$ & $7,258.0$ & $3,418.1$ & $3,554.7$ & $2,461.1$ \\
\hline GP (million USD) & 46.4 & 67.5 & 32.3 & 33.9 & 24.2 \\
\hline
\end{tabular}

Stock Exchange, Osaka Stock Exchange and Nagoya Stock Exchange and at regional stock exchanges ("Mature Market Sample"). The second sample consists of IPOs at growth stock exchanges ("Growth Market Sample"). Appendix A provides an overview of all Japanese stock exchanges and their classification as Growth Market, Mature Market or Excluded Market.

Table 1 describes the Growth Market Sample and the Mature Market Sample. Firms in the Growth Market Sample are younger and gross proceeds are lower. Within the Growth Market Sample, firms listed at the OTC stock market are on average older. This is partially driven by the fact that the OTC market is the only stock exchange in the Growth Market Sample that was operating during the auction period. The Growth Market Sample consists of 1,702 observations and is 
significantly larger than the Mature Market Sample with 410 observations. Therefore, our main focus lies on the Growth Market Sample. However, all analyses are also performed for the Mature Market Sample and presented in Appendix C. If not explicitly referred to the Mature Market Sample, the following discussion always refers to the Growth Market Sample. Most observations in the Growth Market Sample are IPOs at the JASDAQ/OTC market. Therefore, an additional subsample that only includes JASDAQ/OTC listings is also analysed ("OTC Subsample").

For the price accuracy analysis, monthly stock price data for each IPO firm is required. As an identifier for each firm only the local Japanese Security Code is available. Through extensive matching and verification, the ISIN number for 1,784 out of 2,112 IPOs could be identified and validated. ${ }^{15}$ The Growth Market Sample for the analysis of price accuracy consists of 1,448 observations and the Mature Market Sample of 336 observations. Based on the ISIN number, stock price data for each IPO firm and index prices for the benchmark indices are obtained from Thomson Reuters Datastream (2020). ${ }^{16}$

\section{Results on Underpricing}

The analysis of underpricing is split into three sections. First, descriptive statistics are provided. Afterwards, the results of the multiple linear regression models are discussed. Finally, the findings of the regression discontinuity designs are presented. We present here the results for the Growth Market Sample. The corresponding results for the Mature Market Sample are qualitatively similar and can be found in Appendix C.

\subsection{Descriptive Statistics (Underpricing)}

Underpricing in Japan fluctuated significantly over time as shown in Table 2. While underpricing between 1993 and 1998 was rather low, initial returns strongly increased in 1999. Afterwards, underpricing reverted but remained at higher levels and peaked again in the years 2004 and 2005

\footnotetext{
${ }^{15}$ Based on information from Wharton Research Data Services, Mizuho Corporate Bank and Bank of TokyoMitsubishi, the ISIN numbers for 1,784 out of 2,112 IPOs were successfully identified and cross-checked. In the cross-checking procedure, it was evaluated if the stock price time series in Thomson Reuters Datastream (2020) starts exactly on the IPO date defined in the data obtained from Kaneko and Pettway. Further, it was validated that the unadjusted closing price on the first trading day in Thomson Reuters Datastream (2020) matches the first day closing share price in the obtained data set.

${ }^{16}$ Adjusted prices (P) is the default option for stock price data in Thomson Reuters Datastream (2020). However, it does not incorporate dividend payments. Therefore, the analysis is based on the total return index (RI) that accounts for dividend payments. All prices are in the local currency (Japanese Yen).
} 


\section{Table 2: Underpricing by Year}

\section{Underpricing between 01/01/1993 and 31/12/2007 (Growth Market Sample)}

Obs. abbreviates the number of observations and Und. stands for average underpricing (in \%). OTC is a subsample of IPOs at the Over-the-Counter market (converted to JASDAQ in 2004). Mothers covers all IPOs at the Mothers stock exchange. NASDAQJ is a subsample of IPOs at NASDAQ Japan and Hercules. Others is a sample of IPOs at Neo, Centrex, Q-Board, Osaka New Market and Ambitious stock exchange. Note that there is an overlap between the two methods because the last auctioned IPO took place seven days after the first book-built IPO.

\begin{tabular}{|c|c|c|c|c|c|c|c|c|c|c|}
\hline \multirow[b]{2}{*}{ Year } & \multicolumn{2}{|c|}{ Full Sample } & \multicolumn{2}{|c|}{ Отс } & \multicolumn{2}{|c|}{ Mothers } & \multicolumn{2}{|c|}{ NASDAQJ } & \multicolumn{2}{|c|}{ Others } \\
\hline & Obs. & Und. & Obs. & Und. & Obs. & Und. & Obs. & Und. & Obs. & Und. \\
\hline 1993 & 54 & 8.9 & 54 & 8.9 & - & - & - & - & - & - \\
\hline 1994 & 106 & 7.6 & 106 & 7.6 & - & - & - & - & - & - \\
\hline 1995 & 137 & 8.7 & 137 & 8.7 & - & - & - & - & - & - \\
\hline 1996 & 110 & 9.4 & 110 & 9.4 & - & - & - & - & - & - \\
\hline 19971 & 74 & 0.8 & 74 & 0.8 & - & - & - & - & - & - \\
\hline 19972 & 29 & 10.2 & 29 & 10.2 & - & - & - & - & - & - \\
\hline 1998 & 62 & 23.8 & 62 & 23.8 & - & - & - & - & - & - \\
\hline 1999 & 76 & 135.6 & 73 & 134.8 & 2 & 227.6 & - & - & 1 & 10.0 \\
\hline 2000 & 161 & 19.8 & 97 & 21.2 & 27 & 7.6 & 33 & 27.0 & 4 & 8.1 \\
\hline 2001 & 149 & 49.8 & 97 & 34.4 & 7 & 98.0 & 43 & 76.3 & 2 & 58.1 \\
\hline 2002 & 99 & 35.3 & 68 & 29.0 & 8 & 19.1 & 23 & 59.8 & 0 & 0.0 \\
\hline 2003 & 101 & 58.8 & 62 & 37.2 & 31 & 101.9 & 7 & 73.3 & 1 & -43.1 \\
\hline 2004 & 149 & 112.3 & 71 & 94.2 & 56 & 137.6 & 16 & 105.1 & 6 & 108.4 \\
\hline 2005 & 138 & 148.7 & 65 & 104.9 & 36 & 166.4 & 22 & 267.7 & 15 & 121.2 \\
\hline 2006 & 151 & 89.6 & 56 & 58.6 & 41 & 107.7 & 37 & 145.4 & 17 & 27.0 \\
\hline 2007 & 106 & 56.1 & 46 & 42.1 & 23 & 88.3 & 25 & 60.7 & 12 & 38.8 \\
\hline
\end{tabular}

1) Auction period (1st January $-7^{\text {th }}$ October); 2) Bookbuilding period (30 $30^{\text {th }}$ September $-31^{\text {st }}$ December)

with average initial returns above $100 \%$. Compared to the US, underpricing was approximately on the same level in the 1990s but higher during the dot-com bubble 1999/2000 and thereafter (see Loughran \& Ritter, 2004, for underpricing over time in the US).

The development of underpricing over time is presented in Figure 3 (the dot-com bubble $1999 / 2000$ is the shaded area). One can see that underpricing in the auction period is less volatile than in the bookbuilding period.

The bookbuilding and auction subsamples are described in Table 3. The bookbuilding period covers a significantly longer time period and thus contains more observations. The largest five underwriters coordinated $80.87 \%$ of all IPOs in the auction period and $66.74 \%$ in the bookbuilding period. IPO auctions are on average underpriced by $7.42 \%$, while book-built IPOs have an average initial return of $72.77 \%$. According to a simple t-test, auctions have significantly lower initial returns $(t=-12.90, p=0.000)$. However, firms going public by bookbuilding are on average younger, expected issue sizes are lower, fewer secondary shares are on sale and market returns 


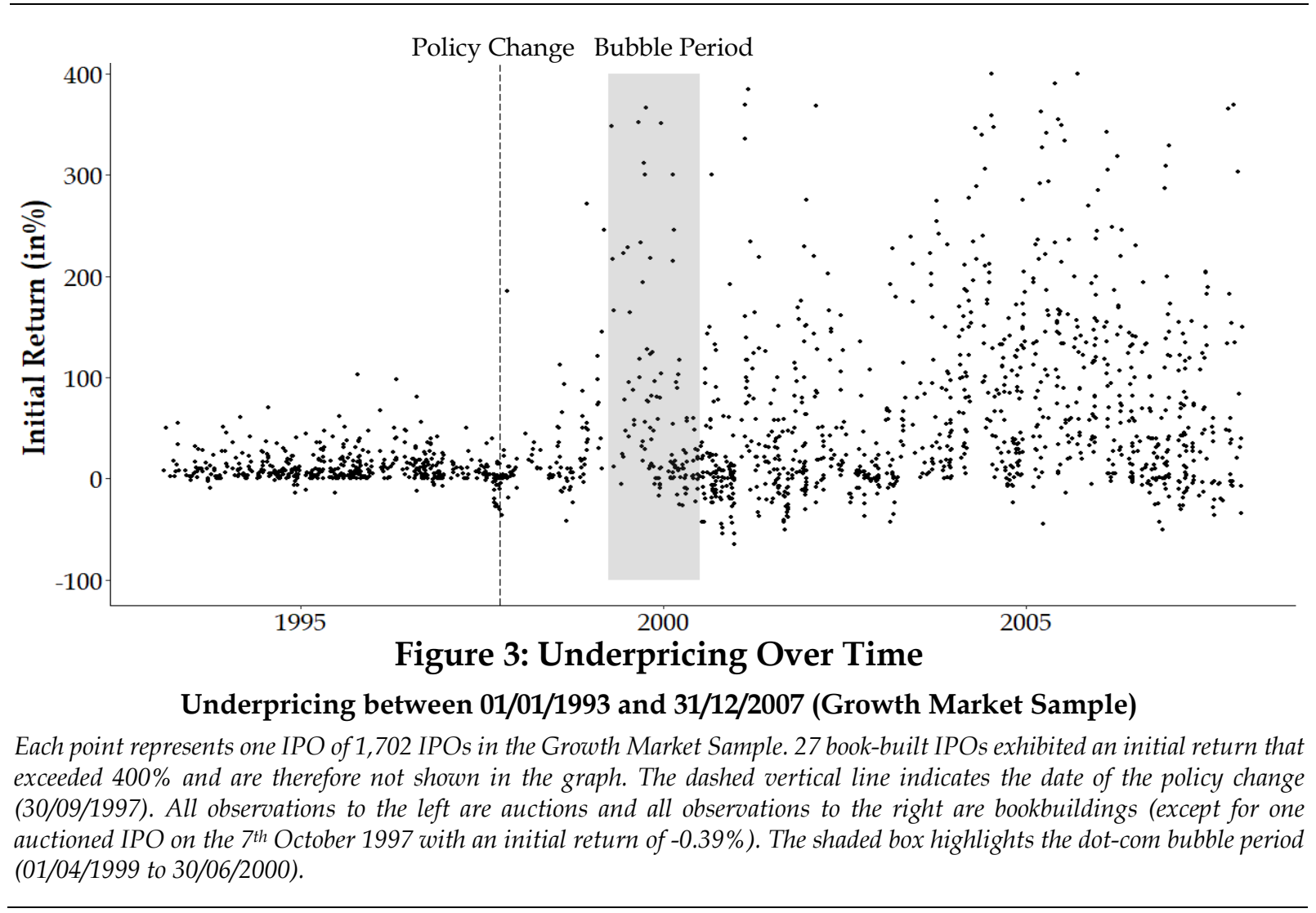

and market volatility before the IPO were higher. Previous research identified these factors as drivers of high underpricing. In the following, several econometric analyses are conducted to analyse the influence of the price discovery method on underpricing without ignoring such confounding factors.

\subsection{Linear regression Analyses (Underpricing)}

We analyse the sample with a Method dummy for the IPO method. Model 1 to Model 3 in Table 4 analyse the Growth Market Sample and Model 4 to Model 6 in Table 4 are based on the OTC Subsample. A point of concern is the influence of the dot-com bubble period (April 1999 to July 2000) on the results. While Model 1 and Model 4 do not control for this period, Model 2 and Model 5 introduce a dummy variable. Model 3 and Model 6 exclude dot-com bubble IPOs from the analysis.

The Method coefficient estimate is statistically significant at the $0.1 \%$-level in all six models with values between 35.83 and 37.51 (percentage points) for the Growth Market Sample (29.07 to 33.41 for the OTC Subsample). Underpricing is thus significantly higher for bookbuilding than for 


\section{Table 3: Underpricing - Descriptive Statistics}

\section{Japanese IPOs between 01/01/1993 and 31/12/2007 (Growth Market Sample)}

Top 5 Underwriter refers to the number of IPOs underwritten by one of the five largest investment banks. Bubble Period refers to the number of IPOs between the 01/04/1999 and 30/06/2000. See Section 4.2.3 for a detailed description of each covariate. The currency of the expected issue size is Japanese Yen.

\begin{tabular}{|c|c|c|c|c|}
\hline \multirow[b]{2}{*}{ Observations } & \multicolumn{2}{|c|}{ Auction Subsample } & \multicolumn{2}{|c|}{ Bookbuilding Subsample } \\
\hline & \multicolumn{2}{|c|}{481} & \multicolumn{2}{|c|}{1,221} \\
\hline Top 5 Underwriter & \multicolumn{2}{|c|}{389} & \multicolumn{2}{|c|}{815} \\
\hline \multirow[t]{2}{*}{ Bubble Period } & \multicolumn{2}{|c|}{0} & \multicolumn{2}{|c|}{121} \\
\hline & Average & Median & Average & Median \\
\hline Underpricing & $7.42 \%$ & $3.97 \%$ & $72.77 \%$ & $33.96 \%$ \\
\hline Firm Age & 30.34 & 30.07 & 19.61 & 15.97 \\
\hline log (Firm Age) & 3.30 & 3.40 & 2.65 & 2.77 \\
\hline Expected Issue Size & $2,767 \mathrm{~m}$ & $1,864 \mathrm{~m}$ & $2,495 \mathrm{~m}$ & $1,015 \mathrm{~m}$ \\
\hline $\log ($ Exp. Issue Size) & 21.38 & 21.35 & 20.84 & 20.74 \\
\hline Insider Sales & $39.37 \%$ & $44.59 \%$ & $35.62 \%$ & $37.50 \%$ \\
\hline Market Return & $-1.85 \%$ & $-3.52 \%$ & $0.54 \%$ & $-1.63 \%$ \\
\hline Market Volatility & $0.0065 \%$ & $0.0043 \%$ & $0.0205 \%$ & $0.0095 \%$ \\
\hline
\end{tabular}

hybrid price-discriminatory auctions after controlling for firm characteristics, IPO specific factors and market conditions. This confirms the findings of Kaneko and Pettway (2003).

The results in all six models also indicate that older firms exhibit lower initial returns. This can be attributed to lower ex-ante price uncertainty and is consistent with Kaneko and Pettway (2003), Arikawa and Imad'eddine (2010), Kirkulak (2004), Kirkulak (2008) and Kirkulak and Davis (2005). The market return coefficient is statistically significant at the $0.1 \%$-level in all six models. This indicates that market returns before the IPO are not fully incorporated in the offer price. A one percentage point higher market return before the IPO increases underpricing by 2.0 percentage points based on the results of Model 1 to Model 3. Thus, IPOs in "hot" markets are associated with higher underpricing. These results are consistent with Lowry and Schwert (2004) and Loughran and Ritter (2002) who argue that public information such as pre-IPO market returns are not fully incorporated into the offer price. The expected issue size is negatively related to underpricing and the coefficients are significant at the $0.1 \%$-level (except for Models 4 and 5). This confirms the results of Kaneko and Pettway (2003) and Arikawa and Imad'eddine (2010). Kirkulak (2008) and Kirkulak and Davis (2005) suggest that higher percentages of secondary shares on sale in the IPO lower underpricing. The negative Insider Sales coefficients in Table 4 


\section{Table 4: Underpricing - Regression Results (Full Sample) Japanese IPOs between 01/01/1993 and 31/12/2007 (Growth Market Sample)}

In all six OLS regressions, the dependent variable is underpricing. P-values shown in parenthesis are based on heteroscedasticity-consistent standard errors (HC3). See Section 4.2.3 for a detailed description of each covariate. ExpIS abbreviates the expected issue size. In Model 1 to Model 3 the Growth Market Sample is analysed. In Model 4 to Model 6 the OTC Subsample is investigated. Model 1 and Model 4 do not account for the dot-com bubble 1999/2000. Model 2 and Model 5 introduce a dot-com bubble 1999/2000 dummy variable that equals 1 for observations between 01/04/1999 and 30/06/2000. Model 3 and Model 6 exclude observations between 01/04/1999 and 30/06/2000 from the analysis.

\begin{tabular}{|c|c|c|c|c|c|c|}
\hline Data & Model 1 & Model 2 & Model 3 & Model 4 & Model 5 & Model 6 \\
\hline Stock Exchange & All & All & All & OTC & OTC & OTC \\
\hline Bubble Period & - & Dummy & Data exc. & - & Dummy & Data exc. \\
\hline \multicolumn{7}{|l|}{ Results } \\
\hline Intercept & $\begin{array}{c}359.60 \\
(0.000)^{* * *}\end{array}$ & $\begin{array}{c}357.06 \\
(0.000)^{* * *}\end{array}$ & $\begin{array}{c}409.09 \\
(0.000)^{* * *}\end{array}$ & $\begin{array}{c}137.14 \\
(0.001)^{* *}\end{array}$ & $\begin{array}{c}148.24 \\
(0.000)^{* * *}\end{array}$ & $\begin{array}{c}186.18 \\
(0.000)^{* * *}\end{array}$ \\
\hline Method & $\begin{array}{c}37.28 \\
(0.000)^{* * *}\end{array}$ & $\begin{array}{c}37.51 \\
(0.000)^{* * *}\end{array}$ & $\begin{array}{c}35.83 \\
(0.000)^{* * * *}\end{array}$ & $\begin{array}{c}33.41 \\
(0.000)^{* * * *}\end{array}$ & $\begin{array}{c}32.16 \\
(0.000)^{* * *}\end{array}$ & $\begin{array}{c}29.07 \\
(0.000)^{* * * *}\end{array}$ \\
\hline Log Age & $\begin{array}{c}-27.53 \\
(0.000)^{* * *}\end{array}$ & $\begin{array}{c}-27.46 \\
(0.000)^{* * *}\end{array}$ & $\begin{array}{c}-25.03 \\
(0.000)^{* * * *}\end{array}$ & $\begin{array}{c}-22.96 \\
(0.000)^{* * * *}\end{array}$ & $\begin{array}{c}-23.07 \\
(0.000)^{* * *}\end{array}$ & $\begin{array}{c}-16.00 \\
(0.000)^{* * * *}\end{array}$ \\
\hline Log ExpIS & $\begin{array}{c}-11.63 \\
(0.000)^{* * *}\end{array}$ & $\begin{array}{c}-11.53 \\
(0.000)^{* * *}\end{array}$ & $\begin{array}{c}-14.56 \\
(0.000)^{* * * *}\end{array}$ & $\begin{array}{c}-1.69 \\
(0.399)\end{array}$ & $\begin{array}{c}-2.17 \\
(0.252)\end{array}$ & $\begin{array}{c}-5.48 \\
(0.001)^{* * *}\end{array}$ \\
\hline Insider Sales & $\begin{array}{c}-0.32 \\
(0.010)^{* *}\end{array}$ & $\begin{array}{c}-0.32 \\
(0.009)^{* *}\end{array}$ & $\begin{array}{l}-0.23 \\
(0.050)\end{array}$ & $\begin{array}{c}-0.41 \\
(0.001)^{* *}\end{array}$ & $\begin{array}{c}-0.40 \\
(0.001)^{* *}\end{array}$ & $\begin{array}{c}-0.24 \\
(0.016)^{*}\end{array}$ \\
\hline Market Return & $\begin{array}{c}2.01 \\
(0.000)^{* * * *}\end{array}$ & $\begin{array}{c}2.04 \\
(0.000)^{* * *}\end{array}$ & $\begin{array}{c}1.96 \\
(0.000)^{* * * *}\end{array}$ & $\begin{array}{c}1.74 \\
(0.000)^{* * * *}\end{array}$ & $\begin{array}{c}1.57 \\
(0.000)^{* * *}\end{array}$ & $\begin{array}{c}1.46 \\
(0.000)^{* * * *}\end{array}$ \\
\hline Market Volat. & $\begin{array}{c}-108.40 \\
(0.056)\end{array}$ & $\begin{array}{l}-85.92 \\
(0.313)\end{array}$ & $\begin{array}{l}155.48 \\
(0.411)\end{array}$ & $\begin{array}{l}-21.12 \\
(0.704)\end{array}$ & $\begin{array}{r}-125.49 \\
(0.182)\end{array}$ & $\begin{array}{l}402.62 \\
(0.139)\end{array}$ \\
\hline Underwriter & $\begin{array}{c}5.58 \\
(0.256)\end{array}$ & $\begin{array}{c}5.72 \\
(0.246)\end{array}$ & $\begin{array}{c}5.31 \\
(0.274)\end{array}$ & $\begin{array}{c}2.02 \\
(0.673)\end{array}$ & $\begin{array}{c}1.51 \\
(0.754)\end{array}$ & $\begin{array}{c}1.21 \\
(0.767)\end{array}$ \\
\hline Bubble & & $\begin{array}{c}-5.07 \\
(0.764)\end{array}$ & & & $\begin{array}{c}22.85 \\
(0.254)\end{array}$ & \\
\hline Observations & 1,702 & 1,702 & 1,581 & 1,207 & 1,207 & 1,104 \\
\hline Adj. R-squared & 0.232 & 0.232 & 0.238 & 0.241 & 0.243 & 0.227 \\
\hline F-value & 74.50 & 65.18 & 71.52 & 55.65 & 49.47 & 47.13 \\
\hline p-value & $0.000^{* * *}$ & $0.000^{* * *}$ & $0.000^{* * *}$ & $0.000 * * *$ & $0.000^{\star * *}$ & $0.000 * * *$ \\
\hline
\end{tabular}

provide supporting evidence for this. Finally, all models find no statistically significant relation between underpricing and underwriter reputation as well as underpricing and market volatility. This is consistent with Kaneko and Pettway (2003).

Ritter and Welch (2002) argue that underpricing is non-stationary and subject to substantial timevariations, which makes the results of empirical research sensitive to the choice of the sample period. The sensitivity of the results in Table 4 to the sample period is investigated in Figure 4 . 

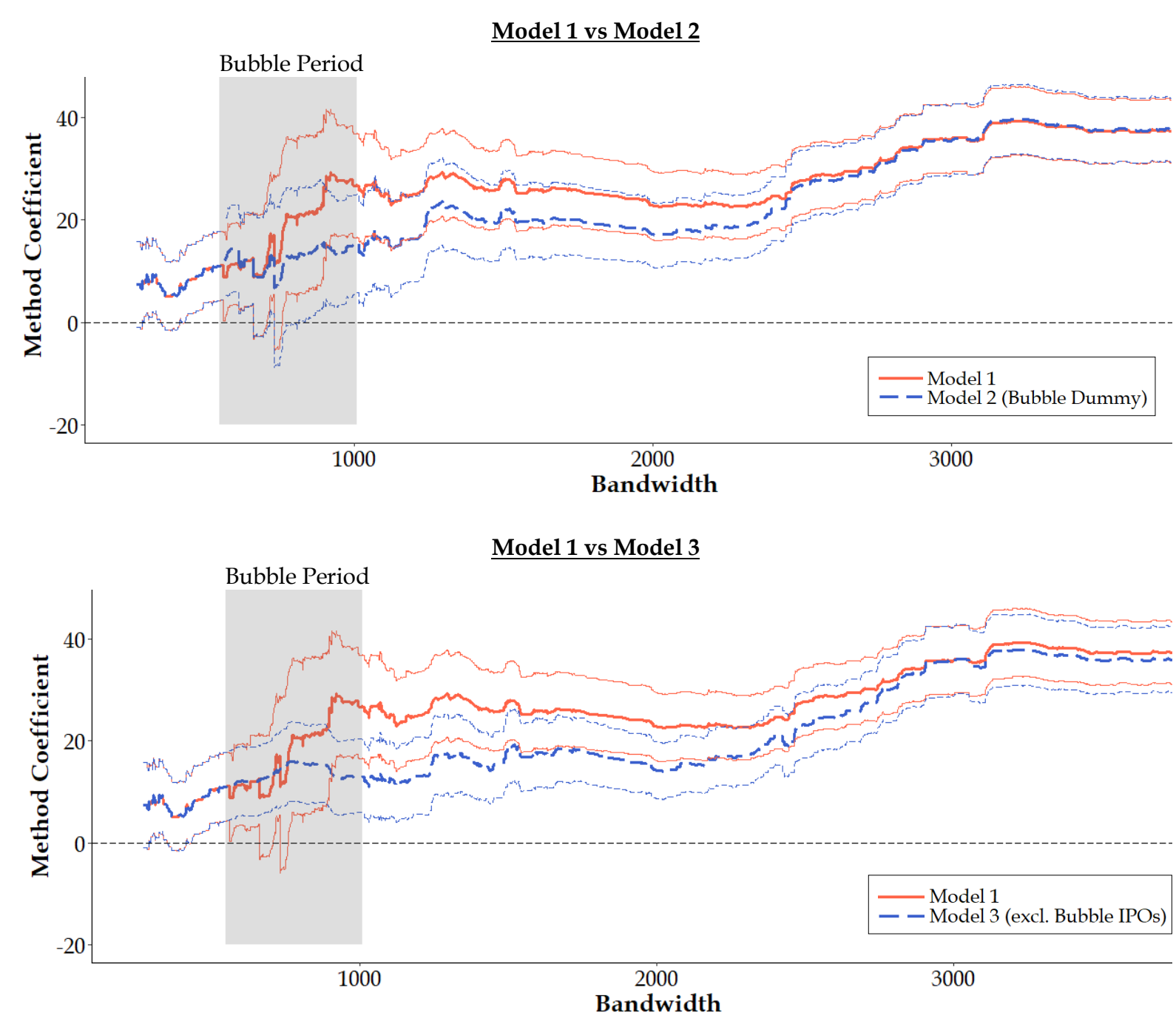

\section{Figure 4: Method Coefficient and Bandwidth (Multiple Linear Regression)}

Method Coefficient Sensitivity and Dot-com Bubble 1999/2000 (Growth Market Sample)

This figure presents the estimate of the Method coefficient for 10,410 OLS regressions. In all regressions, the dependent variable is underpricing. The straight (red) line is based on the regression equation of Model 1 in Table 4. The dashed (blue) lines in the upper graph and the lower graph account for the dot-com bubble 1999/2000 and are based on the regression equation of Model 2 in Table 4 and Model 3 in Table 4, respectively. The shaded box highlights the bandwidth that covers the dot-com bubble period (01/04/1999 to 30/06/2000). Further, 95\%-confidence intervals are presented. Bandwidth specifies the data that is included in the regression analysis. Note that even though the dashed (blue) line in the lower graph excludes dotcom bubble 1999/2000 observations from the analysis, the Method coefficient changes during this period because the number of observations from the auction period is increasing with a growing bandwidth.

The graph plots the relation between the Method coefficient estimate and the bandwidth, which specifies the data that is analysed in the regression. The first data point in Figure 4 plots the Method coefficient estimate for a bandwidth of 270 days. This means that only observations from 270 days before the policy change to 270 days after the policy change are analysed. The very last 
data point (bandwidth of 3,740) is based on the full Growth Market Sample and the Method coefficient estimate is therefore equal to the estimate reported in Table 4 . The straight (red) line is based on the specification of Model 1 in Table 4. The dashed (blue) line in the upper panel includes an additional bubble dummy (Model 2 in Table 4). Further, the dashed (blue) line in the lower panel excludes observations during the dot-com bubble 1999/2000 (Model 3 in Table 4). The graphs include 95\%-confidence intervals.

The highest Method coefficient for pre-bubble bandwidths of 270 to 548 is estimated at 11.0. Excessive underpricing during the dot-com bubble 1999/2000 seems to significantly increase the Method coefficient estimate (straight, red line), when these data are included. The highest estimate of the Method coefficient for the dot-com bubble 1999/2000 bandwidths of 548 to 1,040 (grey box) is estimated at 29.2. When controlling for the dot-com bubble 1999/2000, the estimates of the Method coefficient for this period represented by the two dashed (blue) lines remain below 16.0. The development of the Method coefficient in the post-bubble period is particularly interesting. By increasing the bandwidth, the Method coefficient estimates increase for all three model specifications. During the dot-com bubble 1999/2000 initial returns reached excessive levels. Even though underpricing reverted to lower levels afterwards, Figure 4 indicates that it remained on higher levels than before the bubble.

\subsection{Regression Discontinuity Designs (Underpricing)}

The results thus far confirm the findings of Kaneko and Pettway (2003) and increase the robustness by investigating data from different time periods, varying subsamples, and other model specifications (and, in Appendix C, an additional sample from mature stock exchanges). However, Figure 4 reveals that the results might be sensitive to the choice of the sample period. Under the assumption that there are time-variations, the explanatory power of observations far away from the cut point may be limited.

In the following, we use regression discontinuity designs to disentangle the influence of the policy change on underpricing from other unobserved time-varying factors. As introduced in Section 4.4, there are two complementary RD strategies, the global and the local strategy.

\subsubsection{RD Global Strategy (Underpricing)}

The global strategy of the regression discontinuity design accounts for unobserved time-varying effects by a polynomial time trend. Table 5 presents the Method coefficient estimates for 


\section{Table 5: Underpricing - RD Global Strategy Results Japanese IPOs between 01/01/1993 and 31/12/2007 (Growth Market Sample)}

The table presents the results of the Method coefficient for 24 OLS regressions with underpricing as dependent variable. In all regressions, the covariates introduced in Section 4.2 .3 are included in the regression equation. In Model 2 and Model 4 a bubble dummy is included in the regression equation that equals 1 for observations between 01/04/1999 and 30/06/2000. In Model 3 and Model 4 the OTC Subsample is investigated. For each model, six OLS regressions are conducted with different specifications of $f$ (Time). P-values shown in parenthesis are based on heteroscedasticity-consistent standard errors (HC3). No model excludes IPOs during the dot-com bubble 1999/2000 because the underlying idea of the global strategy is that every single observation is included in the analysis and that the time trend specification captures time-variations.

\section{$\underline{\text { Data }}$}

Stock Exchange

Bubble

Observations

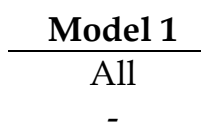

1,702

\begin{tabular}{c} 
Model 2 \\
\hline All \\
Dummy \\
1,702
\end{tabular}

$-15.59$

$(0.011)^{*}$

$-10.49$

$(0.038)^{*}$

$-20.49$

$(0.002)^{* *}$

34.43

Fourth-order Polynomial

Time Trend

Fifth-order Polynomial

Time Trend

Sixth-order Polynomial

Time Trend
$-10.669$

$-6.73$

(0.270)

$-12.18$

(0.117)

42.05

$(0.000)^{* * *}$

28.17

$(0.000)^{* * *}$

25.32

$(0.001)^{* * *}$
$(0.000)^{* * *}$

23.40

$(0.000)^{* * *}$

23.53

$(0.001)^{* *}$



1,207

7.09

(0.296)

7.53

(0.159)

8.88

(0.210)

34.81

$(0.000)^{* * *}$

28.77

$(0.000)^{* * *}$

17.62

$(0.005)^{\text {** }}$

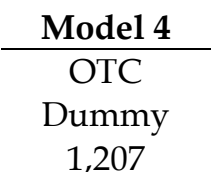

1,207

(0.668)

2.21

(0.615)

0.05

(0.993)

28.96

$(0.000)^{* * *}$

23.90

$(0.000)^{* * *}$

18.08

$(0.003)^{* *}$

Significance levels are as follows: ${ }^{*}=0.05 ; * * 0.01 ;{ }^{* *}=0.001$

regressions with first- to sixth-order polynomial time trends. Model 1 and Model 2 investigate the Growth Market Sample while Model 3 and Model 4 analyse the OTC Subsample. Further, Model 2 and Model 4 introduce a dot-com bubble dummy variable.

The Method coefficient estimates for a linear, quadratic and cubic time trend in Table 5 are partly positive, partly negative and mainly insignificant. Higher-order polynomials are more flexible and therefore less driven by observations far away from the policy discontinuity. Fourth- to sixthorder polynomial time trends yield statistically significant results across all four models in Table 5 and the Method coefficient estimates are more consistent. These regression results indicate that underpricing for bookbuilding is between 23.40 and 42.05 percentage points higher than for auctions (OTC Subsample: 17.62 to 34.81 percentage points). The results for a fourth-order polynomial time trend are in a similar range to the Method coefficients reported in Table 4, while the Method coefficient estimates for fifth- and sixth-order polynomial time trends tend to be 


\section{Table 6: Underpricing - RD Local Strategy Results \\ Japanese IPOs between 09/04/1996 and 10/03/1999 (Growth Market Sample)}

The table presents the results of the Method coefficient for 24 regressions with underpricing as dependent variable. In all regressions, the covariates introduced in Section 4.2.3 are included in the regression equation. P-values shown in parenthesis are based on heteroscedasticity-consistent standard errors (HC3). Bandwidth specifies the data that is included in the regression analysis. In Model 1 and Model 4 a rectangular kernel is used (=OLS regression). Model 2 and Model 5 are based on a triangular kernel and Model 3 and Model 6 are based on an epanechnikov kernel. While all models include a linear time trend, Model 4 to Model 6 also include an interaction term between the linear time trend and the Method dummy. Since the time trend variable is equal to zero at the cut point, the Method dummy alone specifies the treatment effect.

\begin{tabular}{|c|c|c|c|c|c|c|c|}
\hline & & Model 1 & Model 2 & Model 3 & Model 4 & Model 5 & Model 6 \\
\hline Kernel & & Rect. & Trian. & Epan. & Rect. & Trian. & Epan. \\
\hline Interaction $\mathrm{Te}$ & & No & No & No & Yes & Yes & Yes \\
\hline Bandwidth & Obs. & $\begin{array}{c}\text { Method } \\
\text { Coeffi. }\end{array}$ & $\begin{array}{c}\text { Method } \\
\text { Coeffi. }\end{array}$ & $\begin{array}{c}\text { Method } \\
\text { Coeffi. }\end{array}$ & $\begin{array}{c}\text { Method } \\
\text { Coeffi. }\end{array}$ & $\begin{array}{c}\text { Method } \\
\text { Coeffi. }\end{array}$ & $\begin{array}{c}\text { Method } \\
\text { Coeffi. }\end{array}$ \\
\hline 270 days & 119 & $\begin{array}{c}12.81 \\
(0.088)\end{array}$ & $\begin{array}{c}8.24 \\
(0.270)\end{array}$ & $\begin{array}{c}9.79 \\
(0.181)\end{array}$ & $\begin{array}{c}11.79 \\
(0.122)\end{array}$ & $\begin{array}{c}7.99 \\
(0.291)\end{array}$ & $\begin{array}{c}9.25 \\
(0.218)\end{array}$ \\
\hline 360 days & 177 & $\begin{array}{c}14.58 \\
(0.013)^{*}\end{array}$ & $\begin{array}{c}10.81 \\
(0.124)\end{array}$ & $\begin{array}{c}12.40 \\
(0.071)\end{array}$ & $\begin{array}{l}12.67 \\
(0.066)\end{array}$ & $\begin{array}{c}9.25 \\
(0.218)\end{array}$ & $\begin{array}{l}10.23 \\
(0.176)\end{array}$ \\
\hline 450 days & 242 & $\begin{array}{c}8.66 \\
(0.140)\end{array}$ & $\begin{array}{c}11.86 \\
(0.041)^{*}\end{array}$ & $\begin{array}{c}12.70 \\
(0.020)^{*}\end{array}$ & $\begin{array}{c}3.23 \\
(0.665)\end{array}$ & $\begin{array}{c}9.56 \\
(0.146)\end{array}$ & $\begin{array}{c}9.94 \\
(0.118)\end{array}$ \\
\hline 540 days & 270 & $\begin{array}{c}3.89 \\
(0.544)\end{array}$ & $\begin{array}{l}10.37 \\
(0.055)\end{array}$ & $\begin{array}{c}9.92 \\
(0.059)\end{array}$ & $\begin{array}{c}-2.80 \\
(0.718)\end{array}$ & $\begin{array}{c}6.45 \\
(0.299)\end{array}$ & $\begin{array}{c}5.25 \\
(0.399)\end{array}$ \\
\hline
\end{tabular}

Significance levels are as follows: ${ }^{*}=0.05 ; * *=0.01 ; * *=0.001$

lower. Even though there are variations in the Method coefficient estimates in Table 5, the results overall provide evidence that underpricing is significantly higher for bookbuilding than for auctions.

\subsubsection{RD Local Strategy (Underpricing)}

The estimates of the Method coefficient for the local linear regression with bandwidths between 270 days and 540 days are presented in Table 6. The lower limit of 270 days is chosen because the number of observations for smaller bandwidths is too low to have explanatory power. The upper limit is defined at 540 days to exclude the dot-com bubble 1999/2000. Models 1 to 3 do not include an interaction term between the linear time trend and the Method dummy while Models 4 to 6 include such a term. Models 1 and 4 use a rectangular kernel, Models 2 and 4 a triangular kernel, and Models 3 and 6 an epanechnikov kernel. The results for the Growth Market Sample and the OTC Subsample are the same because the OTC market was the only growth stock exchange operating before the dot-com bubble period 1999/2000. 



Figure 5: Method Coefficient and Bandwidth (RD Local Strategy)

Bandwidth Sensitivity of the Method Coefficient (Growth Market Sample)

The figure presents the Method coefficient estimates of 1,620 regressions. In all regressions, the dependent variable is underpricing, and the covariates introduced in Section 4.2.3 together with a linear time trend are included in the regression equation. The lower figure includes an additional interaction term between the linear time trend and the Method dummy in the regression equation. The straight (red) line presents the results for a rectangular kernel. The dashed (blue) line stands for a regression based on a triangular kernel and the dotted (green) line presents the result for an epanechnikov kernel. The corresponding 95\% confidence intervals are also shown. Bandwidth specifies the data that is included in the regression.

The results in Table 6 indicate that bookbuilding leads to higher underpricing than auctions. Only the Method coefficient estimate of Model 4 with a bandwidth of 540 days is negative. This coefficient is highly insignificant. The statistically significant Method coefficients at the 5\%-level indicate that underpricing for bookbuilding is between 11.86 and 14.58 percentage points higher than for auctions.

These results are confirmed and graphically illustrated in Figure 5. The upper graph is based on a regression equation without interaction term and the lower graph includes an interaction term 
between the linear time trend and the Method dummy. The three types of lines (colours) show the results based on three different kernels. The corresponding 95\% confidence intervals are also presented. A triangular kernel and an epanechnikov kernel assign observations closer to the cut point a higher weighting. By extending the bandwidth, the weighting of additional observations is rather low which leads to a smooth development of the Method coefficient estimate. With a rectangular kernel, all observations have the same weight and additional observations can therefore lead to abrupt shifts in the estimate of the Method coefficient. It seems that increasing the bandwidth for models with a triangular kernel or an epanechnikov kernel mainly narrows the confidence intervals while keeping the Method coefficient at approximately the same level.

In conclusion, the local linear regressions also indicate that initial returns are higher for bookbuilding than for auctions. The results suggest that by evaluating only observations close to the policy discontinuity, the Method coefficient is estimated to be somewhat lower than in the multiple linear regression analysis in Table 4 . This confirms the pattern observed in Figure 4 . It indicates that the Method coefficient increases by including dot-com bubble 1999/2000 and postbubble observations in the analysis.

As the Mature Market Sample has a much smaller sample size, with only few observations close to the cut point, the appendix does not contain a local linear regression analysis for the Mature Market Sample.

\section{Results on Price Accuracy}

We first provide descriptive statistics. and then the results of the linear regression analyses. This is followed by the findings from the regression discontinuity designs. Finally, we briefly discuss the robustness to using buy-and-hold returns over a 36-month period instead of a 12-month period. We only show the results from the Growth Market Sample in the main text, as before, while the results from the Mature Market Sample, which are qualitatively similar unless otherwise stated, can be found in Appendix C.

\subsection{Descriptive Statistics (Price Accuracy)}

Descriptive statistics of the bookbuilding and auction subsample are provided in Table 7. Auctioned IPOs deviate on average from the benchmark by 27.33 percentage points and 30.75

percentage points for the JASDAQ benchmark and the Topix benchmark, respectively 


\section{Table 7: Price Accuracy - Descriptive Statistics}

\section{Japanese IPOs between 01/01/1993 and 31/12/2007 (Growth Market Sample)}

Top 5 Underwriter refers to the number of IPOs that were underwritten by one of the five largest investment banks. Bubble Period refers to the number of IPOs between the 01/04/1999 and 30/06/2000. Abs. AR 12m stands for absolute abnormal buy-and-hold return over a 12-month post-listing period. The calculation of absolute abnormal buy-and-hold returns is described in Section 4.2.2. See Section 4.2.3 for a detailed description of each covariate. The currency of the expected issue size is Japanese Yen.

Observations

Top 5 Underwriter

Bubble Period

\section{Auction Subsample}

466

379

0
Bookbuilding Subsample

982

666

106

\begin{tabular}{|c|c|c|c|c|}
\hline Dependent Variable & Average & Median & Average & Median \\
\hline Abs. AR $12 \mathrm{~m}$ JASDAQ & $27.33 \%$ & $22.48 \%$ & $66.48 \%$ & $41.14 \%$ \\
\hline Abs. AR 12m Topix & $30.75 \%$ & $25.71 \%$ & $69.77 \%$ & $43.43 \%$ \\
\hline \multicolumn{5}{|l|}{ Independent Variables } \\
\hline Firm Age & 30.33 & 30.15 & 21.48 & 18.47 \\
\hline log (Firm Age) & 3.31 & 3.41 & 2.76 & 2.92 \\
\hline Expected Issue Size & $2,775 \mathrm{~m}$ & $1,856 \mathrm{~m}$ & $2,737 \mathrm{~m}$ & $1,080 \mathrm{~m}$ \\
\hline $\log$ (Exp. Issue Size) & 21.38 & 21.34 & 20.90 & 20.80 \\
\hline Insider Sales & $39.33 \%$ & $44.67 \%$ & $36.94 \%$ & $39.39 \%$ \\
\hline Market Return & $-2.11 \%$ & $-3.69 \%$ & $-0.15 \%$ & $-2.77 \%$ \\
\hline Market Volatility & $0.0065 \%$ & $0.0043 \%$ & $0.0214 \%$ & $0.0103 \%$ \\
\hline
\end{tabular}

(considering 12-month absolute abnormal returns). For bookbuilding, the absolute abnormal buy-and-hold return is on average 66.48 percent based on the JASDAQ benchmark and 69.77 percent for the Topix benchmark. The median values are significantly lower for both price discovery methods which indicates that some outliers strongly under- or outperform the benchmark. However, the median absolute abnormal buy-and-hold returns are still significantly higher for bookbuilding than for auctions.

\subsection{Linear Regression Analyses (Price Accuracy)}

The results of the regression analyses are presented in Table 8 (JASDAQ benchmark) and Table 9 (Topix benchmark). The Method coefficients are positive and statistically significant at the $0.1 \%$ level in all six models in both tables with values between 34.04 and 36.91 for the Growth Market Sample (39.25 to 42.48 for the OTC Subsample). In other words, the absolute deviation of the 12month buy-and-hold return from the benchmark return is on average between 34.04 and 36.91 percentage points higher for bookbuilding than for auctions. The lower deviation of auctioned 


\section{Table 8: Price Accuracy - Regression Results (JASDAQ Benchmark) \\ Japanese IPOs between 01/01/1993 and 31/12/2007 (Growth Market Sample)}

In all six OLS regressions, the dependent variable is the absolute abnormal buy-and-hold return over a 12-month post-listing period based on the JASDAQ index benchmark. Model 1 to Model 3 are based on the Growth Market Sample and Model 4 to Model 6 are based on the OTC Subsample. While Model 1 and Model 4 do not control for the dot-com bubble 1999/2000, Model 2 and Model 5 introduce a bubble dummy variable. Further, Model 3 to Model 6 exclude observations between 01/04/1999 and 30/06/2000 from the analysis. P-values shown in parenthesis are based on heteroscedasticity-consistent standard errors (HC3). See Section 4.2.3 for a description of each covariate. Exp. Issue abbreviates the expected issue size.

\begin{tabular}{|c|c|c|c|c|c|c|}
\hline Data & Model 1 & Model 2 & Model 3 & Model 4 & Model 5 & Model 6 \\
\hline$\overline{\text { Data }}$ & All & All & All & OTC & OTC & OTC \\
\hline Bubble Period & - & Dummy & Data exc. & - & Dummy & Data exc. \\
\hline Benchmark & JASDAQ & JASDAQ & JASDAQ & JASDAQ & JASDAQ & JASDAQ \\
\hline Period & 12 months & 12 months & 12 months & 12 months & 12 months & 12 months \\
\hline \multicolumn{7}{|l|}{$\underline{\text { Results }}$} \\
\hline \multirow[t]{2}{*}{ Intercept } & 213.95 & 211.89 & 218.02 & 227.01 & 224.47 & 221.04 \\
\hline & $(0.010)^{* *}$ & $(0.010)^{* *}$ & $(0.011)^{*}$ & $(0.044)^{*}$ & $(0.044)^{*}$ & $(0.060)$ \\
\hline \multirow[t]{2}{*}{ Method } & 34.04 & 34.31 & 35.25 & 39.25 & 39.54 & 40.02 \\
\hline & $(0.000)^{* * *}$ & $(0.000)^{* * *}$ & $(0.000)^{* * *}$ & $(0.000)^{* * *}$ & $(0.000)^{* * *}$ & $(0.000)^{* * *}$ \\
\hline \multirow[t]{2}{*}{ Log Age } & -11.70 & -11.66 & -11.78 & -22.11 & -22.11 & -23.21 \\
\hline & $(0.031)^{*}$ & $(0.031)^{*}$ & $(0.037)^{*}$ & $(0.026)^{*}$ & $(0.026)^{*}$ & $(0.029)^{*}$ \\
\hline \multirow[t]{2}{*}{ Log Exp. Issue } & -7.82 & -7.74 & -8.03 & -6.79 & -6.67 & -6.41 \\
\hline & $(0.026)^{*}$ & $(0.027)^{*}$ & $(0.028)^{*}$ & $(0.122)$ & $(0.124)$ & $(0.161)$ \\
\hline \multirow[t]{2}{*}{ Insider Sales } & 0.21 & 0.20 & 0.23 & 0.20 & 0.20 & 0.24 \\
\hline & (0.150) & $(0.152)$ & $(0.116)$ & $(0.245)$ & $(0.246)$ & (0.187) \\
\hline \multirow[t]{2}{*}{ Market Return } & 0.09 & 0.14 & 0.08 & -0.12 & -0.07 & -0.15 \\
\hline & $(0.545)$ & $(0.442)$ & $(0.704)$ & $(0.482)$ & $(0.736)$ & $(0.520)$ \\
\hline \multirow[t]{2}{*}{ Market Volat. } & -181.56 & -149.53 & -301.59 & -189.29 & -163.66 & -263.13 \\
\hline & $(0.000)^{* * *}$ & $(0.005)^{* *}$ & $(0.196)$ & $(0.001)^{* *}$ & $(0.004)^{* *}$ & $(0.390)$ \\
\hline \multirow[t]{2}{*}{ Underwriter } & 15.49 & 15.65 & 15.94 & 14.32 & 14.43 & 14.76 \\
\hline & $(0.028)^{*}$ & $(0.028)^{*}$ & $(0.035)^{*}$ & $(0.068)$ & $(0.067)$ & $(0.080)$ \\
\hline \multirow[t]{2}{*}{ Bubble } & & -7.10 & & & -5.74 & \\
\hline & & $(0.414)$ & & & $(0.576)$ & \\
\hline Observations & 1,448 & 1,448 & 1,342 & 1,147 & 1,147 & 1,049 \\
\hline Adj. R-squa. & 0.030 & 0.029 & 0.029 & 0.039 & 0.038 & 0.039 \\
\hline F-value & 7.34 & 6.44 & 6.79 & 7.62 & 6.67 & 7.00 \\
\hline $\mathrm{p}$-value & $0.000^{* * *}$ & $0.000^{* * *}$ & $0.000^{* * *}$ & $0.000^{* * *}$ & $0.000^{* * *}$ & $0.000^{* * *}$ \\
\hline
\end{tabular}

IPOs indicates that the price accuracy is higher. This is in line with previous empirical evidence (Beierlein \& Kato, 2003; Pettway et al., 2008), but it stands in contrast to the theoretical model provided by Sherman (2005). The results in Tables 8 and 9 also indicate that older and more mature firms are priced more accurately. 


\section{Table 9: Price Accuracy - Regression Results (Topix Benchmark) \\ Japanese IPOs between 01/01/1993 and 31/12/2007 (Growth Market Sample)}

In all six OLS regressions, the dependent variable is the absolute abnormal buy-and-hold return over a 12-month post-listing period based on the Topix index benchmark. Model 1 to Model 3 are based on the Growth Market Sample and Model 4 to Model 6 are based on the OTC Subsample. While Model 1 and Model 4 do not control for the dot-com bubble 1999/2000, Model 2 and Model 5 introduce a bubble dummy variable. Further, Model 3 and Model 6 exclude observations between 01/04/1999 and 30/06/2000 from the analysis. P-values shown in parenthesis are based on heteroscedasticity-consistent standard errors (HC3). See Section 4.2.3 for a description of each covariate. Exp. Issue abbreviates the expected issue size.

\begin{tabular}{|c|c|c|c|c|c|c|}
\hline$\underline{\text { Data }}$ & Model 1 & Model 2 & Model 3 & Model 4 & Model 5 & Model 6 \\
\hline Data & All & All & All & OTC & OTC & OTC \\
\hline Bubble Period & - & Dummy & Data exc. & - & Dummy & Data exc. \\
\hline Benchmark & Topix & Topix & Topix & Topix & Topix & Topix \\
\hline Period & 12 months & 12 months & 12 months & 12 months & 12 months & 12 months \\
\hline \multicolumn{7}{|l|}{ Results } \\
\hline \multirow[t]{2}{*}{ Intercept } & 164.27 & 158.52 & 164.14 & 169.97 & 161.57 & 156.55 \\
\hline & $(0.071)$ & (0.079) & $(0.086)$ & $(0.169)$ & $(0.188)$ & $(0.229)$ \\
\hline \multirow[t]{2}{*}{ Method } & 34.85 & 35.60 & 36.91 & 40.76 & 41.73 & 42.48 \\
\hline & $(0.000)^{* * *}$ & $(0.000)^{* * *}$ & $(0.000)^{* * *}$ & $(0.000)^{* * *}$ & $(0.000)^{* * *}$ & $(0.000)^{* * *}$ \\
\hline \multirow[t]{2}{*}{ Log Age } & -13.08 & -12.95 & -13.14 & -25.39 & -25.39 & -27.13 \\
\hline & $(0.021)^{*}$ & $(0.022)^{*}$ & $(0.027)^{*}$ & $(0.014)^{*}$ & $(0.014)^{*}$ & $(0.014)^{*}$ \\
\hline \multirow[t]{2}{*}{ Log Exp. Issue } & -5.05 & -4.82 & -5.07 & -3.47 & -3.09 & -2.63 \\
\hline & (0.196) & $(0.215)$ & $(0.216)$ & $(0.483)$ & $(0.530)$ & $(0.615)$ \\
\hline \multirow[t]{2}{*}{ Insider Sales } & 0.17 & 0.17 & 0.19 & 0.18 & 0.17 & 0.20 \\
\hline & $(0.249)$ & $(0.264)$ & $(0.233)$ & $(0.322)$ & $(0.340)$ & (0.308) \\
\hline \multirow[t]{2}{*}{ Market Return } & -0.11 & 0.03 & -0.02 & -0.38 & -0.23 & -0.30 \\
\hline & (0.487) & $(0.878)$ & (0.941) & $(0.033)^{*}$ & $(0.322)$ & $(0.247)$ \\
\hline \multirow[t]{2}{*}{ Market Volat. } & -191.09 & -101.86 & -294.22 & -207.91 & -123.06 & -264.93 \\
\hline & $(0.000)^{* * *}$ & $(0.063)$ & $(0.233)$ & $(0.001)^{* * *}$ & $(0.033)^{*}$ & (0.408) \\
\hline \multirow[t]{2}{*}{ Underwriter } & 14.65 & 15.11 & 16.00 & 15.16 & 15.53 & 16.65 \\
\hline & $(0.052)$ & $(0.046)^{*}$ & $(0.047)^{*}$ & $(0.073)$ & $(0.067)$ & $(0.067)$ \\
\hline \multirow[t]{2}{*}{ Bubble } & & -19.77 & & & -19.02 & \\
\hline & & $(0.023)^{*}$ & & & $(0.068)$ & \\
\hline Observations & 1,448 & 1,448 & 1,342 & 1,147 & 1,147 & 1,049 \\
\hline Adj. R-squa. & 0.025 & 0.025 & 0.025 & 0.038 & 0.037 & 0.038 \\
\hline F-value & 6.38 & 5.71 & 5.99 & 7.41 & 6.57 & 6.92 \\
\hline $\mathrm{p}$-value & $0.000^{* * *}$ & $0.000^{* * *}$ & $0.000^{* * *}$ & $0.000^{* * *}$ & $0.000^{* * *}$ & $0.000^{* * *}$ \\
\hline
\end{tabular}

\subsection{Regression Discontinuity Designs (Price Accuracy)}

We again present both complementary strategies of the regression discontinuity design. 


\section{Table 10: Price Accuracy - RD Global Strategy Results Japanese IPOs between 01/01/1993 and 31/12/2007 (Growth Market Sample)}

The table presents the Method coefficient estimates of 24 OLS regressions with absolute abnormal buy-and-hold returns over a 12-month post-listing period as dependent variable. Model 1 and Model 2 are based on the Growth Market Sample and Model 3 and Model 4 on the OTC Subsample. In all regressions, the covariates introduced in Section 4.2 .3 and a bubble dummy are included in the regression equation. Model 1 and Model 3 are based on the JASDAQ index benchmark and Model 2 and Model 4 on the Topix index benchmark. For each model, six OLS regressions are conducted with different specifications of $f$ (Time). P-values shown in parenthesis are based on heteroscedasticity-consistent standard errors (HC3).

\section{$\underline{\text { Data }}$}

Stock Exchange

Bubble

Benchmark

Period

Observations

\begin{tabular}{c} 
Model 1 \\
\hline All \\
Dummy \\
JASDAQ \\
12 months \\
1,448
\end{tabular}

Method Coefficient Estimates

Linear Time Trend

Quadratic Time Trend

Cubic Time Trend

Fourth-order Polynomial

Time Trend

Fifth-order Polynomial

Time Trend

Sixth-order Polynomial

Time Trend

\begin{tabular}{c} 
Model 2 \\
\hline All \\
Dummy \\
Topix \\
12 months \\
1,448
\end{tabular}

\begin{tabular}{c} 
Model 3 \\
\hline OTC \\
Dummy \\
JASDAQ \\
12 months \\
1,147
\end{tabular}

\begin{tabular}{c} 
Model 4 \\
\hline OTC \\
Dummy \\
Topix \\
12 months \\
1,147
\end{tabular}

$\begin{array}{cc}109.78 & 103.34 \\ (0.000)^{* * *} & (0.000)^{* * *} \\ 110.17 & 104.48 \\ (0.000)^{* * *} & (0.001)^{* * *} \\ 123.20 & 117.89 \\ (0.001)^{* * *} & (0.003)^{* *} \\ 147.83 & 153.05 \\ (0.001)^{* *} & (0.002)^{* *} \\ 142.87 & 144.85 \\ (0.001)^{* * *} & (0.001)^{* *} \\ 164.30 & 165.93 \\ (0.000)^{* * *} & (0.001)^{* * *}\end{array}$

120.03

$(0.000)^{* * *}$

115.85

$(0.000)^{* * *}$

133.37

$(0.002)^{* *}$

154.00

$(0.001)^{* *}$

147.43

$(0.001)^{* *}$

162.48

$(0.001)^{* * *}$

Significance levels are as follows: ${ }^{*}=0.05 ;{ }^{* *}=0.01 ;{ }^{* *}=0.001$

\subsubsection{RD Global Strategy (Price Accuracy)}

The Method coefficients for the global strategy of the regression discontinuity design are presented in Table 10. Model 1 and Model 2 analyse the Growth Market Sample. The results indicate that the price accuracy for auctions is significantly higher than for bookbuilding. The results show little sensitivity to the order of the polynomial time trend. Further, the Method coefficient estimates in Table 10 are higher than the estimates of the regression analysis in Table 8 and Table 9. The regression results in Model 3 and Model 4 in Table 10 are based on the OTC Subsample and also indicate that price accuracy for auctions is significantly higher than for bookbuilding. 


\section{Table 11: Price Accuracy - RD Local Strategy Results \\ Japanese IPOs between 09/04/1996 and 10/03/1999 (Growth Market Sample)}

The table presents the Method coefficient estimates of 48 regressions with absolute abnormal buy-and-hold returns over a 12month post-listing period as dependent variable. In all regressions, the covariates introduced in Section 4.2 .3 and a linear time trend are included in the regression equation. Model 7 to Model 12 include an additional interaction term between the linear time trend and the Method dummy in the regression equation. The benchmark in Model 1 to Model 3 and Model 7 to Model 9 is the JASDAQ index. Model 4 to Model 6 and Model 10 to Model 12 are based on the Topix index as benchmark. In Model 1, Model 4, Model 7 and Model 10 a rectangular kernel is used (=OLS regression). Model 2, Model 5, Model 8 and Model 11 are based on a triangular kernel and Model 3, Model 6, Model 9 and Model 12 are based on an epanechnikov kernel. P-values shown in parenthesis are based on heteroscedasticity-consistent standard errors (HC3). Bandwidth specifies the data that is included in the regression.

\begin{tabular}{|c|c|c|c|c|c|c|c|}
\hline \multirow{2}{*}{\multicolumn{2}{|c|}{ Benchmark }} & Model 1 & Model 2 & Model 3 & Model 4 & Model 5 & Model 6 \\
\hline & & $\overline{\text { JASDAQ }}$ & $\overline{\text { JASDAQ }}$ & $\overline{\text { JASDAQ }}$ & Topix & Topix & Topix \\
\hline \multicolumn{2}{|l|}{ Period } & $12 \mathrm{~m}$ & $12 \mathrm{~m}$ & $12 \mathrm{~m}$ & $12 \mathrm{~m}$ & $12 \mathrm{~m}$ & $12 \mathrm{~m}$ \\
\hline \multirow{2}{*}{\multicolumn{2}{|c|}{$\begin{array}{l}\text { Kernel } \\
\text { Interaction Term }\end{array}$}} & Rect. & Trian. & Epan. & Rect. & Trian. & Epan. \\
\hline & & No & No & No & No & No & No \\
\hline Bandwidth & Obs. & $\begin{array}{l}\text { Method } \\
\text { Coeffi. }\end{array}$ & $\begin{array}{l}\text { Method } \\
\text { Coeffi. }\end{array}$ & $\begin{array}{l}\text { Method } \\
\text { Coeffi. }\end{array}$ & $\begin{array}{l}\text { Method } \\
\text { Coeffi. }\end{array}$ & $\begin{array}{l}\text { Method } \\
\text { Coeffi. }\end{array}$ & $\begin{array}{l}\text { Method } \\
\text { Coeffi. }\end{array}$ \\
\hline 270 days & 119 & $\begin{array}{c}20.80 \\
(0.167)\end{array}$ & $\begin{array}{c}12.72 \\
(0.413)\end{array}$ & $\begin{array}{c}16.09 \\
(0.291)\end{array}$ & $\begin{array}{c}19.59 \\
(0.213)\end{array}$ & $\begin{array}{c}11.55 \\
(0.465)\end{array}$ & $\begin{array}{c}15.02 \\
(0.331)\end{array}$ \\
\hline 360 days & 175 & $\begin{array}{c}58.50 \\
(0.015)^{*}\end{array}$ & $\begin{array}{l}19.90 \\
(0.247)\end{array}$ & $\begin{array}{l}26.65 \\
(0.161)\end{array}$ & $\begin{array}{c}60.10 \\
(0.024)^{*}\end{array}$ & $\begin{array}{l}17.69 \\
(0.315)\end{array}$ & $\begin{array}{c}24.76 \\
(0.210)\end{array}$ \\
\hline 450 days & 239 & $\begin{array}{c}86.27 \\
(0.020)^{*}\end{array}$ & $\begin{array}{c}46.45 \\
(0.016)^{*}\end{array}$ & $\begin{array}{c}57.24 \\
(0.014)^{*}\end{array}$ & $\begin{array}{l}101.72 \\
(0.011)^{*}\end{array}$ & $\begin{array}{c}49.34 \\
(0.018)^{*}\end{array}$ & $\begin{array}{c}62.07 \\
(0.014)^{*}\end{array}$ \\
\hline \multirow[t]{2}{*}{540 days } & 261 & $\begin{array}{c}92.96 \\
(0.020)^{*}\end{array}$ & $\begin{array}{c}61.24 \\
(0.013)^{*}\end{array}$ & $\begin{array}{c}72.10 \\
(0.014)^{*}\end{array}$ & $\begin{array}{c}120.31 \\
(0.006)^{* *}\end{array}$ & $\begin{array}{c}69.69 \\
(0.009)^{* *}\end{array}$ & $\begin{array}{c}83.86 \\
(0.009)^{* *}\end{array}$ \\
\hline & & Model 7 & Model 8 & Model 9 & Model 10 & Model 11 & Model 12 \\
\hline Benchmark & & $\overline{\text { JASDAQ }}$ & $\overline{\text { JASDAQ }}$ & $\overline{\text { JASDAQ }}$ & Topix & Topix & Topix \\
\hline Period & & $12 \mathrm{~m}$ & $12 \mathrm{~m}$ & $12 \mathrm{~m}$ & $12 \mathrm{~m}$ & $12 \mathrm{~m}$ & $12 \mathrm{~m}$ \\
\hline Kernel & & Rect. & Trian. & Epan. & Rect. & Trian. & Epan. \\
\hline Interaction Term & & Yes & Yes & Yes & Yes & Yes & Yes \\
\hline Bandwidth & Obs. & $\begin{array}{l}\text { Method } \\
\text { Coeffi. }\end{array}$ & $\begin{array}{l}\text { Method } \\
\text { Coeffi. }\end{array}$ & $\begin{array}{l}\text { Method } \\
\text { Coeffi. }\end{array}$ & $\begin{array}{l}\text { Method } \\
\text { Coeffi. }\end{array}$ & $\begin{array}{l}\text { Method } \\
\text { Coeffi. }\end{array}$ & $\begin{array}{l}\text { Method } \\
\text { Coeffi. }\end{array}$ \\
\hline 270 days & 119 & $\begin{array}{c}8.33 \\
(0.596)\end{array}$ & $\begin{array}{c}7.39 \\
(0.662)\end{array}$ & $\begin{array}{c}9.33 \\
(0.568)\end{array}$ & $\begin{array}{c}6.29 \\
(0.714)\end{array}$ & $\begin{array}{c}5.80 \\
(0.736)\end{array}$ & $\begin{array}{c}7.68 \\
(0.643)\end{array}$ \\
\hline 360 days & 175 & $\begin{array}{c}2.01 \\
(0.951)\end{array}$ & $\begin{array}{l}-10.15 \\
(0.719)\end{array}$ & $\begin{array}{l}-15.14 \\
(0.672)\end{array}$ & $\begin{array}{l}-15.38 \\
(0.660)\end{array}$ & $\begin{array}{l}-17.22 \\
(0.551)\end{array}$ & $\begin{array}{l}-24.27 \\
(0.507)\end{array}$ \\
\hline 450 days & 239 & $\begin{array}{l}41.62 \\
(0.311)\end{array}$ & $\begin{array}{c}0.87 \\
(0.965)\end{array}$ & $\begin{array}{c}3.54 \\
(0.870)\end{array}$ & $\begin{array}{l}48.37 \\
(0.281)\end{array}$ & $\begin{array}{l}-6.20 \\
(0.769)\end{array}$ & $\begin{array}{c}-3.96 \\
(0.867)\end{array}$ \\
\hline 540 days & 261 & $\begin{array}{c}51.08 \\
(0.255)\end{array}$ & $\begin{array}{l}17.25 \\
(0.405)\end{array}$ & $\begin{array}{l}25.18 \\
(0.344)\end{array}$ & $\begin{array}{c}7.47 \\
(0.128)\end{array}$ & $\begin{array}{l}17.65 \\
(0.439)\end{array}$ & $\begin{array}{c}28.54 \\
(0.332)\end{array}$ \\
\hline
\end{tabular}

Significance levels are as follows: ${ }^{*}=0.05 ;{ }^{* *}=0.01 ;{ }^{* *}=0.001$

In conclusion, the global strategy of the regression discontinuity design confirms the results of the multiple linear regression analysis. Price accuracy over a 12-month post-listing period is 
significantly higher for auctions than for bookbuilding. For the Mature Market sample (analysed in Appendix C), the results are similar but the method coefficients are of smaller magnitude (around 65 to 75 ).

\subsubsection{RD Local Strategy (Price Accuracy)}

The results of the local strategy of the regression discontinuity design are presented in Table 11. Models 1 to 6 do not include an interaction term between the Method dummy and the linear time trend, in contrast to Models 7 to 12. Models 1 to 3 use JASDAQ as benchmark, while the other models use Topix. The models use again rectangular (Models 1, 4, 7, 10), triangular $(2,5,8,11)$ or epanechnikov $(3,6,9,12)$ kernels. The results indicate that the price accuracy is higher for auctions than for bookbuilding with statistically significant Method coefficients between 46.45 and 120.31 .

The results are consistent across different benchmark choices and kernel specifications. The results for the Growth Market Sample and the OTC Subsample are again the same since the OTC market was the only growth stock exchange operating before the dot-com bubble. The Mature Market Sample is too small for local linear regression analyses.

\subsection{Robustness: Price Accuracy for a Post-listing Period of 36 Months}

The analyses performed for absolute abnormal buy-and-hold returns over a 12-month post-listing period are also conducted for absolute abnormal buy-and-hold returns over a 36-month postlisting period. The results are presented in Appendix E. The results for the Growth Market Sample and the OTC Subsample tend to indicate that also over a longer post-listing period, the price accuracy of auctions is higher. Compared to a 12-month post-listing period, the Method coefficient estimates tend to be of lower statistical significance, however. The results for the Mature Market Sample hardly find significant differences in price accuracy between auctions and bookbuilding over a 36-month post-listing period (for that sample the difference in price accuracy thus seems to diminish for longer post-listing periods).

\section{Additional Analyses, Implications and Limitations}

The results of the empirical analysis are summarized in Table 12. There is robust evidence that bookbuilding leads to higher initial returns than hybrid price-discriminatory auctions. 


\begin{tabular}{|c|c|c|c|}
\hline & $\begin{array}{l}\text { Table 12: Ov } \\
\text { Japanese IPOs betw }\end{array}$ & $\begin{array}{l}\text { riew of the Rest } \\
01 / 01 / 1993 \text { and } 31\end{array}$ & \\
\hline $\begin{array}{l}\text { The table summarizes } \\
\text { main text, Mature Ma } \\
\text { the Method coefficient. } \\
\text { coefficients (Sig.). The } \\
\text { polynomial time trends }\end{array}$ & $\begin{array}{l}\text { the results of the empirical analys } \\
\text { rket Sample results from the app } \\
\text { The multiple linear regression } \\
R D \text { global strategy presents the } \\
\left(4^{\text {th }}-6^{\text {th }}\right) \text {. }\end{array}$ & $\begin{array}{l}\text { Growth Market Sample } \\
\text { ix). The values presente } \\
\text { the RD local strategy } \\
\text { nge of significant Meth }\end{array}$ & $\begin{array}{l}\text { OTC sample report results from the } \\
\text { this table represent the estimates of } \\
\text { nt the range of significant Method } \\
\text { efficients for fourth- to sixth-order }\end{array}$ \\
\hline & Growth Market Sample & OTC Subsample & Mature Market Sample \\
\hline Underpricing & & & \\
\hline Multiple Linear & $35.83 \%-$ & $29.07 \%-$ & $13.56 \%-$ \\
\hline Regression (Sig.) & $37.51 \%$ & $33.41 \%$ & $16.35 \%$ \\
\hline Reg. Dis. - Global & $23.40 \%-$ & $17.62 \%-$ & $16.70 \%-$ \\
\hline Strategy $\left(4^{\text {th }}-6^{\text {th }}\right)$ & $42.05 \%$ & $34.81 \%$ & $21.26 \%$ \\
\hline Reg. Dis. - Local & $11.86 \%-$ & $11.86 \%-$ & Sample too \\
\hline Strategy (Sig.) & $14.58 \%$ & $14.58 \%$ & small \\
\hline Price Accuracy (12 & months) & & \\
\hline Multiple Linear & $34.04 \%-$ & $39.25 \%-$ & $25.37 \%-$ \\
\hline Regression (Sig.) & $36.91 \%$ & $42.48 \%$ & $32.06 \%$ \\
\hline $\begin{array}{l}\text { Reg. Dis. - Global } \\
\text { Strategy }\left(4^{\text {th }}-6^{\text {th }}\right)\end{array}$ & $\begin{array}{c}142.87 \%- \\
165.93 \%\end{array}$ & $\begin{array}{c}146.21 \%- \\
16248 \%\end{array}$ & $\begin{array}{c}64.88 \%- \\
6766 \%\end{array}$ \\
\hline 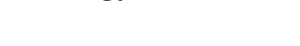 & & & \\
\hline Reg. Dis. - Local & $46.45 \%-$ & $46.45 \%-$ & Sample too \\
\hline Strategy (Sig.) & $120.31 \%$ & $120.31 \%$ & small \\
\hline
\end{tabular}

The influence of the policy change on underpricing is economically relevant. With average gross proceeds of USD 26.6 million in the Growth Market sample, the average wealth loss for issuers by choosing bookbuilding over price-discriminatory auctions is estimated to be between USD 3.2 million (underpricing of 11.86\%) and USD 11.2 million (underpricing of $42.05 \%$ ). The average wealth loss for issuers in the Mature Market sample choosing the bookbuilding method over hybrid price-discriminatory auctions is in a similar range to the Growth Market Sample. With average gross proceeds of USD 46.4 million, the average wealth loss in the Mature Market Sample is estimated to be between USD 6.3 million (underpricing of 13.56\%) and USD 9.9 million (underpricing of $21.26 \%$ ).

As there is a theoretical argument that higher underpricing in bookbuilding is a consequence of higher information production by investors which leads to a higher price accuracy (Sherman, 2005), we also analyse price accuracy in the aftermarket. However, we find no empirical evidence for this theory. The absolute abnormal buy-and-hold return over a 12-month post-listing period 
is significantly higher for bookbuilding than for auctions which indicates that the price accuracy is lower. The results of the OTC Subsample and the Mature Market Sample are consistent with the Growth Market Sample. The model of Sherman (2005) is based on the underlying assumption that the interests of the issuer and the underwriter are aligned (Sherman, 2005). Therefore, our results indicate that the interests of the issuer and the underwriter may not be fully aligned. This suggests that agency conflicts are present.

In the following, we provide brief additional analyses as first attempts to answer questions that are raised by our empirical results. First, why do book-built IPOs on average show greater underpricing? Second, can the difference in price accuracy be explained by better performance of book-built IPOs in the aftermarket? We then provide a critical assessment of why the bookbuilding method superseded the auction method even though empirical research indicates that bookbuilding leads to higher underpricing and less accurate aftermarket prices. In the end of the section, we talk about the potential limitations of (the identification in) our empirical analysis.

\subsection{Filing Range and Underpricing}

An analysis of the price formation and adjustment process can shed some additional light on the reasons of high underpricing in bookbuilding. The analysis of the filing range in Table 13 shows that high underpricing in bookbuilding comes from IPOs priced at the upper price limit of the filing range. IPOs priced at the lower price limit have average initial returns of only $3.1 \%$ and IPOs with an offer price within the filing range result in underpricing at comparable levels to auctions. Underpricing of IPOs priced at the upper price limit is excessive with average initial returns of $86.1 \%$. It is remarkable that $82.6 \%$ of book-built IPOs in the sample are priced at the upper price limit of the filing range. ${ }^{17}$

Kutsuna et al. (2009) analyse the price formation process in Japanese bookbuilding in more detail and conclude that "because the filing range constraint often is binding on the upside, the offer price cannot fully adjust to positive market-wide news once the range is set". They attribute excessive underpricing in bookbuilding to the binding upper price limit of the filing range.

\footnotetext{
17 This potential effect is already noticed in Kaneko and Pettway (2003), who report that 306 out of the 469 Japanese bookbuildings in their sample are priced at the upper price limit of the filing range and conclude that "significantly higher initial returns [in bookbuilding] are related to the underwriter setting the upper limit of the initial price range too low" (Kaneko \& Pettway, 2003).
} 


\section{Table 13: Filing Range Analysis}

\section{Japanese IPOs between 01/01/1993 and 31/12/2007 (Growth Market Sample)}

The offer price adjustment reports the adjustment from the expected offer price to the offer price. The first-day adjustment is defined as the adjustment from the offer price to the closing price on the first trading day (=underpricing). The total adjustment reports the full adjustment from the expected offer price to the closing share price on the first trading day. See Appendix B for the formulas of the expected offer price and the offer price. Book-built IPOs are further divided into three categories based on whether the offer price is at the lower or upper limit of the filing range or within the filing range.

\begin{tabular}{|c|c|c|c|c|}
\hline & Observations & $\begin{array}{c}\text { Offer Price } \\
\text { Adjustment }\end{array}$ & $\begin{array}{c}\text { First-Day } \\
\text { Adjustment }\end{array}$ & $\begin{array}{c}\text { Total } \\
\text { Adjustment }\end{array}$ \\
\hline Auction & 481 & $26.3 \%$ & $7.4 \%$ & $35.7 \%$ \\
\hline Bookbuilding & 1,221 & $6.4 \%$ & $72.8 \%$ & $83.8 \%$ \\
\hline Lower Price Limit & 62 & $-10.6 \%$ & $3.1 \%$ & $-7.9 \%$ \\
\hline Within Filing Range & 150 & $0.5 \%$ & $12.2 \%$ & $12.7 \%$ \\
\hline Upper Price Limit & 1,009 & $8.3 \%$ & $86.1 \%$ & $101.5 \%$ \\
\hline
\end{tabular}

However, attributing high underpricing in Japanese bookbuilding solely to the binding characteristic of the upper price limit seems too simple. The overwhelming number of IPOs priced at the upper price limit suggests that the misspecification of the upper price limit cannot be explained by misjudgement of the underwriter but rather by intentional mispricing. Kutsuna et al. (2009) argue that "the upper bound in Japanese IPOs appears to serve, a fortiori, as a demonstration of commitment to compensate investors." With average initial returns of $72.8 \%$ for bookbuilding in this sample, this compensation for investors seems excessive. Diverging interests between the issuer and the underwriter might drive the intentional misspecification of the upper limit of the filing range.

\subsection{Price Accuracy and Aftermarket Performance}

Our results indicate that the returns of book-built IPOs deviate stronger from the index benchmark than the returns of IPO auctions. It could be argued that the higher absolute abnormal returns of bookbuilding are driven by a better aftermarket performance, thus by higher abnormal returns. Therefore, we briefly also consider the aftermarket performance of the two price discovery methods (the results can be found in Appendix D). A regression analysis with abnormal buy-and-hold returns instead of absolute abnormal buy-and-hold returns as dependent variable can be found in Table D1 (Appendix D). The estimates of the Method coefficient are sensitive to the choice of the benchmark index. With abnormal returns being calculated based on the JASDAQ benchmark, there is no significant difference in aftermarket performance between 
bookbuilding and auctions identified. On the other hand, with the Topix index as benchmark, the regression results tend to indicate that book-built- IPOs outperform IPO auctions. However, these results must be interpreted carefully. The median abnormal buy-and-hold return with auctions is higher than with bookbuilding independent of the benchmark choice. Therefore, the regression results could be driven by outliers. To check this, we conduct an additional regression with winsorised data, excluding the data with the highest $10 \%$ and lowest $10 \%$ abnormal buy-andhold returns (the data are excluded in auction and bookbuilding subsamples separately). The regression results are presented in Table D2 (Appendix D). The results based on the Topix benchmark indicate no significant difference in aftermarket performance between auctions and bookbuilding. The results based on the JASDAQ benchmark suggest that auctions outperform bookbuilding in the aftermarket. Taking all these analyses on aftermarket performance together, it seems that there is little systematic difference between the IPO mechanisms. The difference in price accuracy thus does not seem to be driven by a difference in aftermarket performance.

\subsection{Puzzling Popularity of Bookbuilding}

The question persists why issuers in Japan switched immediately after the introduction of bookbuilding to this method and never again used auctions to price and allocate IPOs. Pettway et al. (2008) describe this phenomenon as a puzzle.

There are some benevolent attempts to explain this. Degeorge, Derrien, and Womack (2007) explain the global adaption of bookbuilding by the analyst hype. They argue that issuers enter into a tacit agreement with underwriters. Issuers are willing to bear higher direct and indirect costs in the bookbuilding method in exchange for better and more favourable analyst coverage by the underwriter in the aftermarket. This is in line with Cliff and Denis (2004) who report that underpricing to a certain extent compensates for coverage from highly ranked analysts of the underwriter in the aftermarket. Jovanovic and Szentes (2007) argue that only low-quality firms choose an auction method because in bookbuilding more information about firm quality is produced and revealed. This creates an adverse selection which dries out the demand from investors for auctioned IPOs and ultimately creates a situation where only the bookbuilding method is used. ${ }^{18}$ Lowry, Michaely and Volkova (2017) provide an extensive literature review

\footnotetext{
${ }^{18}$ Kutsuna and Smith (2004) find evidence for the existence of adverse selection in the Japan. They conclude that some high-quality firms decided not to go public with a hybrid price-discriminatory auction due to limited ability to distinguish themselves from low-quality firms. They derive that bookbuilding is favoured
} 
and conclude that "we need a better understanding why bookbuilding is still the most common and dominant going public venue."

Another potential explanation could be that it is not issuers or investors but underwriters who favour bookbuilding. The underwriter is only a facilitator of the price discovery process in the auction method but has significant pricing and share allocation discretion in bookbuilding. Arikawa and Imad'eddine (2010) show that the Japanese IPO market directly after the regulatory change in 1997 was an oligopoly with the top three underwriters (Nomura, Daiwa, Nikko) having a market share of about $70 \%$. It could be that these underwriters colluded and pitched the bookbuilding method more aggressively. An IPO is for most firms a one-time event and the decision-makers rely considerably on the recommendations of the underwriter. The three dominant underwriters may have established bookbuilding as the method of choice as soon as it was introduced in Japan.

\subsection{Limitations}

Non-experimental data always have some limitations, potentially making a causal interpretation of estimates difficult. ${ }^{19}$ We provide a variety of empirical analyses, as the importance of potential biases is different for the different methods. We briefly discuss these biases here.

There may be a slight survival bias in the analysis, because the sample only consists of successful IPOs (that resulted in a listing of a company at the stock exchange). If the bookbuilding method has lower risk of failure, the true performance of the bookbuilding method relative to auctions would improve under the consideration of IPO failures. However, according to Kutsuna and Smith (2004), IPO failures in Japanese hybrid price-discriminatory auctions were rare or even non-existent.

by issuers because their cost estimation does not account for the opportunity cost of underinvestment in auctions and bookbuilding should lead to more accurate aftermarket prices. However, aftermarket prices are less accurate for bookbuilding, as our results show.

19 The high level of control in experimental settings, with the possibility to randomize participants to treatments to facilitate a causal interpretation, has led to experimental studies on IPO pricing (e.g., Weber, Duffy \& Schram, 2018; Füllbrunn \& Neugebauer, 2019). However, the high level of control in the laboratory comes at the expense of lower external validity, and meaningful estimates of magnitudes relevant for the world outside the laboratory can only seldomly be obtained. 
Further, there may be a selection bias if the bookbuilding method attracted riskier firms, which tend to be underpriced more severely. A bias in favour of the auction method cannot be fully ruled out, despite the fact that firm age is included as a control variable.

In an optimal regression discontinuity design, the individual (the issuer) cannot manipulate the assignment variable. In the institutional setting of the Japanese IPO market, this assumption does not hold for IPOs close to the policy discontinuity. From the announcement that bookbuilding was to be introduced until the regulatory change entered into force, issuers could time their IPO to have their shares listed by their favoured method. This means that the estimator of the treatment effect, in particular making use of the local approach, may be biased. However, we would like to emphasize that this bias should be negligible under the global approach and for OLS with the full sample, where observations close to the cut-off are less important; these results are similar to (and rather a bit stronger than) the results from the local approach.

\section{Concluding Remarks}

We investigate the influence of the IPO method on underpricing in the Japanese IPO market, exploiting a regulatory change. We find that IPOs with hybrid price-discriminatory auctions are underpriced much less than IPOs with bookbuilding. This holds for a variety of econometric analyses, namely (i) linear regression analyses with different bandwidths, controlling for firm characteristics, IPO specific factors and market conditions, (ii) an RDD with a global strategy with higher order polynomials for time (the effect is not present with only lower order polynomials) and (iii) an RDD with a local strategy, using different kernels and bandwidths.

We also show that the stocks are priced less accurately in the aftermarket for bookbuilding than for hybrid price-discriminatory auctions. This stands in contrast to theoretical arguments that higher underpricing in bookbuilding is a consequence of higher information production by investors (leading to a higher price accuracy; Sherman, 2005). Instead, it is an indication that interests between the issuer and the underwriter are not aligned. Underpricing in bookbuilding thus seems to be at least partially driven by principle-agent conflicts.

Our results are consistent across different growth stock exchanges, regional stock exchanges and the Second Sections of Tokyo Stock Exchange, Osaka Stock Exchange and Nagoya Stock Exchange. 


\section{References}

Albada, A., \& Yong, O. (2019). A Review of IPO Underpricing Phenomenon in Asia. Internationl Journal of Banking and Finance, 14, 1-26.

Allen, F., \& Faulhaber, G. R. (1989). Signalling by Underpricing in the IPO Market. Journal of Financial Economics, 23(2), 303-323.

Arikawa, Y., \& Imad'eddine, G. (2010). Venture Capital Affiliation with Underwriters and the Underpricing of Initial Public Offerings in Japan. Journal of Economics and Business, 62(6), 502516.

Baron, D. P. (1982). A Model of the Demand for Investment Banking Advising and Distribution Services for New Issues. Journal of Finance, 37(4), 955-976.

Beatty, R. P., \& Ritter, J. R. (1986). Investment Banking, Reputation, and the Underpricing of Initial Public Offerings. Journal of Financial Economics, 15(1-2), 213-232.

Beckman, J., Garner, J., Marshall, B., \& Okamura, H. (2001). The Influence of Underwriter Reputation, Keiretsu Affiliation, and Financial Health on the Underpricing of Japanese IPOs. Pacific-Basin Finance Journal, 9(5), 513-534.

Beierlein, J., \& Kato, H. K. (2003). IPO Mechanisms: A Comparison of Book-Building, Discriminatory Price Auctions and Uniform Price Auctions. International Finance Review, 4, 135-152.

Bento, A., Kaffine, D., Roth, K., \& Zaragoza-Watkins, M. (2014). The Effects of Regulation in the Presence of Multiple Unpriced Externalities: Evidence from the Transportation Sector. American Economic Journal: Economic Policy, 6(3), 1-29.

Benveniste, L. M., \& Spindt, P. A. (1989). How Investment Bankers Determine the Offer Price and Allocation of New Issues. Journal of Financial Economics, 24(2), 343-361.

Boutron, E., Gajewski, J., Gresse, C., \& Labégorre, F. (2006). IPO Procedures in Europe: The Development of Practices and Perspectives. Revue d'économie Financière, 82, 89-105.

Bradley, D. J., \& Jordan, B. D. (2002). Partial Adjustment to Public Information and IPO Underpricing. Journal of Financial and Quantitative Analysis, 37(4), 595-616.

Bubna, A., \& Prabhala, N. R. (2011). IPOs With and Without Allocation Discretion: Empirical Evidence. Journal of Financial Intermediation, 20(4), 530-561.

Burger, N. E., Kaffine, D. T., \& Yu, B. (2014). Did California's Hand-Held Cell Phone Ban Reduce Accidents? Transportation Research Part A: Policy and Practice, 66, 162-172

Butler, A. W., Keefe, M. O. C., \& Kieschnick, R. (2014). Robust Determinants of IPO Underpricing and Their Implications for IPO Research. Journal of Corporate Finance, 27, 367-383. 
Cai, J., \& Wei, K. C. J. (1997). The Investment and Operating Performance of Japanese Initial Public Offerings. Pacific-Basin Finance Journal, 5(4), 389-417.

Carter, R., \& Manaster, S. (1990). Initial Public Offerings and Underwriter Reputation. Journal of Finance, 45(4), 1045-1067.

Cattaneo, M. D., Titiunik, R., \& Vazquez-Bare, G. (2020). The Regression Discontinuity Design. In L. Curini \& R. Franzese (Eds.), The SAGE Handbook of Research Methods in Political Science and International Relations (2nd ed., pp. 835-857). SAGE Publications Ltd.

Cliff, M. T., \& Denis, D. J. (2004). Do Initial Public Offering Firms Purchase Analyst Coverage with Underpricing? Journal of Finance, 59(6), 2871-2901.

Davis, L. W., \& Kahn, M. E. (2010). International Trade in Used Vehicles: The Environmental Consequences of NAFTA. American Economic Journal: Economic Policy, 2(4), 58-82.

Degeorge, F., Derrien, F., \& Womack, K. L. (2007). Analyst Hype in IPOs: Explaining the Popularity of Bookbuilding. Review of Financial Studies, 20(4), 1021-1058.

Derrien, F., \& Womack, K. L. (2003). Auctions vs. Bookbuilding and the Control of Underpricing in Hot IPO Markets. Review of Financial Studies, 16(1), 31-61.

Füllbrunn, S., Neugebauer, T., \& Nicklisch, A. (2019). Underpricing of initial public offerings in experimental asset markets. Experimental Economics, 1-28.

Gelman, A., \& Imbens, G. (2019). Why High-Order Polynomials Should Not Be Used in Regression Discontinuity Designs. Journal of Business and Economic Statistics, 37(3), 447-456.

Habib, M. A., \& Ljungqvist, A. P. (2001). Underpricing and Entrepreneurial Wealth Losses in IPOs : Theory and Evidence. Review of Financial Studies, 14(2), 433-458.

Hanley, K. W. (1993). The Underpricing of Initial Public Offerings and the Partial Adjustment Phenomenon. Journal of Financial Economics, 34(2), 231-250.

Hausman, C., \& Rapson, D. S. (2018). Regression Discontinuity in Time: Considerations for Empirical Applications. Annual Review of Resource Economics, 10(1), 533-552.

Huang, H.-Y., Chiang, M.-H., Lin, J.-H., \& Lin, Y. (2017). Fixed-Price, Auction, and Bookbuilding IPOs: Empirical Evidence in Taiwan. Finance Research Letters, 22, 11-19.

Ibbotson, R. G. (1975). Price Performance of Common Stock New Issues. Journal of Financial Economics, 2(3), 235-272.

Ibbotson, R. G., Sindelar, J. L., \& Ritter, J. R. (1994). The Market's Problems with the Pricing of Initial Public Offerings. Journal of Applied Corporate Finance, 7(1), 66-74.

Imbens, G., \& Kalyanaraman, K. (2012). Optimal Bandwidth Choice for the Regression Discontinuity Estimator. Review of Economic Studies, 79(3), 933-959. 
Jacob, R., Zhu, P., Somers, M.-A., \& Bloom, H. (2012). A Practical Guide to Regression Discontinuity.

Jagannathan, R., Jirnyi, A., \& Sherman, A. G. (2015). Share Auctions of Initial Public Offerings: Global evidence. Journal of Financial Intermediation, 24(3), 283-311.

Japan Securities Research Institute. (2014). Securities Market in Japan 2014. Japan Securities Research Institute.

Jovanovic, B., \& Szentes, B. (2007). IPO Underpricing: Auctions vs. Book Building.

Kaneko, T., \& Pettway, R. H. (2003). Auctions Versus Book Building of Japanese IPOs. PacificBasin Finance Journal, 11(4), 439-462.

Kerins, F., Kutsuna, K., \& Smith, R. (2007). Why are IPOs Underpriced? Evidence from Japan's Hybrid Auction-Method Offerings. Journal of Financial Economics, 85(3), 637-666.

Kirkulak, B. (2004). Why Extreme Underpricings Occurred? Evidence From Japanese IPO Market. Journal of Faculty of Business, 5(2), 111-128.

Kirkulak, B. (2008). The Initial and Long-Run Returns of Japanese Venture Capital-Backed and Non-Venture Capital-Backed IPOs. International Journal of Managerial Finance, 4(2), 112-135.

Kirkulak, B., \& Davis, C. (2005). Underwriter Reputation and Underpricing: Evidence From the Japanese IPO Market. Pacific-Basin Finance Journal, 13(4), 451-470.

Kutsuna, K., Smith, J. K., \& Smith, R. L. (2009). Public Information, IPO Price Formation, and Long-Run Returns: Japanese Evidence. Journal of Finance, 64(1), 505-546.

Kutsuna, K., \& Smith, R. (2004). Why Does Book Building Drive Out Auction Methods of IPO Issuance? Evidence from Japan. Review of Financial Studies, 17(4), 1129-1166.

Lee, D. S., \& Lemieux, T. (2010). Regression Discontinuity Designs in Economics. Journal of Economic Literature, 48(2), 281-355.

Liu, X., \& Ritter, J. R. (2010). The Economic Consequences of IPO Spinning. Review of Financial Studies, 23(5), 2024-2059.

Ljungqvist, A., \& Wilhelm, W. J. (2003). IPO Pricing in the Dot-com Bubble. Journal of Finance, $58(2), 723-752$.

Logue, D. E. (1973). On the Pricing of Unseasoned Equity Issues: 1965-1969. Journal of Financial and Quantitative Analysis, 8(1), 91-103.

Loughran, T., \& Ritter, J. R. (2002). Why Don't Issuers Get Upset About Leaving Money on the Table in IPOs? The Review of Financial Studies, 15(2), 413-443.

Loughran, T., \& Ritter, J. R. (2004). Why Has IPO Underpricing Changed Over Time? Financial Management, 33(3), 5-37. 
Lowry, M., Michaely, R., \& Volkova, E. (2017). Initial Public Offerings: A Synthesis of the Literature and Directions for Future Research. Foundations and Trends in Finance, 11(3-4), 154-320.

Lowry, M., \& Schwert, G. W. (2004). Is the IPO Pricing Process Efficient? Journal of Financial Economics, 71(1), 3-26.

Pettway, R. H., \& Kaneko, T. (1996). The Effects of Removing Price Limits and Introducing Auctions Upon Short-Term IPO Returns: The Case of Japanese IPOs. Pacific-Basin Finance Journal, 4(2-3), 241-258.

Pettway, R. H., Thosar, S., \& Walker, S. (2008). Auctions Versus Book-Built IPOs in Japan: A Comparison of Aftermarket Volatility. Pacific-Basin Finance Journal, 16(3), 224-235.

Pukthuanthong, K., Varaiya, N. P., \& Walker, T. J. (2007). Bookbuilding Versus Auction Selling Methods: A Study of US IPOs. Venture Capital, 9(4), 311-345.

Reilly, F. K. (1973). Further Evidence on Short-Run Results For New Issue Investors. Journal of Financial and Quantitative Analysis, 8(1), 83-90.

Ritter, J. R. (1991). The Long-Run Performance of Initial Public Offerings. Journal of Finance, 46(1), 3-27.

Ritter, J. R. (2003). Investment Banking and Securities Issuance. In G. M. Constantinides, M. Harris, \& R. M. Stulz (Eds.), Handbook of the Economics of Finance (Vol. 1, pp. 253-304). ELSEVIER B.V.

Ritter, J. R., \& Welch, I. (2002). A Review of IPO Activity, Pricing, and Allocations. Journal of Finance, 57(4), 1795-1828.

Rock, K. (1986). Why New Issues Are Underpriced. Journal of Financial Economics, 15(1-2), 187212.

Sherman, A. E. (2000). IPOs and Long-Term Relationships: An Advantage of Book Building. Review of Financial Studies, 13(3), 697-714.

Sherman, A. E. (2005). Global Trends in IPO Methods: Book Building Versus Auctions with Endogenous Entry. Journal of Financial Economics, 78(3), 615-649.

Sherman, A. E., \& Titman, S. (2002). Building the IPO Order Book: Underpricing and Participation Limits with Costly Information. Journal of Financial Economics, 65(1), 3-29.

Stoll, H. R., \& Curley, A. J. (1970). Small Business and the New Issues Market for Equities. Journal of Financial and Quantitative Analysis, 5(3), 309-322.

Thistlethwaite, D. L., \& Campbell, D. T. (1960). Regression-Discontinuity Analysis: An Alternative to the Ex Post Facto Experiment. Journal of Educational Psychology, 51(6), 309-317.

Thomson Reuters Datastream. (2020). Excel Add-in Thomson Reuters Datastream. Retrieved on the 
30 of April 2020

Tinic, S. M. (1988). Anatomy of Initial Public Offerings of Common Stock. Journal of Finance, 43(4), 789-822.

Welch, I. (1989). Seasoned Offerings, Imitation Costs, and the Underpricing of Initial Public Offerings. Journal of Finance, 44(2), 421-449.

Weber, M., Duffy, J., \& Schram, A. (2018). An experimental study of bond market pricing. The Journal of Finance, 73(4), 1857-1892.

Welch, I. (1992). Sequential Sales, Learning, and Cascades. Journal of Finance, 47(2), 695-732. 


\section{Appendix A:Japanese Stock Exchanges [for Online Publication]}

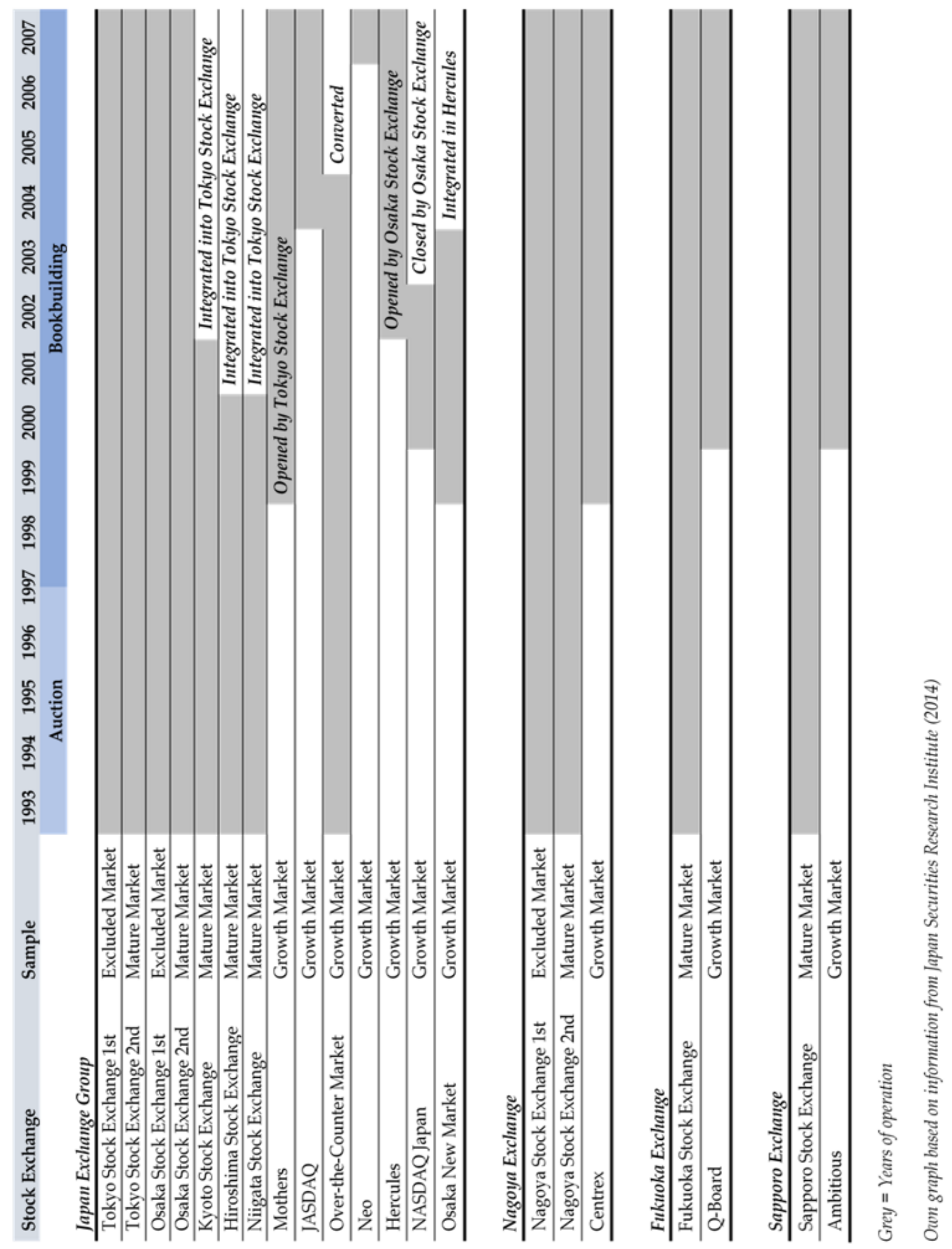




\section{Appendix B: Covariate Formulas [for Online Publication]}

\section{Covariate Formulas \\ Including Offer Price and Expected Offer Price Formulas}

This table provides the formulas for the calculation of each covariate, the offer price and the expected offer price. All calculations are based on the local currency (Japanese Yen).

Offer Price and Expected Offer Price Formulas

\begin{tabular}{ccc}
\hline Auction Subsample & & Bookbuilding Subsample \\
$\frac{\text { Lower Limit on Bids }}{0.85}$ & $\quad$ Average of the Filing Range
\end{tabular}

Expected Offer Price (EOP)

Offer Price (OP)
$\%$ of Auctioned Shares * WESB

$+\%$ of POT Shares * Price POT

Price defined by Underwriter

Note:

$\%$ of Auctioned Shares $=$ Percentage of Shares Sold in the Auction Tranche WESB $=$ Weighted Average of Successful Bids

$\%$ of POT Shares $=$ Percentage of Shares Sold in the Public Offer Tranche POT = Public Offer Tranche

\section{Covariate Formulas}

Firm Age (log)

Expected Issue Size (log)

Insider Sales (in \%)

Underwriter

(Dummy)

Market Return

(in \%)

Market Volatility

(in \%) $\log (I P O$ date - Founding date)

$\log (E O P *$ Total Number of Shares on Sale $)$

$$
\frac{\text { Number of Secondary Shares on Sale }}{\text { Total Number of Shares on Sale }} * 100
$$

Top 5 Underwriters

$$
\frac{\text { Index } C P_{I P O} \text { date }}{- \text { Index } C P_{I P O} \text { date }-60 \text { trading days }} * 100
$$

Variance of Daily Index Prices 20 Trading Days before IPO *100 


\section{Appendix C: Mature Market Sample Results [for Online Publication]}

Appendix C presents the results for the Mature Market Sample.

\section{List of Tables}

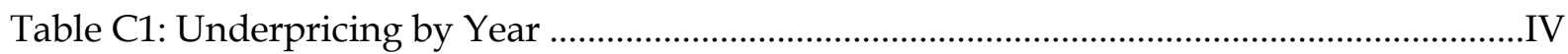

Table C2: Underpricing - Descriptive Statistics .......................................................................... V

Table C3: Underpricing - Regression Results (Full Sample) ..................................................... II

Table C4: Underpricing - RD Global Strategy Results ............................................................ VII

Table C5: Price Accuracy - Descriptive Statistics...................................................................... VIII

Table C6: Price Accuracy - Regression Results ..........................................................................IX

Table C7: Price Accuracy - RD Global Strategy Results.........................................................

\section{List of Figures}

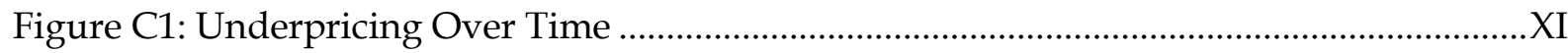

Figure C2: Method Coefficient and Bandwidth (Multiple Linear Regression) ....................... XII 


\section{Table C1: Underpricing by Year}

\section{Underpricing between 01/01/1993 and 31/12/2007 (Mature Market Sample)}

Obs. abbreviates the number of observations and Und. stands for average underpricing (in \%). Three subsamples are described based on the Second Sections of Tokyo Stock Exchange, Osaka Stock Exchange and Nagoya Stock Exchange. Regional Exchanges is a subsample of IPOs at stock exchanges in Kyoto, Hiroshima, Niigata, Fukuoka and Sapporo.

\begin{tabular}{|c|c|c|c|c|c|c|c|c|c|c|}
\hline \multirow[b]{2}{*}{ Year } & \multicolumn{2}{|c|}{$\begin{array}{c}\text { Full } \\
\text { Sample }\end{array}$} & \multicolumn{2}{|c|}{$\begin{array}{c}2^{\text {nd }} \text { Section } \\
\text { Tokyo SE }\end{array}$} & \multicolumn{2}{|c|}{$\begin{array}{c}2^{\text {nd }} \text { Section } \\
\text { Osaka SE }\end{array}$} & \multicolumn{2}{|c|}{$\begin{array}{l}2^{\text {nd }} \text { Section } \\
\text { Nagoya SE }\end{array}$} & \multicolumn{2}{|c|}{$\begin{array}{c}\text { Regional } \\
\text { Exchanges }\end{array}$} \\
\hline & Obs. & Und. & Obs. & Und. & Obs. & Und. & Obs. & Und. & Obs. & Und. \\
\hline 1993 & 34 & 13.2 & 10 & 17.9 & 12 & 9.6 & 8 & 15.0 & 4 & 8.4 \\
\hline 1994 & 42 & 12.1 & 10 & 10.0 & 19 & 5.1 & 2 & 7.1 & 11 & 27.1 \\
\hline 1995 & 50 & 9.4 & 14 & 9.4 & 20 & 7.4 & 9 & 9.5 & 7 & 14.9 \\
\hline 1996 & 50 & 7.8 & 12 & 8.2 & 24 & 11.4 & 5 & 1.7 & 9 & 1.1 \\
\hline 19971 & 24 & -0.7 & 8 & 2.9 & 9 & -3.6 & 6 & 4.5 & 1 & -33.8 \\
\hline 19972 & 13 & 4.6 & 1 & 0.0 & 11 & 5.3 & 0 & 0.0 & 1 & 2.5 \\
\hline 1998 & 20 & 12.9 & 10 & 17.4 & 7 & 4.0 & 1 & 20.6 & 2 & 17.5 \\
\hline 1999 & 28 & 51.9 & 5 & 68.3 & 13 & 62.8 & 5 & 40.9 & 5 & 18.2 \\
\hline 2000 & 35 & 9.5 & 17 & 9.0 & 12 & 10.2 & 4 & 12.8 & 2 & 2.5 \\
\hline 2001 & 16 & 17.1 & 12 & 12.4 & 3 & 21.0 & 1 & 61.9 & 0 & 0.0 \\
\hline 2002 & 19 & 28.9 & 15 & 35.9 & 3 & -1.9 & 1 & 16.8 & 0 & 0.0 \\
\hline 2003 & 15 & 32.8 & 12 & 35.3 & 3 & 22.7 & 0 & 0.0 & 0 & 0.0 \\
\hline 2004 & 18 & 58.2 & 14 & 55.2 & 3 & 52.8 & 0 & 0.0 & 1 & 116.9 \\
\hline 2005 & 13 & 83.5 & 11 & 33.0 & 1 & 83.4 & 0 & 0.0 & 1 & 640.0 \\
\hline 2006 & 24 & 25.1 & 16 & 4.9 & 3 & -7.1 & 1 & 3.0 & 4 & 135.5 \\
\hline 2007 & 9 & 12.1 & 7 & 21.1 & 0 & 0.0 & 1 & -34.0 & 1 & -4.7 \\
\hline
\end{tabular}

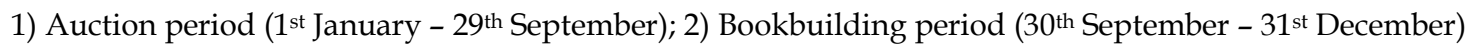




\section{Table C2: Underpricing - Descriptive Statistics}

\section{Japanese IPOs between 01/01/1993 and 31/12/2007 (Mature Market Sample)}

Top 5 Underwriter refers to the number of IPOs underwritten by one of the five largest investment banks. Bubble Period refers to the number of IPOs between the 01/04/1999 and 30/06/2000. See Section 4.2.3 for a detailed description of each covariate. The currency of the expected issue size is Japanese Yen.

\begin{tabular}{|c|c|c|c|c|}
\hline \multirow[b]{2}{*}{ Observations } & \multicolumn{2}{|c|}{ Auction Subsample } & \multicolumn{2}{|c|}{ Bookbuilding Subsample } \\
\hline & \multicolumn{2}{|c|}{200} & \multicolumn{2}{|c|}{210} \\
\hline Top 5 Underwriter & \multicolumn{2}{|c|}{185} & \multicolumn{2}{|c|}{178} \\
\hline \multirow[t]{2}{*}{ Bubble Period } & \multicolumn{2}{|c|}{0} & \multicolumn{2}{|c|}{38} \\
\hline & Average & Median & Average & Median \\
\hline Underpricing & $9.00 \%$ & $4.31 \%$ & $29.82 \%$ & $9.17 \%$ \\
\hline Firm Age & 36.56 & 35.65 & 33.40 & 30.61 \\
\hline $\log$ (Firm Age) & 3.51 & 3.57 & 3.32 & 3.42 \\
\hline Expected Issue Size & $5,356 \mathrm{~m}$ & $3,166 \mathrm{~m}$ & $3,564 \mathrm{~m}$ & $2,031 \mathrm{~m}$ \\
\hline $\log ($ Exp. Issue Size) & 21.90 & 21.88 & 21.31 & 21.43 \\
\hline Insider Sales & $34.33 \%$ & $37.75 \%$ & $42.48 \%$ & $45.14 \%$ \\
\hline Market Return & $0.29 \%$ & $-0.49 \%$ & $0.51 \%$ & $-0.30 \%$ \\
\hline Market Volatility & $0.0103 \%$ & $0.0071 \%$ & $0.0172 \%$ & $0.0144 \%$ \\
\hline
\end{tabular}




\section{Table C3: Underpricing - Regression Results (Full Sample)}

Japanese IPOs between 01/01/1993 and 31/12/2007 (Mature Market Sample)

In all three OLS regressions, the dependent variable is underpricing. P-values shown in parenthesis are based on heteroscedasticity-consistent standard errors (HC3). See Section 4.2.3 for a detailed description of each covariate. ExpIS abbreviates the expected issue size. Model 1 does not account for the dot-com bubble 1999/2000. Model 2 introduces a dummy variable that equals 1 for observations between 01/04/1999 and 30/06/2000. Model 3 excludes observations between 01/04/1999 and 30/06/2000 from the analysis.

\begin{tabular}{lccc} 
Data & Model 1 & Model 2 & Model 3 \\
\cline { 2 - 3 } \cline { 3 - 4 } Stock Exchange & All & All & All \\
Bubble Period & - & Dummy & Data exc. \\
Results & & & \\
Intercept & 167.81 & 171.58 & 242.05 \\
Method & $(0.102)$ & $(0.088)$ & $(0.028)^{*}$ \\
& 16.35 & 15.17 & 13.56 \\
Log Age & $(0.000)^{* * *}$ & $(0.000)^{* * *}$ & $(0.000)^{* * *}$ \\
& -18.69 & -18.78 & -18.95 \\
Log ExpIS & $(0.032)^{*}$ & $(0.030)^{*}$ & $(0.042)^{*}$ \\
& -2.94 & -3.08 & -6.26 \\
Insider Sales & $(0.346)$ & $(0.312)$ & $(0.059)$ \\
& -0.24 & -0.24 & -0.27 \\
Market Return & $(0.060)$ & $(0.069)$ & $(0.053)$ \\
& 1.34 & 1.30 & 1.26 \\
Market Volat. & $(0.000)^{* * *}$ & $(0.001)^{* * * *}$ & $(0.002)^{* * *}$ \\
& -107.90 & -127.94 & -150.45 \\
Underwriter & $(0.431)$ & $(0.341)$ & $(0.248)$ \\
& -21.43 & -21.78 & -20.63 \\
Bubble & $(0.062)$ & $(0.055)$ & $(0.084)$ \\
& & 6.45 & \\
Observations & & $(0.520)$ & \\
Adj. R-squared & 410 & & 372 \\
F-value & 0.176 & 410 & 0.191 \\
p-value & 13.50 & 0.175 & 13.52 \\
Significance levels are as follows: ${ }^{*}=0.05 ; * * 000^{* * *}$ & \\
\hline
\end{tabular}




\section{Table C4: Underpricing - RD Global Strategy Results Japanese IPOs between 01/01/1993 and 31/12/2007 (Mature Market Sample)}

The table presents the results of the Method coefficient for 12 OLS regressions with underpricing as dependent variable. In all regressions, the covariates introduced in Section 4.2 .3 are included in the regression equation. In Model 2 a bubble dummy is included in the regression equation that equals 1 for observations between April 1999 and June 2000. For both models, six OLS regressions are conducted with different specifications of $f$ (Time). P-values shown in parenthesis are based on heteroscedasticity-consistent standard errors (HC3). No model excludes IPOs during the dot-com bubble 1999/2000 because the underlying idea of the global strategy is that every single observation is included in the analysis and that the time trend specification captures time-variations.

Data

Stock Exchange

Bubble

Observations
Model 1

All

410
Model 2

All

Dummy

410

Method Dummy Coefficients

Linear Time Trend

13.85

9.99

(0.137)

(0.267)

Quadratic Time Trend

15.83

12.64

$(0.029)^{*}$

(0.077)

Cubic Time Trend

6.62

1.75

(0.473)

(0.837)

Fourth-order Polynomial

20.53

17.64

Time Trend

$(0.031)^{*}$

(0.052)

19.58

16.70

Time Trend

$(0.024)^{*}$

$(0.044)^{*}$

Sixth-order Polynomial

19.58

Time Trend

21.26

$(0.033)^{*}$

Significance levels are as follows: ${ }^{*}=0.05 ;{ }^{* *}=0.01 ;{ }^{* *}=0.001$ 


\section{Table C5: Price Accuracy - Descriptive Statistics}

\section{Japanese IPOs between 01/01/1993 and 31/12/2007 (Mature Market Sample)}

Top 5 Underwriter refers to the number of IPOs that were underwritten by one of the five largest investment banks. Bubble Period refers to the number of IPOs between the 01/04/1999 and 30/06/2000. Abs. AR stands for absolute abnormal buy-and-hold return over a 12-month post-listing period. The calculation of absolute abnormal buy-and-hold returns is described in Section 4.2.2. See Section 4.2.3 for a detailed description of each covariate. The currency of the expected issue size is Japanese Yen.

Observations

Auction Subsample

Top 5 Underwriter

Bubble Period
155

143

0
Bookbuilding Subsample

181

157

32

\begin{tabular}{|c|c|c|c|c|}
\hline Dependent Variable & Average & Median & Average & Median \\
\hline Abs. AR $12 m$ Topix & $27.92 \%$ & $23.09 \%$ & $54.72 \%$ & $28.48 \%$ \\
\hline Abs. AR $12 \mathrm{~m}$ Nikkei225 & $28.22 \%$ & $22.65 \%$ & $55.39 \%$ & $29.68 \%$ \\
\hline \multicolumn{5}{|l|}{ Independent Variables } \\
\hline Firm Age & 37.45 & 36.22 & 35.07 & 32.68 \\
\hline log (Firm Age) & 3.54 & 3.59 & 3.39 & 3.49 \\
\hline Expected Issue Size & $5,024 \mathrm{~m}$ & $3,125 \mathrm{~m}$ & $3,660 \mathrm{~m}$ & $2,040 \mathrm{~m}$ \\
\hline $\log ($ Exp. Issue Size) & 21.89 & 21.86 & 21.35 & 21.44 \\
\hline Insider Sales & $35.79 \%$ & $40.00 \%$ & $42.94 \%$ & $45.65 \%$ \\
\hline Market Return & $-0.11 \%$ & $-1.04 \%$ & $-0.20 \%$ & $-1.22 \%$ \\
\hline Market Volatility & $0.0104 \%$ & $0.0072 \%$ & $0.0173 \%$ & $0.0148 \%$ \\
\hline
\end{tabular}




\section{Table C6: Price Accuracy - Regression Results}

\section{Japanese IPOs between 01/01/1993 and 31/12/2007 (Mature Market Sample)}

In all six OLS regressions, the dependent variable is the absolute abnormal buy-and-hold return over a 12-month post-listing period. Model 1 to Model 3 are based on the Topix index benchmark and Model 4 to Model 6 are based on the Nikkei 225 index benchmark. While Model 1 and Model 4 do not control for the dot-com bubble 1999/2000, Model 2 and Model 5 introduce a bubble dummy variable. Further, Model 3 to Model 6 exclude observations between 01/04/1999 and 30/06/2000 from the analysis. P-values shown in parenthesis are based on heteroscedasticity-consistent standard errors (HC3). See Section 4.2.3 for a description of each covariate. Exp. Issue abbreviates the expected issue size.

\section{$\underline{\text { Data }}$}

Data

Bubble Period

Benchmark

Period

$\underline{\text { Results }}$

Intercept

Method

Log Age

Log Exp. Issue

Insider Sales

Market Return

Market Volat.

Underwriter

Bubble

Observations

Adj. R-squa.

F-value

p-value

\begin{tabular}{ccc} 
Model 1 & & Model 2 \\
\cline { 1 - 1 } All & & All \\
- & & Dummy \\
Topix & & Topix
\end{tabular}

12 months 12 months

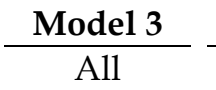

Data exc.

Topix

12 months

\begin{tabular}{c} 
Model 4 \\
\hline All \\
- \\
Nikkei 225 \\
12 months
\end{tabular}

12

Model

All

Dummy

Nikkei 225

12 months
Model 6

Data exc.

Nikkei 225

12 months

Significance levels are as follows: ${ }^{*}=0.05 ;{ }^{* *}=0.01 ;{ }^{* * *}=0.001$ 


\section{Table C7: Price Accuracy - RD Global Strategy Results Japanese IPOs between 01/01/1993 and 31/12/2007 (Mature Market Sample)}

The table presents the results of the Method coefficient for 12 OLS regressions with absolute abnormal buy-and-hold returns over a 12-month post-listing period as dependent variable. In all regressions, the covariates introduced in Section 4.2 .3 and a bubble dummy that equals 1 for observations between April 1999 and June 2000 are included in the regression equation. The benchmark is in Model 1 the Topix index and in Model 2 the JASDAQ index. For both models, six OLS regressions are conducted with different specifications of $f($ Time). P-values shown in parenthesis are based on heteroscedasticityconsistent standard errors (HC3).

\section{Data}

Stock Exchange

Bubble

Benchmark

Period

Observations
Model 1

All

Dummy

Topix

12 months

336

76.49

$(0.007)^{* *}$

64.76

$(0.010)^{*}$

65.15

$(0.046)^{*}$

66.31

$(0.035)^{*}$

65.54

$(0.027)^{*}$

67.66

$(0.020)$ *
Model 2

All

Dummy

Nikkei 225

12 months

336

75.90

$(0.011)^{*}$

64.49

$(0.014)^{*}$

64.82

(0.055)

65.71

$(0.044)^{*}$

64.88

$(0.034)^{*}$

65.61

$(0.028)^{*}$

Significance levels are as follows: ${ }^{*}=0.05 ;{ }^{* *}=0.01 ;{ }^{* *}=0.001$ 


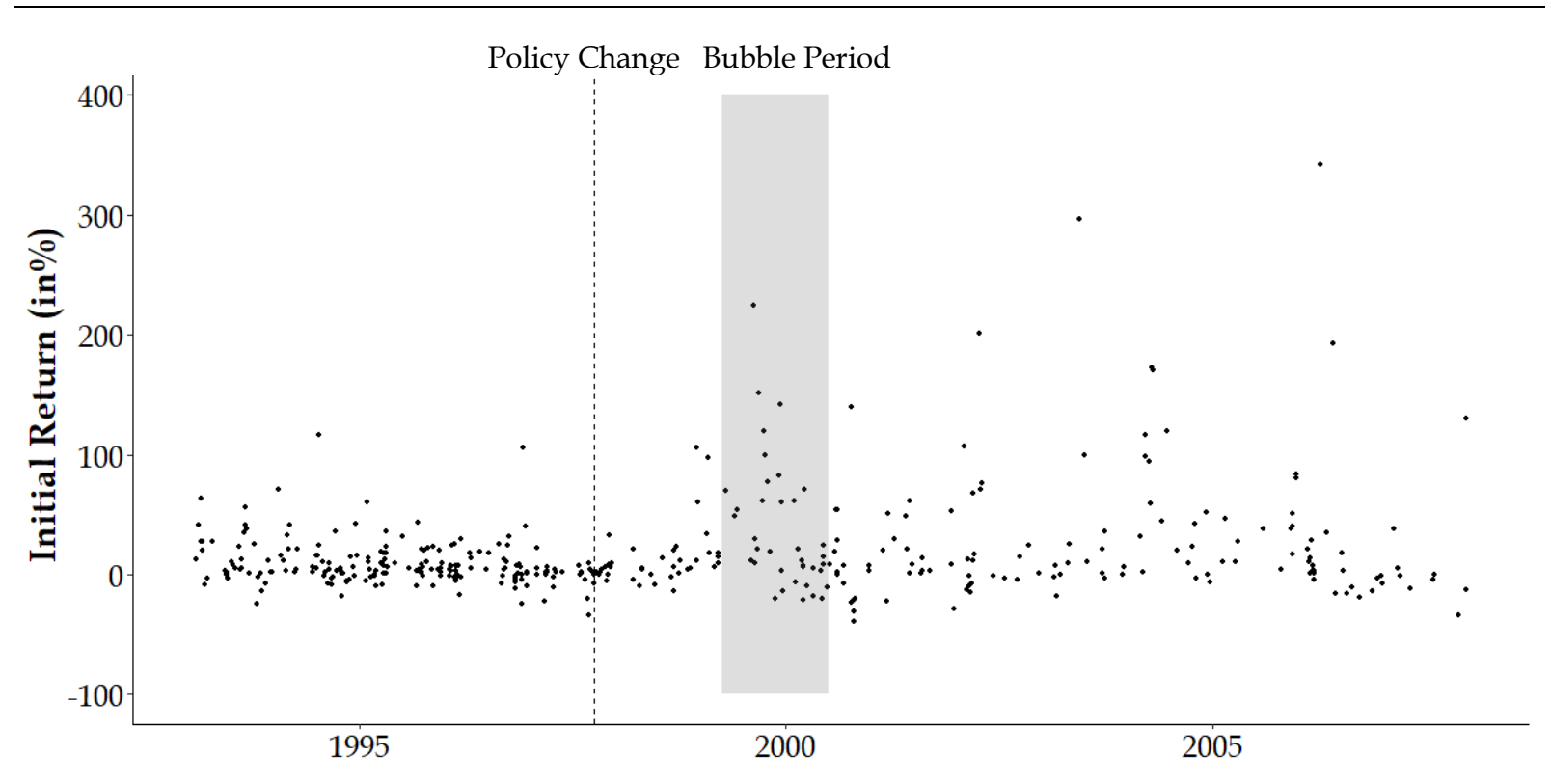

Figure C1: Underpricing Over Time

\section{Underpricing between 01/01/1993 and 31/12/2007 (Mature Market Sample)}

Each point represents one observation. There are 410 observations in the Mature Market Sample. One book-built IPOs exhibited an initial return that exceeded $400 \%$ and is therefore not shown in the graph. The dashed vertical line indicates the date of the policy change (30/09/1997). All observations to the left are auctions and all observations to the right are bookbuildings. The shaded box highlights the dot-com bubble (01/04/1999 to 30/06/2000). 

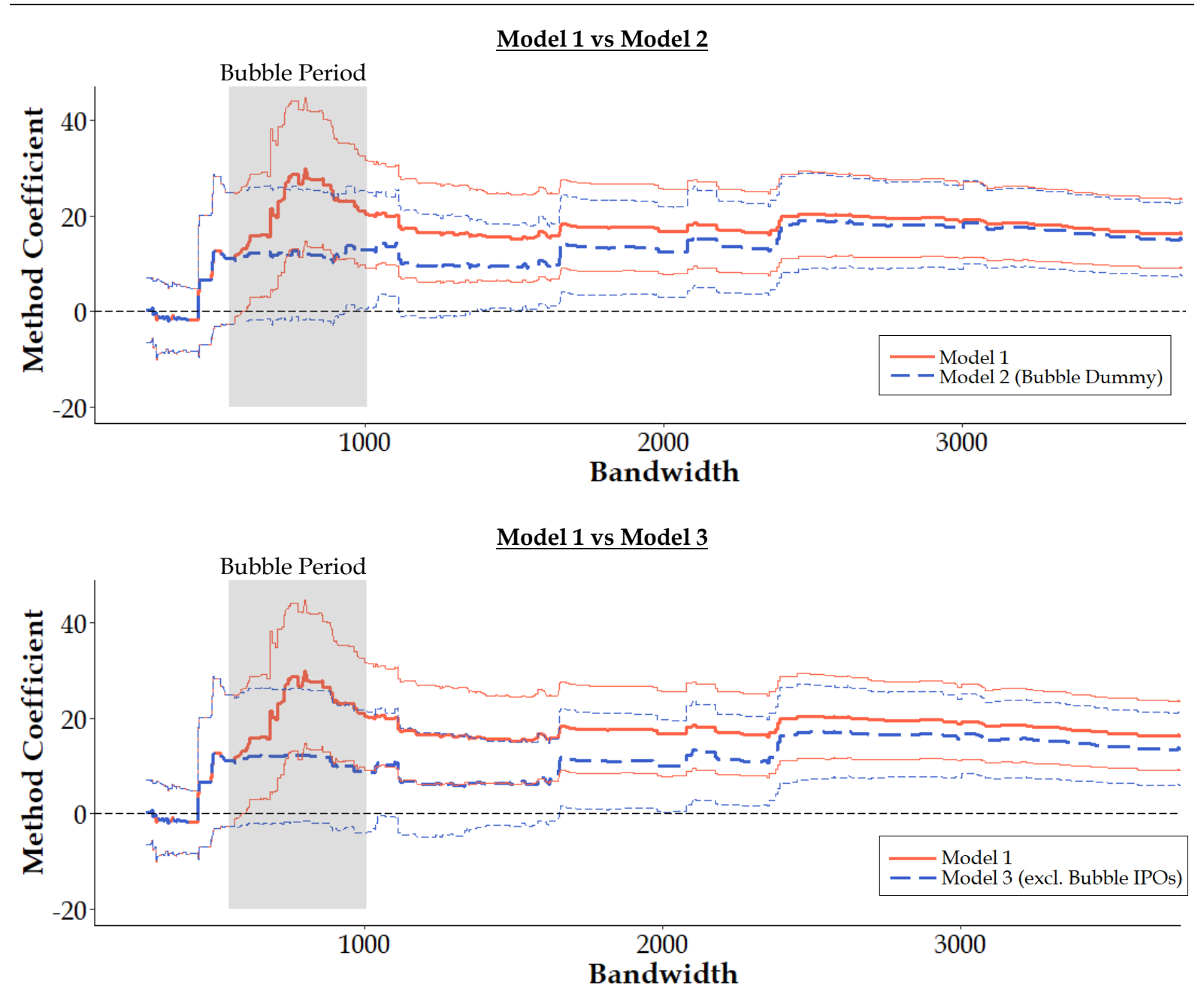

Figure C2: Method Coefficient and Bandwidth (Multiple Linear Regression)

Method Coefficient Sensitivity and Dot-com Bubble 1999/2000 (Mature Market Sample)

This figure presents the estimate of the Method coefficient for 10,410 OLS regressions. In all regressions, the dependent variable is underpricing. The straight (red) line is based on the regression equation of Model 1 in Table C3. The dashed (blue) lines in the upper graph and the lower graph account for the dot-com bubble 1999/2000 and are based on the regression equation of Model 2 in Table C3 and Model 3 in Table C3, respectively. The shaded box highlights the bandwidth that covers the dot-com bubble (01/04/1999 to 30/06/2000). Further, 95\%-confidence intervals are presented. Bandwidth specifies the data that is included in the regression analysis. Note that even though the dashed (blue) line in the lower graph excludes dotcom bubble 1999/2000 observations from the analysis, the Method coefficient changes during this period because the number of observations from the auction period is increasing with a growing bandwidth. 


\section{Appendix D:Aftermarket Performance [for Online Publication]}

Appendix D presents the results of the aftermarket performance analysis. Aftermarket performance is measured by abnormal buy-and-hold returns over a 12-month post-listing period.

\section{List of Tables}

Table D1: Aftermarket Performance - Regression Results ................................................... XIV

Table D2: Aftermarket Performance - Regression Results (excl. Outliers) .............................. XV 


\section{Table D1: Aftermarket Performance - Regression Results Japanese IPOs between 01/01/1993 and 31/12/2007 (Growth Market Sample)}

In all six OLS regressions, the dependent variable is the abnormal buy-and-hold return over a 12-month post-listing period. Model 1 to Model 3 are based on the JASDAQ index benchmark and Model 4 to Model 6 are based on the Topix index benchmark. While Model 1 and Model 4 do not control for the dot-com bubble 1999/2000, Model 2 and Model 5 introduce a bubble dummy variable. Further, Model 3 to Model 6 exclude observations between 01/04/1999 and 30/06/2000 from the analysis. P-values shown in parenthesis are based on heteroscedasticity-consistent standard errors (HC3). See Section 4.2 .3 for a description of each covariate. Exp. Issue abbreviates the expected issue size.

\begin{tabular}{|c|c|c|c|c|c|c|}
\hline Data & Model 1 & Model 2 & Model 3 & Model 4 & Model 5 & Model 6 \\
\hline$\overline{\text { Data }}$ & All & All & All & All & All & All \\
\hline Bubble Period & - & Dummy & Data exc. & - & Dummy & Data exc. \\
\hline Benchmark & JASDAQ & JASDAQ & JASDAQ & Topix & Topix & Topix \\
\hline Period & 12 months & 12 months & 12 months & 12 months & 12 months & 12 months \\
\hline \multicolumn{7}{|l|}{ Results } \\
\hline \multirow[t]{2}{*}{$\overline{\text { Intercept }}$} & 122.59 & 113.78 & 113.13 & 195.12 & 183.65 & 187.18 \\
\hline & $(0.177)$ & $(0.207)$ & $(0.234)$ & $(0.048)^{*}$ & $(0.062)$ & $(0.072)$ \\
\hline \multirow[t]{2}{*}{ Method } & 2.97 & 4.12 & 2.64 & 22.70 & 24.19 & 25.17 \\
\hline & $(0.548)$ & $(0.412)$ & $(0.654)$ & $(0.000)^{* * *}$ & $(0.000)^{* * *}$ & $(0.000)^{* * *}$ \\
\hline \multirow[t]{2}{*}{ Log Age } & -6.11 & -5.91 & -8.12 & -6.16 & -5.89 & -7.41 \\
\hline & $(0.296)$ & $(0.310)$ & (0.183) & (0.310) & (0.329) & $(0.242)$ \\
\hline \multirow[t]{2}{*}{ Log Exp. Issue } & -5.64 & -5.29 & -4.90 & -9.75 & -9.29 & -9.15 \\
\hline & (0.148) & $(0.172)$ & $(0.228)$ & $(0.023)^{*}$ & $(0.029)^{*}$ & $(0.042)^{*}$ \\
\hline \multirow[t]{2}{*}{ Insider Sales } & 0.02 & 0.01 & 0.00 & 0.15 & 0.14 & 0.13 \\
\hline & (0.895) & $(0.940)$ & $(0.986)$ & $(0.382)$ & $(0.420)$ & $(0.451)$ \\
\hline \multirow[t]{2}{*}{ Market Return } & -0.58 & -0.36 & -0.37 & -0.34 & -0.05 & -0.07 \\
\hline & $(0.002)^{* *}$ & $(0.107)$ & $(0.127)$ & $(0.075)$ & $(0.821)$ & (0.792) \\
\hline \multirow[t]{2}{*}{ Market Volat. } & -11.66 & 125.12 & 172.26 & -199.21 & -21.01 & -261.54 \\
\hline & $(0.838)$ & $(0.050)^{*}$ & $(0.510)$ & $(0.002)^{* *}$ & $(0.754)$ & $(0.346)$ \\
\hline \multirow[t]{2}{*}{ Underwriter } & 20.52 & 21.22 & 21.13 & 25.67 & 26.57 & 26.83 \\
\hline & $(0.009)^{* *}$ & $(0.007)^{* *}$ & $(0.012)^{*}$ & $(0.002)^{* *}$ & $(0.001)^{* *}$ & $(0.003)^{* *}$ \\
\hline \multirow[t]{2}{*}{ Bubble } & & -30.30 & & & -39.48 & \\
\hline & & $(0.006)^{* *}$ & & & $(0.000)^{* * *}$ & \\
\hline Observations & 1,448 & 1,448 & 1,342 & 1,448 & 1,448 & 1,342 \\
\hline Adj. R-squa. & 0.006 & 0.007 & 0.004 & 0.015 & 0.016 & 0.013 \\
\hline F-value & 2.24 & 2.25 & 1.72 & 4.08 & 4.01 & 3.57 \\
\hline $\mathrm{p}$-value & $0.029^{*}$ & $0.022^{*}$ & 0.101 & $0.000^{\star * *}$ & $0.000^{* * *}$ & $0.001^{* * *}$ \\
\hline
\end{tabular}




\section{Table D2: Aftermarket Performance - Regression Results (excl. Outliers) Japanese IPOs between 01/01/1993 and 31/12/2007 (Growth Market Sample)}

In all six OLS regressions, the dependent variable is the abnormal buy-and-hold return over a 12-month post-listing period. The analysis excludes from the auction and the bookbuilding subsample, the observations with the highest abnormal buy-andhold returns (90\% quantile) and the lowest abnormal buy-and-hold returns (10\% quantile). Model 1 to Model 3 are based on the JASDAQ index benchmark and Model 4 to Model 6 are based on the Topix index benchmark. While Model 1 and Model 4 do not control for the dot-com bubble 1999/2000, Model 2 and Model 5 introduce a bubble dummy variable. Further, Model 3 to Model 6 exclude observations between 01/04/1999 and 30/06/2000 from the analysis. P-values shown in parenthesis are based on heteroscedasticity-consistent standard errors (HC3). See Section 4.2.3 for a description of each covariate. Exp. Issue abbreviates the expected issue size.

\begin{tabular}{|c|c|c|c|c|c|c|}
\hline Data & Model 1 & Model 2 & Model 3 & Model 4 & Model 5 & Model 6 \\
\hline$\overline{\text { Data }}$ & All & All & All & All & All & All \\
\hline Bubble Period & - & Dummy & Data exc. & - & Dummy & Data exc. \\
\hline Benchmark & JASDAQ & JASDAQ & JASDAQ & Topix & Topix & Topix \\
\hline Period & 12 months & 12 months & 12 months & 12 months & 12 months & 12 months \\
\hline \multicolumn{7}{|l|}{ Results } \\
\hline \multirow[t]{2}{*}{ Intercept } & 2.72 & 2.72 & -0.76 & 36.09 & 33.96 & 33.81 \\
\hline & $(0.904)$ & (0.904) & (0.975) & $(0.126)$ & $(0.152)$ & (0.192) \\
\hline \multirow[t]{2}{*}{ Method } & -7.75 & -7.75 & -6.53 & 2.07 & 2.44 & 3.13 \\
\hline & $(0.000)^{* * *}$ & $(0.000)^{* * *}$ & $(0.002)^{* *}$ & $(0.342)$ & $(0.269)$ & (0.196) \\
\hline \multirow[t]{2}{*}{ Log Age } & 4.81 & 4.81 & 4.10 & 2.49 & 2.58 & 1.31 \\
\hline & $(0.000)^{* * *}$ & $(0.000)^{* * *}$ & $(0.004)^{* *}$ & (0.096) & $(0.083)$ & $(0.426)$ \\
\hline \multirow[t]{2}{*}{ Log Exp. Issue } & -1.30 & -1.30 & -0.95 & -2.83 & -2.76 & -2.55 \\
\hline & (0.204) & $(0.205)$ & (0.381) & $(0.009)^{* *}$ & $(0.011)^{*}$ & $(0.032)^{*}$ \\
\hline \multirow[t]{2}{*}{ Insider Sales } & -0.02 & -0.02 & -0.02 & -0.05 & -0.05 & -0.05 \\
\hline & $(0.671)$ & $(0.671)$ & $(0.726)$ & (0.373) & $(0.351)$ & $(0.430)$ \\
\hline \multirow[t]{2}{*}{ Market Return } & -0.14 & -0.14 & -0.15 & -0.15 & -0.09 & -0.14 \\
\hline & $(0.043)^{*}$ & $(0.066)$ & (0.075). & $(0.049)^{*}$ & $(0.266)$ & (0.131) \\
\hline \multirow[t]{2}{*}{ Market Volat. } & 42.34 & 42.42 & 31.40 & -43.64 & -9.29 & 57.93 \\
\hline & (0.058). & (0.179) & $(0.689)$ & (0.075) & $(0.776)$ & (0.569) \\
\hline \multirow[t]{2}{*}{ Underwriter } & 6.52 & 6.52 & 4.48 & 7.62 & 7.80 & 6.83 \\
\hline & $(0.003)^{* *}$ & $(0.003)^{* *}$ & (0.055). & $(0.002)^{* *}$ & $(0.001)^{* *}$ & $(0.010)^{* *}$ \\
\hline \multirow[t]{2}{*}{ Bubble } & & -0.02 & & & -7.90 & \\
\hline & & (0.997) & & & (0.153) & \\
\hline Observations & 1,156 & 1,156 & 1,072 & 1,156 & 1,156 & 1,072 \\
\hline Adj. R-squa. & 0.045 & 0.045 & 0.027 & 0.017 & 0.017 & 0.010 \\
\hline F-value & 8.85 & 7.74 & 5.29 & 3.80 & 3.57 & 2.51 \\
\hline p-value & $0.000^{* * *}$ & $0.000^{* * *}$ & $0.000^{* * *}$ & $0.000^{* * *}$ & $0.000^{* * *}$ & 0.015 \\
\hline
\end{tabular}

Significance levels are as follows: ${ }^{*}=0.05 ;{ }^{* *}=0.01 ;{ }^{* *}=0.001$ 


\section{Appendix E: Price Accuracy Over 36 Months [for Online Publication]}

Appendix E presents the results of the price accuracy analysis based on absolute abnormal buyand-hold returns over a 36-month post-listing period.

\section{List of Tables}

Table E1: Price Accuracy - Regression Results (Growth Market Sample, JASDAQ)............XVII

Table E2: Price Accuracy - Regression Results (Growth Market Sample, Topix) ............... XVIII

Table E3: Price Accuracy - Regression Results (Mature Market Sample) .............................. XIX

Table E4: Price Accuracy - RD Global Strategy Results (Growth Market Sample) ................ XX

Table E5: Price Accuracy - RD Global Strategy Results (Mature Market Sample)................XXI

Table E6: Price Accuracy - RD Local Strategy Results (Growth Market Sample) .................XXII

Table D1: Aftermarket Performance - Regression Results ....................................................... XIV

Table D2: Aftermarket Performance - Regression Results (excl. Outliers) …............................. XV 
Table E1: Price Accuracy - Regression Results (Growth Market Sample, JASDAQ) Japanese IPOs between 01/01/1993 and 31/12/2007 (Growth Market Sample)

In all six OLS regressions, the dependent variable is the absolute abnormal buy-and-hold return over a 36-month post-listing period based on the JASDAQ index benchmark. Model 1 to Model 3 are based on the Growth Market Sample and Model 4 to Model 6 are based on the OTC Subsample. While Model 1 and Model 4 do not control for the dot-com bubble 1999/2000, Model 2 and Model 5 introduce a bubble dummy variable. Further, Model 3 and Model 6 exclude observations between 01/04/1999 and 30/06/2000 from the analysis. P-values shown in parenthesis are based on heteroscedasticity-consistent standard errors (HC3). See Section 4.2.3 for a description of each covariate. Exp. Issue abbreviates the expected issue size.

\begin{tabular}{|c|c|c|c|c|c|c|}
\hline Data & Model 1 & Model 2 & Model 3 & Model 4 & Model 5 & Model 6 \\
\hline$\overline{\text { Data }}$ & All & All & All & OTC & OTC & OTC \\
\hline Bubble Period & - & Dummy & Data exc. & - & Dummy & Data exc. \\
\hline Benchmark & JASDAQ & JASDAQ & JASDAQ & JASDAQ & JASDAQ & JASDAQ \\
\hline Period & 36 months & 36 months & 36 months & 36 months & 36 months & 36 months \\
\hline \multicolumn{7}{|l|}{ Results } \\
\hline \multirow[t]{2}{*}{$\overline{\text { Intercept }}$} & 800.60 & 802.53 & 851.27 & $1,025.49$ & $1,032.85$ & $1,086.54$ \\
\hline & $(0.001)^{* * *}$ & $(0.001)^{* * *}$ & $(0.001)^{* * *}$ & $(0.003)^{* *}$ & $(0.003)^{* *}$ & $(0.003)^{* *}$ \\
\hline \multirow[t]{2}{*}{ Method } & 13.62 & 13.37 & 14.57 & 24.38 & 23.53 & 22.03 \\
\hline & $(0.067)$ & (0.083) & $(0.100)$ & $(0.002)^{* *}$ & $(0.003)^{* *}$ & $(0.020)^{*}$ \\
\hline \multirow[t]{2}{*}{ Log Age } & -46.36 & -46.41 & -50.24 & -86.94 & -86.94 & -96.70 \\
\hline & $(0.036)^{*}$ & $(0.036)^{*}$ & $(0.038)^{*}$ & $(0.040)^{*}$ & $(0.040)^{*}$ & $(0.043)^{*}$ \\
\hline \multirow{2}{*}{ Log Exp. Issue } & -27.85 & -27.93 & -29.34 & -31.11 & -31.44 & -32.07 \\
\hline & $(0.000)^{* * *}$ & $(0.000)^{* * *}$ & $(0.000)^{* * *}$ & $(0.001)^{* *}$ & $(0.001)^{* *}$ & $(0.001)^{* *}$ \\
\hline \multirow[t]{2}{*}{ Insider Sales } & -0.36 & -0.36 & -0.46 & -0.63 & -0.62 & -0.79 \\
\hline & $(0.444)$ & $(0.444)$ & $(0.384)$ & $(0.347)$ & (0.349) & (0.309) \\
\hline \multirow[t]{2}{*}{ Market Return } & -1.04 & -1.09 & -1.29 & -1.67 & -1.80 & -2.00 \\
\hline & $(0.009)^{* *}$ & $(0.029)^{*}$ & $(0.026)^{*}$ & $(0.002)^{* *}$ & $(0.006)^{* *}$ & $(0.007)^{* *}$ \\
\hline \multirow[t]{2}{*}{ Market Volat. } & -359.89 & -389.83 & -970.29 & -360.39 & -434.76 & -721.51 \\
\hline & $(0.000)^{* * *}$ & $(0.001)^{* *}$ & $(0.004)^{* *}$ & $(0.000)^{* * *}$ & $(0.000)^{* * *}$ & $(0.116)$ \\
\hline \multirow[t]{2}{*}{ Underwriter } & 26.89 & 26.75 & 28.72 & 12.36 & 12.04 & 11.86 \\
\hline & $(0.155)$ & (0.154) & $(0.150)$ & $(0.522)$ & $(0.531)$ & $(0.556)$ \\
\hline \multirow[t]{2}{*}{ Bubble } & & 6.63 & & & 16.67 & \\
\hline & & $(0.707)$ & & & $(0.400)$ & \\
\hline Observations & 1,448 & 1,448 & 1,342 & 1,147 & 1,147 & 1,049 \\
\hline Adj. R-squa. & 0.034 & 0.034 & 0.035 & 0.058 & 0.058 & 0.061 \\
\hline F-value & 8.33 & 7.29 & 8.01 & 11.14 & 9.76 & 10.77 \\
\hline p-value & $0.000^{* * *}$ & $0.000 * * *$ & $0.000^{* * *}$ & $0.000 * * *$ & $0.000 * * *$ & $0.000^{* * *}$ \\
\hline
\end{tabular}




\section{Table E2: Price Accuracy - Regression Results (Growth Market Sample, Topix)}

\section{Japanese IPOs between 01/01/1993 and 31/12/2007 (Growth Market Sample)}

In all six OLS regressions, the dependent variable is the absolute abnormal buy-and-hold return over a 36-month post-listing period based on the Topix index benchmark. Model 1 to Model 3 are based on the Growth Market Sample and Model 4 to Model 6 are based on the OTC Subsample. While Model 1 and Model 4 do not control for the dot-com bubble 1999/2000, Model 2 and Model 5 introduce a bubble dummy variable. Further, Model 3 to Model 6 exclude observations between 01/04/1999 and 30/06/2000 from the analysis. P-values shown in parenthesis are based on heteroscedasticity-consistent standard errors (HC3). See Section 4.2.3 for a description of each covariate. Exp. Issue abbreviates the expected issue size.

\begin{tabular}{|c|c|c|c|c|c|c|}
\hline$\underline{\text { Data }}$ & Model 1 & Model 2 & Model 3 & Model 4 & Model 5 & Model 6 \\
\hline Data & All & All & All & OTC & OTC & OTC \\
\hline Bubble Period & - & Dummy & Data exc. & - & Dummy & Data exc. \\
\hline Benchmark & Topix & Topix & Topix & Topix & Topix & Topix \\
\hline Period & 36 months & 36 months & 36 months & 36 months & 36 months & 36 months \\
\hline \multicolumn{7}{|l|}{$\underline{\text { Results }}$} \\
\hline \multirow[t]{2}{*}{ Intercept } & 826.48 & 822.20 & 874.40 & $1,032.56$ & $1,028.93$ & $1,085.11$ \\
\hline & $(0.001)^{* * *}$ & $(0.001)^{* * *}$ & $(0.001)^{* * *}$ & $(0.003)^{* *}$ & $(0.004)^{* *}$ & $(0.003)^{* *}$ \\
\hline \multirow[t]{2}{*}{ Method } & 19.83 & 20.39 & 21.60 & 32.61 & 33.03 & 31.36 \\
\hline & $(0.010)^{*}$ & $(0.011)^{*}$ & $(0.019)^{*}$ & $(0.000)^{* * *}$ & $(0.000)^{* * *}$ & $(0.002)^{* *}$ \\
\hline \multirow[t]{2}{*}{ Log Age } & -49.43 & -49.33 & -53.15 & -90.84 & -90.84 & -100.89 \\
\hline & $(0.027)^{*}$ & $(0.028)^{*}$ & $(0.031)^{*}$ & $(0.035)^{*}$ & $(0.035)^{*}$ & $(0.037)^{*}$ \\
\hline \multirow[t]{2}{*}{ Log Exp. Issue } & -28.67 & -28.50 & -30.08 & -31.02 & -30.85 & -31.55 \\
\hline & $(0.000)^{* * *}$ & $(0.000)^{* * *}$ & $(0.000)^{* * *}$ & $(0.002)^{* *}$ & $(0.002)^{* *}$ & $(0.002)^{* *}$ \\
\hline \multirow[t]{2}{*}{ Insider Sales } & -0.38 & -0.39 & -0.49 & -0.67 & -0.67 & -0.85 \\
\hline & (0.429) & $(0.421)$ & $(0.362)$ & (0.329) & $(0.323)$ & $(0.283)$ \\
\hline \multirow[t]{2}{*}{ Market Return } & -0.97 & -0.86 & -1.03 & -1.64 & -1.57 & -1.75 \\
\hline & $(0.019)^{*}$ & (0.094) & $(0.084)$ & $(0.004)^{* *}$ & $(0.019)^{*}$ & $(0.022)^{*}$ \\
\hline \multirow[t]{2}{*}{ Market Volat. } & -387.74 & -321.22 & -904.65 & -397.32 & -360.71 & -633.25 \\
\hline & $(0.000)^{* * *}$ & $(0.008)^{* *}$ & $(0.013)^{*}$ & $(0.000)^{* * *}$ & $(0.004)^{* *}$ & $(0.187)$ \\
\hline \multirow[t]{2}{*}{ Underwriter } & 28.74 & 29.08 & 31.43 & 17.65 & 17.81 & 18.32 \\
\hline & (0.139) & (0.132) & $(0.126)$ & (0.378) & $(0.372)$ & $(0.382)$ \\
\hline \multirow[t]{2}{*}{ Bubble } & & -14.74 & & & -8.21 & \\
\hline & & (0.413) & & & $(0.687)$ & \\
\hline Observations & 1,448 & 1,448 & 1,342 & 1,147 & 1,147 & 1,049 \\
\hline Adj. R-squa. & 0.036 & 0.036 & 0.037 & 0.061 & 0.060 & 0.063 \\
\hline F-value & 8.82 & 7.73 & 8.32 & 11.56 & 10.11 & 11.02 \\
\hline$p$-value & $0.000^{* * *}$ & $0.000^{* * *}$ & $0.000^{* * *}$ & $0.000^{* * *}$ & $0.000^{* * *}$ & $0.000^{* * *}$ \\
\hline
\end{tabular}

Significance levels are as follows: ${ }^{*}=0.05 ;{ }^{* *}=0.01 ;{ }^{* *}=0.001$ 


\section{Table E3: Price Accuracy - Regression Results (Mature Market Sample) \\ Japanese IPOs between 01/01/1993 and 31/12/2007 (Mature Market Sample)}

In all six OLS regressions, the dependent variable is the absolute abnormal buy-and-hold return over a 36-month post-listing period. Model 1 to Model 3 are based on the Topix index benchmark and Model 4 to Model 6 are based on the Nikkei 225 index benchmark. While Model 1 and Model 4 do not control for the dot-com bubble 1999/2000, Model 2 and Model 5 introduce a bubble dummy variable. Further, Model 3 to Model 6 exclude observations between 01/04/1999 and 30/06/2000 from the analysis. P-values shown in parenthesis are based on heteroscedasticity-consistent standard errors (HC3). See Section 4.2.3 for a description of each covariate. Exp. Issue abbreviates the expected issue size.

\begin{tabular}{|c|c|c|c|c|c|c|}
\hline Data & Model 1 & Model 2 & Model 3 & Model 4 & Model 5 & Model 6 \\
\hline$\overline{\text { Data }}$ & All & All & All & All & All & All \\
\hline Bubble Period & - & Dummy & Data exc. & - & Dummy & Data exc. \\
\hline Benchmark & Topix & Topix & Topix & Nikkei 225 & Nikkei 225 & Nikkei 225 \\
\hline Period & 36 months & 36 months & 36 months & 36 months & 36 months & 36 month \\
\hline \multicolumn{7}{|l|}{ Results } \\
\hline \multirow[t]{2}{*}{ Intercept } & 286.31 & 270.90 & 300.91 & 289.57 & 272.62 & 298.27 \\
\hline & $(0.062)$ & $(0.075)$ & $(0.075)$ & $(0.060)$ & $(0.074)$ & (0.078) \\
\hline \multirow[t]{2}{*}{ Method } & 2.16 & 7.08 & 6.01 & 4.92 & 10.33 & 9.39 \\
\hline & $(0.790)$ & $(0.425)$ & $(0.500)$ & (0.559) & $(0.260)$ & (0.310) \\
\hline \multirow[t]{2}{*}{ Log Age } & -25.12 & -24.78 & -26.64 & -26.27 & -25.89 & -28.39 \\
\hline & $(0.035)^{*}$ & $(0.037)^{*}$ & $(0.045)^{*}$ & $(0.028)^{*}$ & $(0.031)^{*}$ & $(0.034)^{*}$ \\
\hline \multirow[t]{2}{*}{ Log Exp. Issue } & -7.44 & -6.84 & -7.98 & -7.43 & -6.77 & -7.61 \\
\hline & $(0.206)$ & $(0.242)$ & $(0.218)$ & $(0.208)$ & $(0.248)$ & $(0.242)$ \\
\hline \multirow[t]{2}{*}{ Insider Sales } & 0.15 & 0.13 & 0.13 & 0.15 & 0.13 & 0.12 \\
\hline & (0.515) & $(0.570)$ & $(0.607)$ & $(0.507)$ & $(0.566)$ & $(0.626)$ \\
\hline \multirow[t]{2}{*}{ Market Return } & -1.56 & -1.37 & -1.48 & -1.50 & -1.29 & -1.39 \\
\hline & $(0.001)^{* * *}$ & $(0.003)^{* *}$ & $(0.002)^{* *}$ & $(0.002)^{* *}$ & $(0.006)^{* *}$ & $(0.005)^{* *}$ \\
\hline \multirow[t]{2}{*}{ Market Volat. } & -667.59 & -561.10 & -547.38 & -617.42 & -500.30 & -482.18 \\
\hline & $(0.013)^{*}$ & $(0.037)^{*}$ & (0.052) & $(0.030)^{*}$ & (0.085) & $(0.114)$ \\
\hline \multirow[t]{2}{*}{ Underwriter } & 19.54 & 20.26 & 21.58 & 18.25 & 19.04 & 20.63 \\
\hline & $(0.069)$ & (0.058) & (0.062) & (0.092) & (0.076) & $(0.076)$ \\
\hline \multirow[t]{2}{*}{ Bubble } & & -28.77 & & & -31.64 & \\
\hline & & $(0.000)^{* * *}$ & & & $(0.000)^{* * *}$ & \\
\hline Observations & 336 & 336 & 30 & 336 & 336 & 304 \\
\hline Adj. R-squa. & 0.056 & 0.063 & 0.055 & 0.054 & 0.063 & 0.056 \\
\hline F-value & 3.83 & 3.83 & 3.50 & 3.74 & 3.83 & 3.55 \\
\hline p-value & $0.001^{* * *}$ & $0.000^{* * *}$ & $0.001^{* *}$ & $0.001^{* * *}$ & $0.000^{* * *}$ & $0.001^{* *}$ \\
\hline
\end{tabular}

Significance levels are as follows: ${ }^{*}=0.05 ;{ }^{* *}=0.01 ; * *=0.001$ 


\section{Table E4: Price Accuracy - RD Global Strategy Results (Growth Market Sample) Japanese IPOs between 01/01/1993 and 31/12/2007 (Growth Market Sample)}

The table presents the Method coefficient estimates of 24 OLS regressions with absolute abnormal buy-and-hold returns over a 36-month post-listing period as dependent variable. Model 1 and Model 2 are based on the Growth Market Sample and Model 3 and Model 4 on the OTC Subsample. In all regressions, the covariates introduced in Section 4.2 .3 and a bubble dummy are included in the regression equation. Model 1 and Model 3 are based on the JASDAQ index benchmark and Model 2 and Model 4 on the Topix index benchmark. For each model, six OLS regressions are conducted with different specifications of $f($ Time). P-values shown in parenthesis are based on heteroscedasticity-consistent standard errors (HC3).

\author{
$\underline{\text { Data }}$ \\ Stock Exchange \\ Bubble \\ Benchmark \\ Period \\ Observations
}

Method Coefficient Estimates

Linear Time Trend

Quadratic Time Trend

Cubic Time Trend

Fourth-order Polynomial

Time Trend

Fifth-order Polynomial

Time Trend

Sixth-order Polynomial

Time Trend

\begin{tabular}{c} 
Model 1 \\
\hline All \\
Dummy \\
JASDAQ \\
36 months \\
1,448
\end{tabular}

1,448

\section{Model 2 \\ All \\ Dummy \\ Topix \\ 36 months}

1,448

148.17

115.40

(0.131)

110.24

(0.256)

165.31

(0.255)

173.78

(0.211)

254.04

(0.128)

\begin{tabular}{c} 
Model 3 \\
\hline OTC \\
Dummy \\
JASDAQ \\
36 months \\
1,147
\end{tabular}

133.37

$(0.017)^{*}$

100.52

(0.186)

110.52

(0.275)

131.31

(0.349)

128.56

(0.339)

209.58

(0.196)

\begin{tabular}{c} 
Model 4 \\
\hline OTC \\
Dummy \\
Topix \\
36 months \\
1,147
\end{tabular}

140.81

$(0.014)^{*}$

125.89

(0.104)

121.50

(0.239)

173.22

(0.224)

175.31

(0.200)

258.17

(0.117)

Significance levels are as follows: ${ }^{*}=0.05 ;^{* *}=0.01 ;{ }^{* *}=0.001$ 
Table E5: Price Accuracy - RD Global Strategy Results (Mature Market Sample) Japanese IPOs between 01/01/1993 and 31/12/2007 (Mature Market Sample)

The table presents the Method coefficient estimates of 12 OLS regressions with absolute abnormal buy-and-hold returns over a 36-month post-listing period as dependent variable. In all regressions, the covariates introduced in Section 4.2 .3 and a bubble dummy are included in the regression equation. Model 1 is based on the Topix index benchmark and Model 2 on the Nikkei 225 index benchmark. For each model, six OLS regressions are conducted with different specifications of $f($ Time). P-values shown in parenthesis are based on heteroscedasticity-consistent standard errors (HC3).

$\underline{\text { Data }}$

Stock Exchange

Bubble

Benchmark

Period

Observations

Method Coefficient Estimates

Linear Time Trend

Quadratic Time Trend

Cubic Time Trend

Fourth-order Polynomial

Time Trend

Fifth-order Polynomial

Time Trend

Sixth-order Polynomial

Time Trend
Model 1

All

Dummy

Topix

36 months

336

10.80

(0.525)

$-20.12$

(0.312)

$-41.01$

(0.064)

$-54.57$

$(0.032)^{*}$

$-50.29$

$(0.046)^{*}$

$-31.47$

(0.218)
Model 2

All

Dummy

Nikkei 225

36 months

336

20.49

(0.253)

$-4.78$

(0.820)

$-26.62$

(0.253)

$-36.20$

(0.173)

$-30.80$

(0.242)

14.25

(0.595)

Significance levels are as follows: ${ }^{*}=0.05 ;{ }^{* *}=0.01 ;{ }^{* *}=0.001$ 


\section{Table E6: Price Accuracy - RD Local Strategy Results (Growth Market Sample)}

\section{Japanese IPOs between 09/04/1996 and 10/03/1999 (Growth Market Sample)}

The table presents the Method coefficient estimates of 48 regressions with absolute abnormal buy-and-hold returns over a 36month post-listing period as dependent variable. In all regressions, the covariates introduced in Section 4.2 .3 and a linear time trend are included in the regression equation. Model 7 to Model 12 include an additional interaction term between the linear time trend and the Method dummy. The benchmark in Model 1 to Model 3 and Model 7 to Model 9 is the JASDAQ index. Model 4 to Model 6 and Model 10 to Model 12 are based on the Topix index as benchmark. In Model 1, Model 4, Model 7 and Model 10 a rectangular kernel is used (=OLS regression). Model 2, Model 5, Model 8 and Model 11 are based on a triangular kernel and Model 3, Model 6, Model 9 and Model 12 are based on an epanechnikov kernel. P-values shown in parenthesis are based on heteroscedasticity-consistent standard errors (HC3). Bandwidth specifies the data that is included in the regression.

\begin{tabular}{|c|c|c|c|c|c|c|c|}
\hline & Model 1 & Model 2 & Model 3 & Model 4 & Model 5 & Model 6 \\
\hline \multicolumn{2}{|l|}{ Benchmark } & $\overline{\text { JASDAQ }}$ & $\overline{\mathrm{JASDAQ}}$ & $\overline{\text { JASDAQ }}$ & Topix & Topix & Topix \\
\hline \multicolumn{2}{|l|}{ Period } & $36 \mathrm{~m}$ & $36 \mathrm{~m}$ & $36 \mathrm{~m}$ & $36 \mathrm{~m}$ & $36 \mathrm{~m}$ & $36 \mathrm{~m}$ \\
\hline \multirow{2}{*}{\multicolumn{2}{|c|}{$\begin{array}{l}\text { Kernel } \\
\text { Interaction Term }\end{array}$}} & Rect. & Trian. & Epan. & Rect. & Trian. & Epan. \\
\hline & & No & No & No & No & No & No \\
\hline Bandwidth & Obs. & $\begin{array}{l}\text { Method } \\
\text { Coeffi. }\end{array}$ & $\begin{array}{l}\text { Method } \\
\text { Coeffi. }\end{array}$ & $\begin{array}{l}\text { Method } \\
\text { Coeffi. }\end{array}$ & $\begin{array}{l}\text { Method } \\
\text { Coeffi. }\end{array}$ & $\begin{array}{l}\text { Method } \\
\text { Coeffi. }\end{array}$ & $\begin{array}{l}\text { Method } \\
\text { Coeffi. }\end{array}$ \\
\hline \multirow[t]{2}{*}{270 days } & 119 & 217.40 & 108.27 & 149.56 & 194.78 & 90.12 & 132.22 \\
\hline & & (0.299) & $(0.567)$ & $(0.436)$ & (0.371) & $(0.652)$ & (0.513) \\
\hline \multirow[t]{2}{*}{360 days } & 175 & 146.41 & 156.68 & 180.77 & 164.18 & 152.07 & 181.74 \\
\hline & & (0.306) & $(0.373)$ & $(0.321)$ & $(0.268)$ & $(0.409)$ & $(0.337)$ \\
\hline \multirow[t]{2}{*}{450 days } & 239 & 113.69 & 122.63 & 125.92 & 155.16 & 137.10 & 149.05 \\
\hline & & $(0.361)$ & $(0.380)$ & $(0.358)$ & $(0.227)$ & $(0.349)$ & (0.295) \\
\hline \multirow[t]{3}{*}{540 days } & 261 & 115.00 & 113.04 & 115.70 & 165.33 & 138.87 & 150.54 \\
\hline & & $(0.360)$ & $(0.378)$ & $(0.364)$ & $(0.201)$ & $(0.299)$ & $(0.254)$ \\
\hline & & Model 7 & Model 8 & Model 9 & Model 10 & Model 11 & Model 12 \\
\hline \multicolumn{2}{|l|}{ Benchmark } & $\overline{\mathrm{JASDAQ}}$ & $\overline{\text { JASDAQ }}$ & $\overline{\text { JASDAQ }}$ & Topix & Topix & Topix \\
\hline \multicolumn{2}{|l|}{ Period } & $36 \mathrm{~m}$ & $36 \mathrm{~m}$ & $36 \mathrm{~m}$ & $36 \mathrm{~m}$ & $36 \mathrm{~m}$ & $36 \mathrm{~m}$ \\
\hline \multicolumn{2}{|l|}{ Kernel } & Rect. & Trian. & Epan. & Rect. & Trian. & Epan. \\
\hline \multicolumn{2}{|c|}{ Interaction Term } & Yes & Yes & Yes & Yes & Yes & Yes \\
\hline & Obs. & $\begin{array}{l}\text { Method } \\
\text { Coeffi. }\end{array}$ & $\begin{array}{l}\text { Method } \\
\text { Coeffi. }\end{array}$ & $\begin{array}{l}\text { Method } \\
\text { Coeffi. }\end{array}$ & $\begin{array}{l}\text { Method } \\
\text { Coeffi. }\end{array}$ & $\begin{array}{l}\text { Method } \\
\text { Coeffi. }\end{array}$ & $\begin{array}{l}\text { Method } \\
\text { Coeffi. }\end{array}$ \\
\hline \multirow{2}{*}{270 days } & 119 & 219.36 & 133.17 & 177.88 & 205.61 & 118.24 & 165.64 \\
\hline & & $(0.318)$ & $(0.511)$ & $(0.407)$ & $(0.369)$ & $(0.580)$ & $(0.461)$ \\
\hline \multirow[t]{2}{*}{360 days } & 175 & 218.90 & 186.78 & 218.82 & 233.33 & 185.86 & 224.49 \\
\hline & & (0.307) & $(0.376)$ & $(0.345)$ & (0.288) & (0.398) & (0.348) \\
\hline \multirow[t]{2}{*}{450 days } & 239 & 178.62 & 174.52 & 186.44 & 209.71 & 186.05 & 205.25 \\
\hline & & (0.321) & $(0.357)$ & $(0.342)$ & (0.254) & $(0.343)$ & (0.309) \\
\hline \multirow[t]{2}{*}{540 days } & 261 & 181.52 & 170.57 & 178.37 & 221.48 & 190.59 & 205.95 \\
\hline & & (0.311) & (0.339) & (0.329) & $(0.226)$ & $(0.301)$ & $(0.272)$ \\
\hline
\end{tabular}

Significance levels are as follows: ${ }^{*}=0.05 ;{ }^{* *}=0.01 ;{ }^{* *}=0.001$ 